\title{
Using Human Rights for Development: A Fiji Case Study
}

\section{Mary Llewellyn-Fowler}

A thesis submitted in partial fulfilment of the

Master of Development Studies Degree

Victoria University of Wellington

New Zealand

December 2007 


\begin{abstract}
Over the past decade there has been a marked shift towards human rights in the policy of multilateral development institutions, international non-governmental organisations (NGOs) and government donor agencies. 'Rights-based' development - in which development and poverty alleviation is viewed through a human rights lens - has become the language of choice among the international development community. As their proponents argue, rights-based approaches to development bring a degree of legal accountability to the alleviation of poverty, turning it from an act of charity to one of social justice. While this shift towards human rights is well documented at the global level, less is known about the understanding and use of human rights for development by NGOs at the local level. By focusing on a particular local context - Fiji - this research investigates how local NGOs understand and use human rights for development, and aims to identify the main challenges surrounding the use of human rights at this level. The findings from interviews with representatives of Fijian NGOs suggest that while human rights are being successfully applied to development in Fiji, they also face some challenges. Two of the most significant challenges are the politicised gap between human rights and development organisations and resistance to human rights on cultural grounds. These challenges demonstrate the impact local social, political and cultural contexts can have on the implementation of global ideas, and have numerous implications for the successful application of rights-based approaches to development at the local level.
\end{abstract}




\section{Acknowledgments}

This research could not have been completed without the generous help and support of many people in New Zealand and in Fiji:

\section{In New Zealand}

Thanks to Leonard Chan and Ali Tuhanuku for introducing me to their NGO colleagues in Fiji, to my supervisor John Overton for his enthusiasm and ideas, and to my parents for their tireless proof reading.

\section{In Fiji}

Many thanks to my research participants for taking time out of their busy schedules to share their experiences with me. Thanks also to Vijay Naidu for introducing me to his NGO colleagues, and to both Vijay and his family for their warm hospitality. Finally, thanks to Noelene Nabulivou, Shirley Tagi and their friends for making me feel at home during my stay in Suva, and to Irshad Ali and the team at Save the Children Fiji for welcoming me into their office. 


\section{Table of Contents}

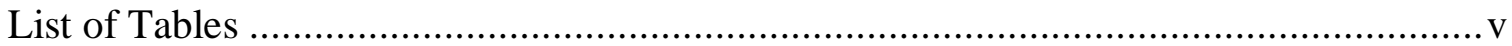

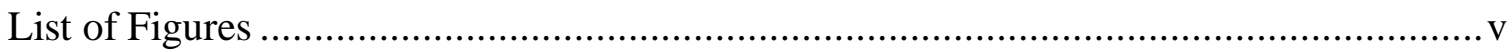

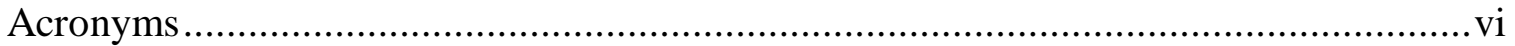

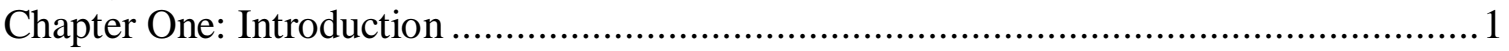

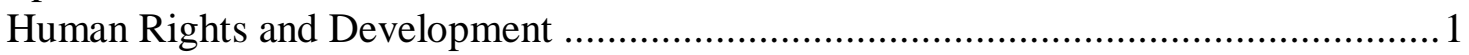

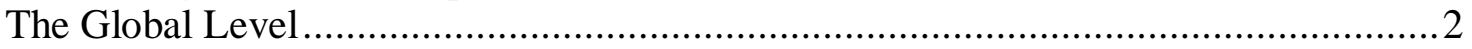

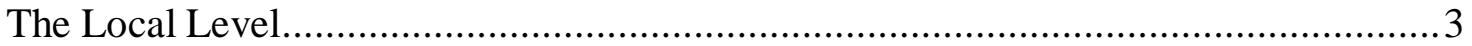

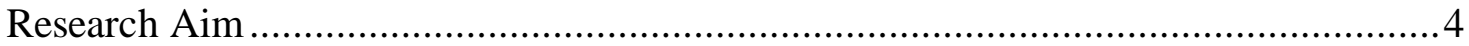

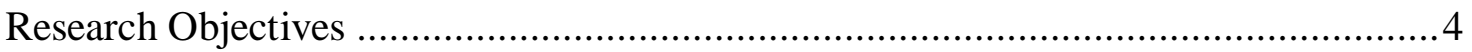

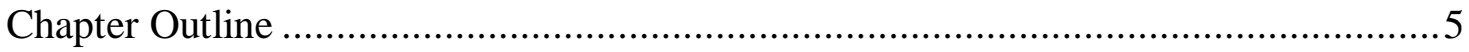

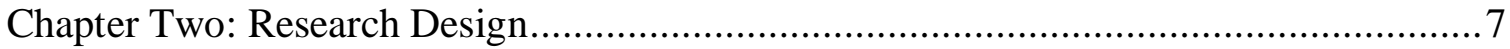

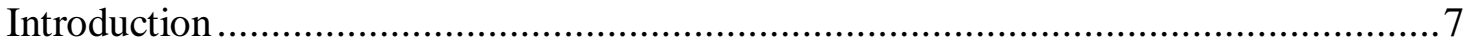

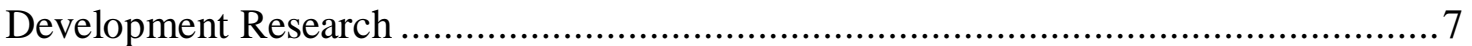

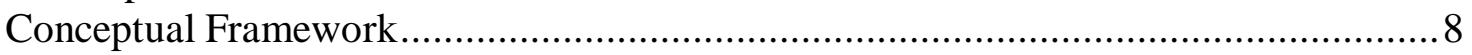

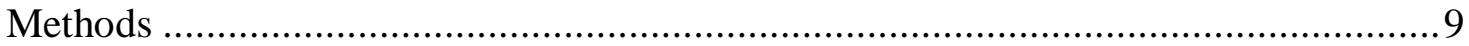

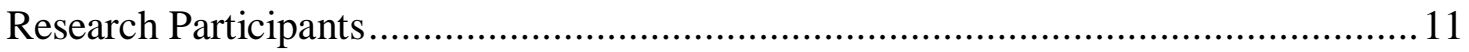

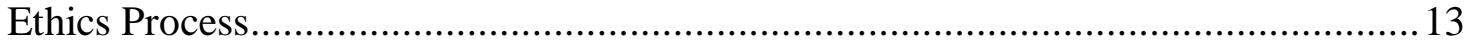

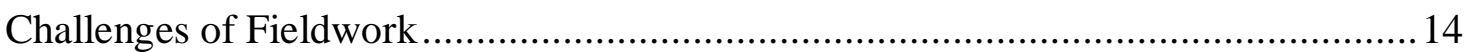

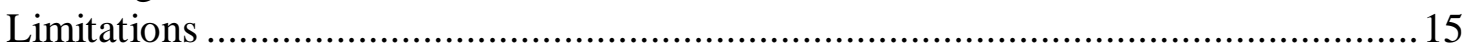

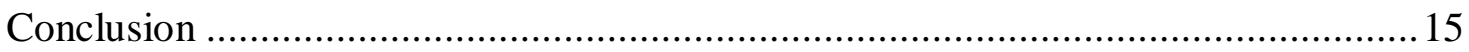

Chapter Three: The International Human Rights Framework ………...........................16

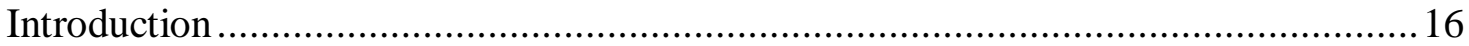

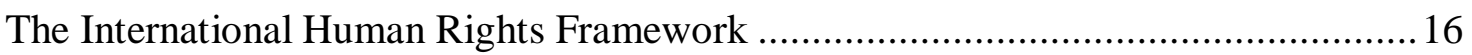

Monitoring and Enforcement of Human Rights Law ............................................21

Non-State Actors and Human Rights ................................................................22

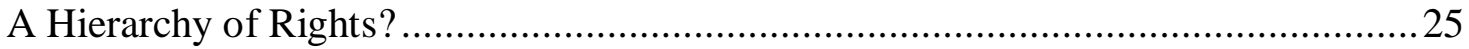

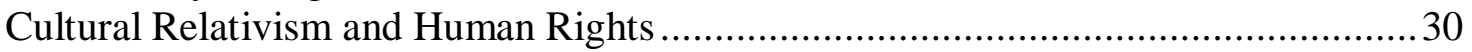

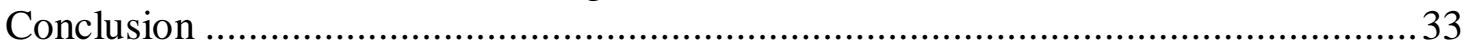

Chapter Four: The History of Human Rights and Development ....................................34

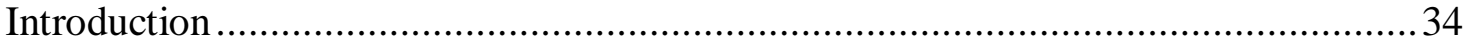

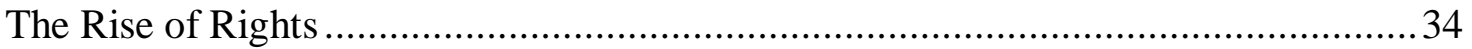

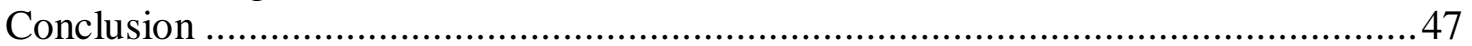

Chapter Five: Human Rights and Development at the Global Level.............................49

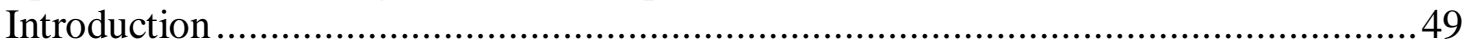

Understanding Human Rights and Development .....................................................49

Using Human Rights for Development: Rights-Based Approaches ...........................56

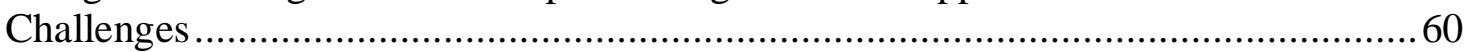

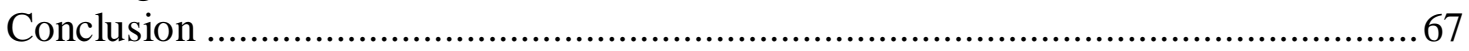

Chapter Six: Human Rights and Development at the Local Level .................................68

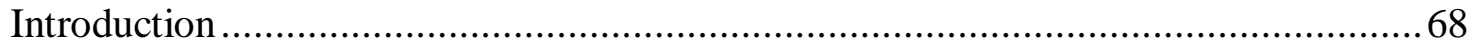

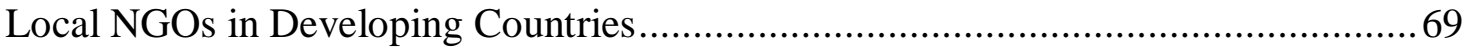

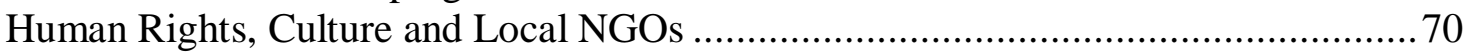

Local NGOs and Rights-Based Approaches ........................................................... 76

Understanding Human Rights and Development .................................................... 76

Using Human Rights for Development ……………......................................... 80

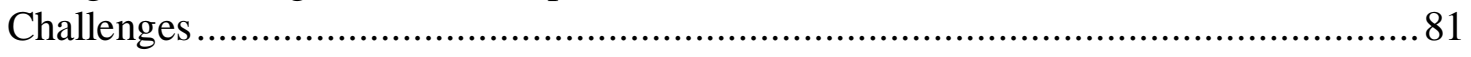




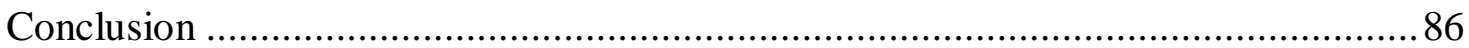

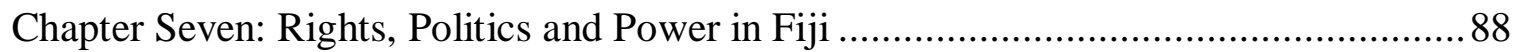

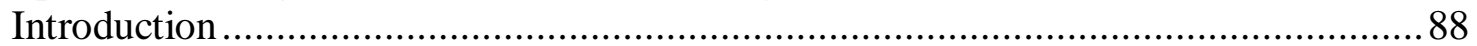

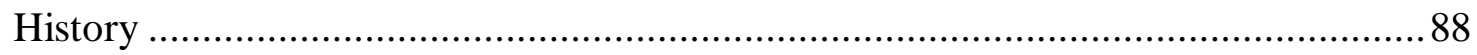

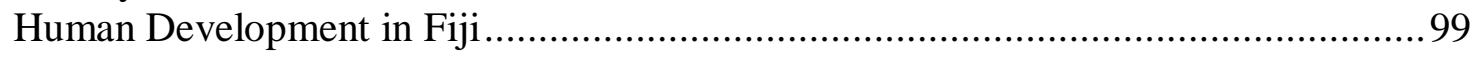

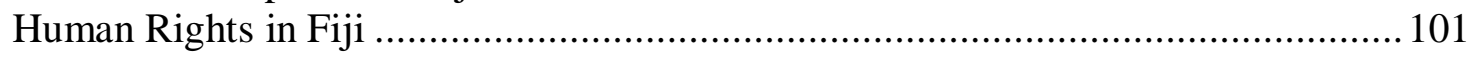

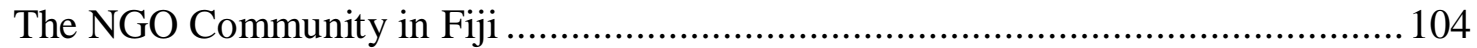

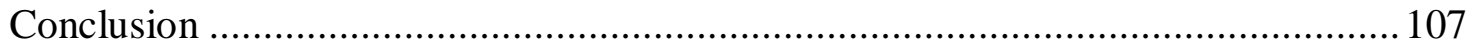

Chapter Eight: Human Rights, Development and Fijian NGOs ................................... 108

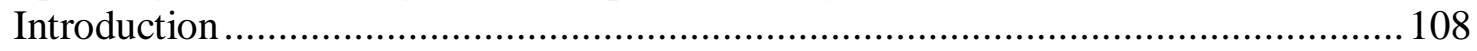

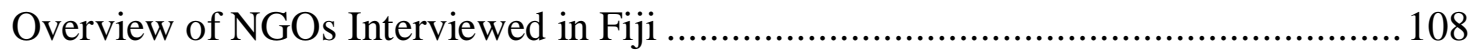

Understanding Human Rights and Development ................................................ 110

Using Human Rights for Development ............................................................... 119

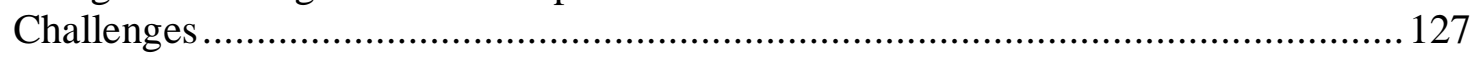

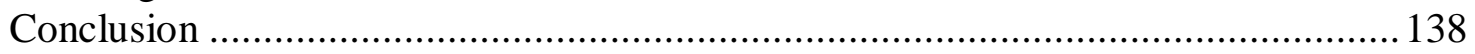

Chapter Nine: Analysis and Discussion ............................................................ 140

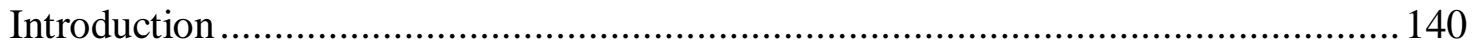

Understanding and Using Human Rights for Development .................................... 140

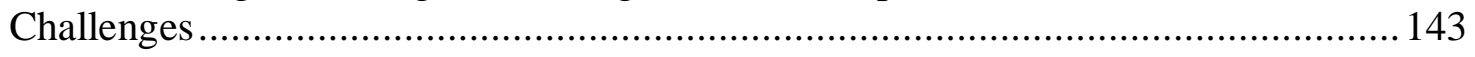

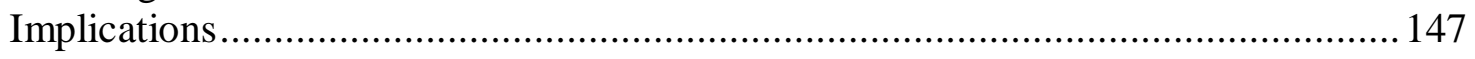

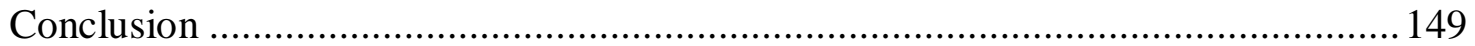

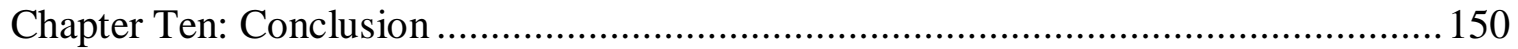

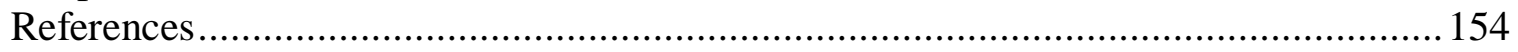

Appendix One: Human Rights and the MDGs .......................................................... 167

Appendix Two: Rights-Based Approaches in Donor Policy ……….............................. 169

Appendix Three: Ethics Forms ………….............................................................. 179 


\section{List of Tables}

Table 1: NGO Representatives Interviewed in Fiji ............................................... 12

Table 2: International Human Rights Treaties ....................................................... 17

Table 3: Perceived Differences Between Development and Human Rights Organisations

Table 4: Poverty in Fiji by Ethic Group ................................................................ 100

Table 5: The Relationship between the MDGS and Human Rights ............................ 167

Table 6: The Millennium Human Rights Goals ..................................................... 168

\section{List of Figures}

Figure 1: The Relationship Between Human Rights, Human Development and Poverty

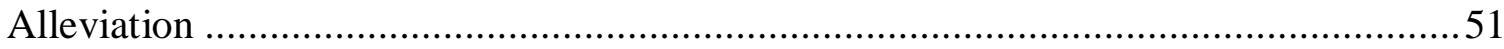

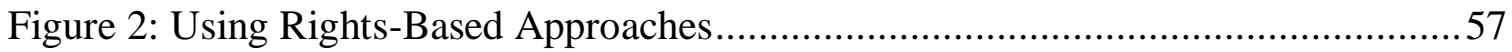




\begin{tabular}{ll} 
Acronyms & \\
AI & Amnesty International \\
AWID & Association of Women in Development \\
CCF & Citizens' Constitutional Forum \\
CEDAW & Convention on the Elimination of All Forms of Discrimination Against \\
& Women \\
CID & Council for International Development \\
CPT & Community Paralegal Training Programme \\
CRC & Convention on the Rights of the Child \\
DAC & Development Committee \\
DFID & Department for International Development \\
DRD & Declaration on the Right to Development \\
ECREA & Ecumenical Centre for Research, Education and Advocacy \\
FHRC & Fiji Human Rights Commission \\
FLP & Fiji Labour Party \\
FWCC & Fiji Women's Crisis Centre \\
FWRM & Fiji Women's Rights Movement \\
GCC & Great Council of Chiefs \\
GDP & Gross Domestic Product \\
GNP & Gross National Product \\
HDI & Human Development Index \\
HDR & Human Development Report \\
HRCA & Human Rights Council of Australia \\
ICCPR & International Covenant on Civil and Political Rights \\
ICESCR & International Covenant on Economic, Social and Cultural Rights \\
ICJ & International Commission of Jurists \\
ICJ & International Court of Justice \\
IDS & Institute of Development Studies \\
ILO & International Labour Organisation \\
IMF & International Monetary Fund \\
MDGs & Millennium Development Goals \\
MPP & Mobile Playgroup Project \\
NFP & National Federation Party \\
NGO & Non-Governmental Organisation \\
NIEO & New International Economic Order \\
NZLC & New Zealand Law Commission \\
ODI & Overseas Development Institute \\
OECD & Organisation for Economic Cooperation and Development \\
OPEC & Organisation of the Petroleum Exporting Countries \\
PANG & Pacific Network on Globalisation \\
PCDF & Partners in Community Development Fiji \\
PIANGO & Pacific Islands Association of Non-Governmental Organisations \\
PIF & Pacific Islands Forum \\
PRAMs & Participatory Rights Assessment Methodologies \\
RFMF & Royal Fiji Military Force \\
RRRT & Regional Rights Resource Team \\
& ThR \\
\hline
\end{tabular}




$\begin{array}{ll}\text { SAPs } & \text { Structural Adjustment Policies } \\ \text { SCF } & \text { Save the Children Fiji } \\ \text { SDL } & \text { Soqosoqo Duavata ni Lewenivanua } \\ \text { SVT } & \text { Soqosoqo ni Vakavulewa } \\ \text { UDHR } & \text { Universal Declaration of Human Rights } \\ \text { UN } & \text { United Nations } \\ \text { UNCESCR } & \text { United Nations Committee on Economic, Social and Cultural Rights } \\ \text { UNCTAD } & \text { United Nations Conference on Trade and Development } \\ \text { UNDAW } & \text { United Nations Division for the Advancement of Women } \\ \text { UNDP } & \text { United Nations Development Programme } \\ \text { UNESCO } & \text { United Nations Educational, Scientific and Cultural Organisation } \\ \text { UNICEF } & \text { United Nations Children's Fund } \\ \text { UNOHCHR } & \text { United Nations Office of the High Commissioner for Human Rights } \\ \text { USP } & \text { University of the South Pacific } \\ \text { WAC } & \text { Women's Action for Change } \\ \text { WB } & \text { World Bank }\end{array}$




\section{Chapter One: Introduction}

The past decade has seen a marked shift in the policy of the multilateral institutions, international non-governmental organisations (NGOs) and government donor agencies that make up the global development community (Molyneux \& Lazar, 2003). Where human rights were once considered to be a by-product of development, good governance and democracy, today they play a central role, influencing everything from stakeholder analysis to programme design. 'Rights-based approaches' to development - those in which development and poverty alleviation are viewed through a human rights lens - can be seen throughout the global development community, appearing in the policy documents of the World Bank and Oxfam alike ${ }^{1}$.

While it is important for human rights to have this support from above, it is equally important for them to be demanded and claimed from below, as it is at this level that rights become meaningful and real in everyday life (VeneKlasen, 2004). However, there is very little known about if and how development and human rights practitioners at the local level use human rights for development, or whether rights-based approaches even have an impact beyond the global level (Ensor \& Gready, 2005; Gaventa \& Jones, 2002; Molyneux \& Lazar, 2003; Pettit \& Wheeler, 2005). How do local NGOs understand the relationship between human rights and development? Do they view poverty and development from a human rights perspective? And what challenges does this shift towards using human rights for development face at the local level? Answers to these questions are important if rights-based approaches are to move beyond global rhetoric and into local reality.

\section{Human Rights and Development}

Human rights and development have traditionally been considered distinct fields of theory and practice (Alston \& Robinson, 2005). Human rights have primarily been associated with campaigns on civil and political rights, focusing on legal reform, political pressure and ethical questioning. Development, particularly economic development, has

\footnotetext{
${ }^{1}$ In this thesis, the terms 'human rights lens' and 'human rights perspective' mean using the principles and standards of the international human rights framework to analyse and address an issue.
} 
been the realm of economists, policy analysts and social scientists, whose focus is on alleviating poverty and improving living standards through economic growth $\left(\mathrm{O}^{\prime} \mathrm{Brien} \&\right.$ Williams, 2004).

Despite these different backgrounds, discussion of the relationship between human rights and development has gained popularity over the past decade. This is partly a response to the failure of mainstream development models to address the persistent poverty and rising inequality that characterises today's world (Ensor \& Gready, 2005; Filmer-Wilson, 2005). It is also due to a specific historical moment: the end of the Cold War and the subsequent reaffirmation of liberal democracy (Robinson, 2006). This revitalised the human rights movement and led to renewed interest in the realisation of human rights. Together, these factors encouraged development practitioners to look at how human rights could be used to complement existing development models. In doing so, they recognised that viewing development problems as the denial of human rights rather than simply the denial of human needs could bring a much needed legal dimension to development and poverty alleviation (Hausermann, 1998a).

\section{The Global Level}

This shift towards human rights is most evident in the past decade's proliferation of rights-based approaches to development (Eyben, 2003). Rights-based approaches to development typically view development problems through a human rights lens, using the principles and standards of the international human rights framework to analyse and address development, poverty and inequality. There is no one rights-based approach to development. Indeed, as an evolving area of development theory and practice, rightsbased approaches to development are understood and used in a variety of ways. However, a generally accepted United Nations (UN) definition describes them as:

A conceptual framework for the process of human development that is normatively based on international human rights standards and operationally directed to promoting and protecting human rights (UNOHCHR, 2006, p. 15). 
Typically, rights-based approaches to development will involve projects that either strengthen the ability of rights-holders (citizens) to claim their rights, or the ability of duty-bearers (the state and its institutions) to fulfil their human rights obligations (Ljungman, 2005). As their proponents argue, these approaches have the potential to transform the goals as well as the practices of development (Jonsson, 2005). This is because the international human rights framework provides a set of legally binding standards which can be used to frame development not as the charitable fulfilment of basic needs, but as the legal fulfilment of basic human rights. In this way, rights-based approaches to development can encourage analysis of the local and global power relationships and structural inequalities which prevent the realisation of human rights (Ensor \& Gready, 2005; Pettit \& Wheeler, 2005; VeneKlasen, 2004).

While there is little doubt surrounding the theoretical benefits that human rights and rights-based approaches can bring to development, commentators have identified numerous conceptual, political, cultural and operational challenges to their success. Critics such as Uvin (2007) and Mohan \& Holland (2001) argue these challenges mean that rather than transforming the current development paradigm, rights-based approaches to development are little more than another donor fad, a rhetorical flourish in which the language of human rights is applied to development with no real change to the wider structural causes of poverty.

\section{The Local Level}

There is a wealth of literature on how the global development community understands and uses rights-based approaches to development, and on the various conceptual, political, cultural and operational challenges such approaches face at the global level. However, there is much less written on if and how this shift in global development policy affects local NGOs working in developing countries; if and how they use human rights for development, and the challenges they face in doing so (Ensor \& Gready, 2005; Gaventa \& Jones, 2002; Molyneux \& Lazar, 2003; Pettit \& Wheeler, 2005) ${ }^{2}$.

\footnotetext{
${ }^{2}$ Local NGO is used in this thesis to refer to NGOs who were established and work locally, in contrast to international NGOs who tend to be based in northern developed states and have a worldwide reach.
} 
Why should it matter if and how local NGOs respond to this shift in global development policy? Because, if any new development theory is to have an impact beyond the policy papers of the global development community, it is vital for it to be used by those working at the local level (Molyneux \& Lazar, 2003). NGOs working at this level often act as intermediaries between the theories and approaches of the global development community and specific local realities (Merry, 2005; Tvedt, 1998). As such, investigating the way they both understand and use these theories and approaches can reveal challenges which may not be apparent from the 'top-down' perspective of the global development community (Merry, 2005). Also, the intermediary role of local NGOs is particularly important when it comes to an approach to development that is based on an idea that is as culturally contested as human rights. Local NGOs are in the unique position to make connections between formal human rights frameworks and what "makes rights become substantive in terms of people's actual experiences" (Pettit \& Wheeler, 2005, p. 6). Therefore, they offer an important perspective on the challenges and realities of using human rights for development, and on whether such new approaches are likely to have an impact beyond the policy papers of the global development community.

\section{Research Aim}

This research contributes to the small body of literature which examines the way human rights are used for development by local NGOs in developing countries. By examining how local Fijian NGOs understand and use human rights for development, it aims to identify the challenges to the practice of human rights for development in the Fijian context and the implications of these challenges on the broader practice of rights-based approaches to development.

\section{Research Objectives}

To achieve the above aim, the research is structured around the following objectives. To:

1. Understand the international human rights framework and the main constraints it faces; 
2. Place contemporary rights-based approaches to development within a broader historical context;

3. Understand the conceptual relationship between human rights and development, and how the global development community understands and uses rights-based approaches to development;

4. Identify the main challenges surrounding the use of rights-based approaches to development as articulated by the global development community;

5. Understand the role local NGOs play in development, and the importance of this role for the local application of global human rights and development ideas;

6. Identify the ways in which local NGOs understand and use human rights for development, and the main challenges to the use of human rights for development at the local level; and,

7. Identify the ways in which Fijian NGOs understand and use human rights for development, and the main challenges to the use of human rights for development in Fiji.

\section{Chapter Outline}

Chapter Two concentrates on the research design, situating the research within a social constructivist conceptual framework and discussing the methods used, the ethics process, and the challenges and limitations of the fieldwork.

Chapter Three addresses objective one by providing an outline of the international human rights framework and some of the main constraints it currently faces, including the role of non-state actors, the relationship between civil and political rights and economic, social and cultural ones, and the ongoing debate between universalism and cultural relativism.

Chapter Four focuses on objective two, placing the human rights shift in contemporary development policy within a broader historical context and demonstrating how human rights have always been part of challenges to mainstream development. 
Chapter Five explores objectives three and four. It begins with an overview of the relationship between human rights and development, and then looks at how the global development community understands and uses rights-based approaches to development. It finishes by presenting the main conceptual, political, cultural and operational challenges to the use of rights-based approaches as identified in the global literature.

Chapter Six moves on to objectives five and six. It begins by examining the important role local NGOs play in development, particularly in 'translating' ideas from global ideas into local realities. It then analyses human rights from a social constructivist perspective, arguing that when it comes to a development approach that is based on the culturally contested idea of human rights, the role of local NGOs is especially important. Finally, Chapter Six presents the findings from case studies of local NGOs, human rights and development. It looks at how local NGOs understand and use human rights for development, and identifies the main conceptual, political, cultural and operational challenges to the use of such approaches at the local level.

Chapter Seven provides the context for objective seven by looking at Fiji's history, its recent political events, its human development and human rights situation, and the local NGO community there.

Chapter Eight presents the findings of objective seven, the Fiji fieldwork. It focuses on how the NGOs interviewed understand and use human rights for development, and identifies some of the main conceptual, political, cultural and operational challenges to the use of such approaches in Fiji.

Chapter Nine addresses the research aim by looking at the findings from Fiji and compares them to the global literature on human rights and development. It then discusses the possible implications of these findings for the use of human rights for development.

Chapter Ten summarises and concludes the thesis and provides suggestions for future research. 


\section{Chapter Two: Research Design}

\section{Introduction}

This chapter discusses the research design. It begins with an overview of how the topic fits into the broader field of development studies, looks at the conceptual underpinnings of the research, and then at the specific methods used. The last sections discuss the ethical and practical challenges of and limitations faced during the research process.

\section{Development Research}

By nature, research in the field of development studies is both action or policy-orientated and interdisciplinary (Mikkelsen, 2005). It is also highly practical and is therefore linked closely to the work of development practitioners. What Mikkelsen (2005, p. 31) calls the "convergence" between development research and practice has driven many of development's theoretical and practical innovations. This convergence of theory and practice is in itself a response to the realisation that generalised, quantitative, and 'topdown' approaches to development are unlikely to secure sustainable results. The participatory, often qualitative, and 'bottom-up' nature of much contemporary development research and practice acknowledges the need for dialogue and mutual learning between researchers, practitioners, and, crucially, development stakeholders. In doing so, it recognises the importance of a local perspective on global ideas and issues.

Due to the interplay of policy and practice and the local and global that characterises development studies, a common thread running through development research is the way in which development theory is translated into everyday development work (Kolthari \& Minogue, 2002; Mikkelsen, 2005). This type of research recognises, as Minogue (2002, p. 135) notes in relation to good governance policy and practice, that "given the nature of the interaction of economic, social and political systems, and the varied cultural contexts this interaction produces, it is to be expected that at the very least, problems of policy transfer and application will occur". Development research often seeks to analyse these contextual problems and to look for ways to adapt policy to local contexts. By examining the recent shift towards human rights in global development policy and identifying the 
challenges surrounding the use of human rights for development at the local level, this thesis is situated within the above tradition of development studies research.

\section{Conceptual Framework}

Underlying this thesis is the assumption that research, particularly research in the social sciences, is a subjective undertaking in which the researcher and research participants cannot be separated from the cultural, social, political and historical processes of which they are a part. It thus applies a social constructivist philosophical approach. Social constructivism considers meaning to be constructed and influenced by lived experiences, cultures, social and political norms and histories (Crotty, 1998; Onuf, 1998). While a detailed discussion of epistemologies in general and social constructivism in particular is beyond the scope of the thesis, this section will provide a brief overview of how a social constructivist approach complements the current research.

While positivism and rationalism assume an independent reality and thus an independent truth, social constructivism raises awareness of the way cultural and social norms shape reality and produce versions of the truth (Leonard, 2006). In doing so, social constructivism provides a useful perspective on the relationship between a global development theory or policy and its application in a specific local context - in this case, the response of the local Fijian NGO community to the global shift towards human rights in development policy.

Social constructivism can also be applied to the subject of human rights. A social constructivist view of human rights attempts to find a middle ground between universalism and cultural relativism (Englehart, 2003). It acknowledges that human rights are basic standards for human behaviour and interaction, but argues that rather than having an independent metaphysical, natural or religious existence, human rights are norms and practices "created, re-created and instanciated by human actors in particular socio-historical settings and conditions" (Stammers, 1999, p. 980). Because they are socially constructed, human rights are dynamic and active and are therefore able to be applied in ways that are sensitive to particular socio-historical or cultural settings (Leonard, 2006). In terms of this research, a social constructivist approach is applied to 
human rights through analysis of the specific cultural, social, political and historical factors which have shaped human rights discourse and have led to its convergence with that of development. Social constructivism is also used to frame the factors that challenge the use of human rights for development in specific local contexts.

As part of a social constructivist philosophy, it is important to be aware of one's own beliefs and values and how these impact on the research process. Janesick (2000, p. 385) notes that "by identifying one's biases, one can see easily where the questions that guide the study are crafted". Therefore I acknowledge that my own interests in critical development theory and alternative approaches to development, as well as my experiences as an intern for Amnesty International, have all influenced my choice of topic and the way I approach it.

In 2006 I did a research internship at Amnesty International on women's rights in the Pacific. This research drew my attention to the challenges surrounding the use of human rights in non-western contexts and demonstrated strategies used by local NGOs to overcome them. During the internship I became aware of rights-based approaches to development and the way human rights could be used to secure not only civil and political but also social and economic gains for marginalised people in developing countries. The potential of rights-based approaches to development to transform unequal power relations and create a more accountable model for human development appealed to my interest in critical and alternative approaches to development. However, having learnt of the challenges that can surround the acceptance of human rights in non-western contexts, I was interested to know if and how this new and potentially empowering shift in global development policy could be applied at the local level. The current research topic developed out of this interest.

\section{Methods}

This research used a combination of primary and secondary sources. The first part involved an extensive literature review which allowed me to understand the history, theory and practice of human rights and rights-based approaches to development, as well as the cultural, social, political and historical context of Fiji. This literature review 
involved secondary sources such as journal articles, books and case studies. These were located from library catalogue and database searches, as well as from the information portals of human rights and development organisations, including the Overseas Development Institute, the Institute of Development Studies in Sussex, the Development Resource Centre in New Zealand, and the various UN agencies. The literature review also involved the use of primary sources such as UN human rights treaties and declarations and the policy documents of donor agencies, all of which were publicly available on the internet. From the literature review, I was able to generate a list of themes around which to focus the second part of my research, the Fiji case study.

A case study model is useful for focusing on a particular context in detail and then comparing this context to global trends (Walsh, 2005). Fiji was chosen as the location for the case study for several reasons: it has a vibrant, diverse and well-established NGO community with close links to New Zealand NGOs; there are many connections between Victoria University of Wellington and the University of the South Pacific in Suva; and most importantly, there has been little research done on the use of human rights for development there.

The fieldwork took place for three weeks during April - May 2007 in Suva, home to much of Fiji's NGO community. Qualitative methods were used because these were considered appropriate for the topic's descriptive and interpretive leanings and for its social constructivist philosophy. As Brockington and Sullivan (2003, p. 72) note, "qualitative research is essential if we are to understand what makes our world meaningful for people". It is therefore a useful way to capture the voices of Fijian NGO representatives discussing how they understand and use human rights for development.

Because of the emphasis placed on capturing voices, discussion based semi-structured interviews were used rather than formal interview procedures (Kvale, 1996). The semistructured interview themes were drawn from the literature review on human rights, development, rights-based approaches to development and the NGO cases studies. However, space was always given for the emergence of new themes and ideas which had not been previously considered, because, as mentioned above, the guiding principle for 
the fieldwork was to provide a picture of the experiences of the NGO community in Fiji. To this end, emphasis was placed on open-ended and flexible questioning and the establishment of a relaxed and informal interview environment, with discussions being recorded electronically rather than notes being taken.

Once back from the field, the recorded interviews were transcribed, presented and analysed according to a framework I developed. This framework was based on how the NGOs understood and used human rights for development, as well as what the literature review revealed to be the four main types of challenges to the use of human rights for development: conceptual; political; cultural; and operational:

1. Conceptual challenges are those relating to the relationship between human rights and development, and the understanding of human rights and rights-based approaches;

2. Political challenges relate to both local and international political factors such as the danger which may surround human rights advocacy and donor unease around activities which challenge the economic and social status quo;

3. Cultural challenges relate to resistance to human rights which may occur on the grounds of culture, such as the perception human rights are an individualistic, western imposition;

4. Operational challenges relate to practical factors which may constrain the use of human rights for development, such as funding problems, difficulties measuring results for monitoring and evaluation purposes, and the adequacy of local legal systems for rights claiming.

For ease of comparison, these headings were used during the review of the global literature on human rights and development, as well as when analysing the NGO case studies and the Fiji fieldwork.

\section{Research Participants}

Before travelling to Fiji for the fieldwork, sixteen potential NGO respondents were identified through the Pacific Islands Association of Non-Governmental Organisations (PIANGO) directory and through internet searches. NGOs were chosen because they worked in the broad areas of community development and/or human rights. Initially, 
email contact was attempted with all sixteen potential NGOs but with little success; only two of those contacted replied and expressed interest. However, generous assistance from several people in New Zealand and in Fiji who have links to the Fijian NGO community enabled contact to be made with some of the previously unresponsive NGOs. In total, twelve representatives from seven Fijian NGOs were interviewed:

\begin{tabular}{|c|c|c|}
\hline Name & Position & NGO \\
\hline Jone Dakuvula & Programme Director & $\begin{array}{l}\text { Citizens' Constitutional } \\
\text { Forum (CCF) }\end{array}$ \\
\hline Father Kevin Barr & Programme Coordinator & $\begin{array}{c}\text { Ecumenical Centre for } \\
\text { Research and Advocacy } \\
\text { (ECREA) }\end{array}$ \\
\hline Virisilia Buadromo & Director & $\begin{array}{c}\text { Fiji Women's Crisis Centre } \\
\text { (FWCC) }\end{array}$ \\
\hline Sandy Fong (PCDF 1) & Community Outreach Worker & \multirow{3}{*}{$\begin{array}{l}\text { Partners in Community } \\
\text { Development Fiji (PCDF) }\end{array}$} \\
\hline Juita Korovulavula (PCDF 2) & Community Outreach Worker & \\
\hline Wesley Morgan (PCDF 3) & Volunteer & \\
\hline Sandra Bernklau & Project Manager & $\begin{array}{c}\text { Regional Rights Resource } \\
\text { Team (RRRT) }\end{array}$ \\
\hline Irshad Ali (SCF 1) & Director & \multirow{3}{*}{ Save the Children Fiji (SCF) } \\
\hline Lynette Peteuli (SCF 2) & Child Rights Officer & \\
\hline Mere Krishna (SCF 3) & Mobile Playgroup Coordinator & \\
\hline Noelene Nabulivou & Coordinator & $\begin{array}{c}\text { Women's Action for Change } \\
\text { (WAC) }\end{array}$ \\
\hline
\end{tabular}

Table 1: NGO Representatives Interviewed in Fiji 
Broadly speaking, three of the NGOs interviewed are typical 'development' NGOs community-based and focusing on promoting equality and tackling poverty by various means (such as advocacy, service delivery and education). Two are explicitly rightsbased development NGOs, and two are primarily human rights NGOs, chosen for the insights they could provide into the challenges that may arise from promoting human rights at the local level and the way they interact with development ideas.

\section{Ethics Process}

Ethics approval was granted by the Victoria University of Wellington Human Ethics Committee prior to the fieldwork (see Appendix Three). Although participants were given the option of anonymity for both themselves and their NGOs, all agreed to the publication of their names and the names of their organisations. However, within the text, participants are only referred to by the name of their NGO, and where two or more representatives from the same NGO were interviewed, they are represented as 1,2 or 3 (as in Table One). After the interviews, all participants were emailed a copy of their transcript to check and amend if desired, with one of the fifteen participants choosing to do so. In order for the research to be of some benefit to the Fijian NGO community, research findings will be made available to all interested participants.

Of course, ethical considerations go beyond merely acquiring university consent. In reality, they should govern the way research is conducted, meaning the researcher should always be aware of the potential impact of their research on their participants. This was of particular relevance to my research in Fiji because of the political situation there. After the December 2006 coup, several representatives of human rights NGOs had been detained by the military regime, a fact which led me to seriously question the ethics of going to Fiji to conduct interviews on such potentially sensitive issues as human rights and development. However, after discussing the viability of this with NGO and academic contacts both here in New Zealand and in Suva, I was assured there should be no problems with undertaking the research. Additionally, prior to leaving and also when in Suva I checked with the participants about their willingness to continue with the research, with all confirming they were happy to do so. 


\section{Challenges of Fieldwork}

The most obvious practical challenge faced during the fieldwork was that on December 6, 2006, there was a coup in Fiji. This meant the fieldwork was postponed from January till mid-April, 2007. As discussed above, questions of participant safety led me to question the ethics of continuing with my research, but I was assured by all involved that I should continue. Once in Fiji, I was surprised by how much open debate and discussion there was on issues of human rights and development. This in itself was probably a reflection of the fact the situation had settled somewhat by April.

In reality, the main challenges encountered during the fieldwork process had less to do with the coup and more to do with gaining access to the representatives of the NGOs I was interested in interviewing. As mentioned above, where connections had already been made through New Zealand contacts this was not a problem, but with other NGOs it was very difficult and in some cases impossible to gain access. This was largely due to the understandable reality that NGOs are often under-staffed and under-resourced, meaning there is little time to do anything other than day to day work. It was also partly because, as several people told me, NGOs in Fiji feel 'over-researched', with a common comment being they often give time to student researchers yet rarely gain anything from it. This made me conscious of making my research less extractive and more relevant for the NGOs I interviewed, a process I tried to facilitate by using an open and discussion-based style of interviewing in which I hope learning was, to some degree, mutual.

Other practical challenges were typical of the realities of being an outsider researching in a different culture. These included differences of language and culture, as well as my lack of knowledge of the complexity of local Fijian and local NGO politics. However, these challenges reflect an issue that is central to the thesis: the way in which local realities impact on global norms. As such, they were illuminating in themselves. Throughout the fieldwork, advice and support from local friends taught me much about these and many other issues, and for this I am very grateful. 


\section{Limitations}

There are several main limitations to the fieldwork aspect of this study. Financial constraints imposed a three week time limit on my stay in Fiji and restricted my fieldwork to Suva, meaning I missed talking to NGOs based elsewhere. Three weeks also gave me very little time to grasp Fiji's complex political and cultural nuances which may impact on my analysis of the findings. Finally, as mentioned above, I was only able to speak with seven of the sixteen NGOs I originally identified. This clearly limits the scope of my findings considerably and means the research is an insufficient basis from which to generalise about the work of local Fijian NGOs in relation to human rights and development. Nevertheless, the findings do offer some insight into the practical challenges of using human rights within a specific local context, challenges which can be compared to the wider literature on human rights and development and from which some general implications for the use of human rights for development can be drawn.

\section{Conclusion}

This chapter has situated the current research within a social constructivist framework, in which it is important to consider the subjectivity of both the researcher and the research participants and to acknowledge the way cultural, social, political and historical constructs influence lived experiences. This approach is useful for the thesis's descriptive and interpretive leanings and its comparison of global ideas with local realities. It means there will be an emphasis on cultural, social, political and historical contexts as they relate to every aspect of the research, from how they influence human rights and rights-based approaches to development, to how they affect the way these ideas are realised in Fiji. 


\section{Chapter Three: The International Human Rights Framework}

\section{Introduction}

An understanding of the international human rights framework and some of the constraints it faces lays the foundations for the relationship between human rights and development. This chapter gives a brief overview of the international human rights framework and of three important issues confronting it today: the role of non-state actors, the relationship between civil and political rights and economic, social and cultural ones, and the ongoing debate between universalism and cultural relativism.

\section{The International Human Rights Framework}

Recognition of the inherent dignity and of the equal and inalienable rights of all members of the human family is the foundation of freedom, justice and peace in the world

- Preamble, Universal Declaration of Human Rights (UN, 1948).

The international human rights framework is a collection of United Nations (UN) treaties and declarations which protect individuals and groups against abuses of universally agreed upon freedoms and entitlements (UNOHCHR, 2006). As a normative framework, it describes how things should be, but it also underpins these norms with legal requirements (Parekh, 1999). The central human rights document is the Universal Declaration of Human Rights (UDHR). The UDHR was adopted in 1948 by the newly established United Nations General Assembly in direct response to the horrors of World War Two and in recognition that protection of the individual must move beyond the sovereign duty of individual states and into the realm of international law. The UDHR's 30 articles outline the basic rights guaranteed to every human being by collective birthright and without discrimination on the grounds of race, colour, sex, language, political opinion, social origin or birth (UNOHCHR, 2006). These include the rights to life, liberty and security of person; to freedom of association, expression, assembly, thought, conscience and religion; to freedom from arbitrary arrest, torture, cruel, inhuman 
or degrading treatment or punishment; and to adequate food, housing, social welfare and just and favourable working conditions.

\section{Treaties and Declarations}

The UDHR is not generally considered to be a legally binding document ${ }^{3}$. However, alongside it sit seven core human rights covenants and treaties which are binding under international law. Each of these treaties covers a different and sometimes overlapping collection of human rights (UNOHCHR, 2006, p. 33):

\begin{tabular}{|c|c|c|c|}
\hline Treaty & Adopted & State Parties & Monitoring Body \\
\hline $\begin{array}{l}\text { International Covenant on } \\
\text { Civil and Political Rights } \\
\text { (ICCPR) }\end{array}$ & 1966 & 155 & Human Rights Council \\
\hline $\begin{array}{c}\text { International Covenant on } \\
\text { Economic, Social and Cultural } \\
\text { Rights (ICESCR) }\end{array}$ & 1966 & 152 & $\begin{array}{l}\text { Committee on Economic, } \\
\text { Social and Cultural Rights }\end{array}$ \\
\hline $\begin{array}{l}\text { International Convention on } \\
\text { the Elimination of All Forms } \\
\text { of Racial Discrimination } \\
\text { (CERD) }\end{array}$ & 1965 & 170 & $\begin{array}{l}\text { Committee on the Elimination } \\
\text { of Racial Discrimination }\end{array}$ \\
\hline $\begin{array}{l}\text { Convention on the Elimination } \\
\text { of All Forms of } \\
\text { Discrimination Against } \\
\text { Women (CEDAW) }\end{array}$ & 1979 & 181 & $\begin{array}{c}\text { Committee on the Elimination } \\
\text { of Discrimination Against } \\
\text { Women }\end{array}$ \\
\hline $\begin{array}{l}\text { Convention Against Torture } \\
\text { and Other Cruel, Inhuman or } \\
\text { Degrading Treatment (CAT) }\end{array}$ & 1984 & 141 & Committee Against Torture \\
\hline $\begin{array}{l}\text { Convention on the Rights of } \\
\text { the Child (CRC) }\end{array}$ & 1989 & 192 & $\begin{array}{l}\text { Committee on the Rights of } \\
\text { the Child }\end{array}$ \\
\hline $\begin{array}{l}\text { International Convention on } \\
\text { the Protection of the Rights of } \\
\text { All Migrant Workers and } \\
\text { Members of their Families }\end{array}$ & 1990 & 34 & $\begin{array}{l}\text { Committee on the Rights of } \\
\text { Migrant Workers }\end{array}$ \\
\hline
\end{tabular}

Table 2: International Human Rights Treaties

\footnotetext{
${ }^{3}$ Although the UDHR has assumed status as customary international law (Reinsich, 2002).
} 
As well as the UDHR and the above treaties, there are numerous supplementary, nonlegally binding declarations, including the:

- Declaration on the Right to Development (1986)

- Vienna Declaration and Programme of Action (1993)

- Declaration on the Elimination of Violence Against Women (1993)

- Declaration on the Rights and Responsibility of Individuals, Groups and Organs of Society to Promote and Protect Universally Recognised Human Rights and Fundamental Freedoms (1998)

- United Nations Millennium Declaration (2000)

\section{Human Rights Principles}

Underlying the international human rights framework are various human rights principles, including those of accountability, participation, universality and indivisibility (UNOHCHR, 2006). While the UDHR and seven core human rights treaties provide the human rights standards, human rights principles guide the way these standards should be realised (Jonsson, 2005).

\section{Accountability}

When a state signs a human rights treaty, it becomes accountable for the incorporation of the rights it contains into its domestic legislation (Alston \& Steiner, 2002). It is also accountable for the respect, protection and fulfilment of these rights. States have the primary responsibility to "create the enabling environment in which all people may enjoy all human rights" and have the obligation to ensure "respect for human rights norms and principles is integrated into all levels of governance and policy-making" (van Weerelt, 2001, p. 8). Accountability goes hand in hand with the rule of law (Alston \& Steiner, 2002). The rule of law, in the form of a just and transparent legal system, ensures human rights, once legislated, are actually upheld. It also ensures that there is no impunity for human rights violations.

\section{Participation}

Participation is an essential aspect of the international human rights framework and is referred to in the UDHR, the ICCPR, the CRC and the Declaration on the Right to 
Development, amongst others ${ }^{4}$. Participation means every person is entitled to participate in and contribute to the political, economic, social and cultural life of the community in which they live. The realisation of participation requires states to provide "supportive environments to enable people to develop and express their full potential" (Ljungman, 2005, p. 11).

\section{Universality}

According to the UDHR, human rights are entitlements universally granted to each person by virtue of their common humanity and on the basis of a common respect for human value. This means the "accident of birth into a particular social group or culture has no bearing on the individual's intrinsic ... right to be treated as a human being" (Merry, 2001, p. 40). In this respect human rights can be distinguished from other rights such as citizenship or contractual rights. Universality forms the basis of the concept of human rights and is the reason for the power of the human rights discourse, because human rights emphasise the "fundamental entitlement of all human beings to live in dignity ... and provide a foundation from which to establish a set of demands premised on the ... worth of the individual" (Goonesekere, 2003, p. 1).

Universality also implies equality and non-discrimination. Therefore, it requires everyone to have equal access to the goods and services necessary to fulfil their basic human needs and rights, and means everyone must be treated equally by public authorities or before the law.

\section{Indivisibility}

The principle of indivisibility recognises all human rights are equally important and certain human rights cannot be suppressed in order to promote others. It means, importantly, there is no hierarchy among different kinds of rights: economic, social and cultural rights are as necessary as civil and political ones (UNDP, 2000). Indivisibility also implies interdependence, meaning the fulfilment of one right is inherently related to the fulfilment of others and that it is difficult or often impossible to realise any one right in isolation. For example, the right to work (UDHR Article 23) cannot be realised

\footnotetext{
${ }^{4}$ See: Articles 21 and 27 of the UDHR; Article 25 of the ICCPR; Articles 12 and 13 of the CRC; Article 2 of the Declaration on the Right to Development.
} 
without a minimal level of realisation of the right to education (UDHR Article 26), while the right to vote (UDHR Article 21) may be unimportant to someone who has nothing to eat (UDHR Article 25). The interdependence and indivisibility of rights mean efforts should be made to realise human rights together. However, where economic constraints prevent a state from realising all rights at once, the concept of progressive realisation allows prioritisation of rights, particularly of the more resource intensive economic, social and cultural rights (UNOHCHR, 2006, p. 12) ${ }^{5}$. If prioritisation is inevitable, efforts must be made to prioritise according to the principles of non-discrimination, equality and participation. Additionally, prioritisation of one right must not result in a 'human rights trade-off' - meaning the fulfilment of one right must not lead to the violation of another (Hunt, Osmani, \& Nowak, 2004; UNOHCHR, 2006).

\section{Human Rights Obligations}

International human rights law recognises two main groups of actors: rights-holders and duty-bearers. We all belong to the first group; we are rights-holders simply because we are human. States belong to the second group. They are the primary duty-bearers in that when they sign and ratify a human rights treaty, they have the legal duty to incorporate the human rights it contains into domestic legislation. This obligation is demonstrated most clearly in Article Two of the International Covenant on Civil and Political Rights (ICCPR) which notes that "each state Party to the present Covenant undertakes to take the necessary steps, in accordance with its constitutional processes ... to adopt such legislative or other measures as may be necessary to give effect to the rights recognised in the present Covenant" (UN, 1966) ${ }^{6}$. As primary duty-bearers, states are obliged to respect, to protect and to fulfil human rights (UNOHCHR, 2006):

\footnotetext{
5 Progressive realisation is not without criticism, with some arguing that it allows states to avoid their human rights obligations (Gledhill, 2001), and others, most often states themselves, arguing that poor, heavily indebted states are unable to afford the realisation of human rights, particularly of economic, social and cultural ones. Countering this latter argument are those who say that state inability is less about a lack of resources and more about a lack of political will, with states often willing to prioritise military expenditure over provision of basic rights (CESCR, 2007).

${ }^{6}$ Multilateral treaties between states require either:

a) A signature - does not bind a state but it does oblige it to behave in a way which does not undermine the obligations of the treaty.

b) Accession - allows a state to agree to be bound by principles of a treaty despite not signing it when the treaty was originally adopted.
} 
- To respect means state behaviour must not interfere with the realisation of human rights;

- To protect means states should take action to ensure that others do not interfere with the realisation of human rights;

- To fulfil means states should take steps to realise human rights. This obligation is subdivided further into facilitation of human rights and provision of human rights. Facilitation requires states to create the conditions which allow people to realise human rights themselves. This means a state can meet its human rights obligations by acting as a regulator or facilitator of other actors who provide services, such as the market or civil society. Provision requires states to provide services to realise rights where conditions prevent people being able to do so themselves. For example, a state could facilitate the right to healthcare through a market system, but were this system to fail, or were people unable to access this system due to poverty, then the state would be obliged to provide these services itself.

\section{Monitoring and Enforcement of Human Rights Law}

Although the international human rights framework is well-documented and monitored, its enforcement is problematic (O'Byrne, 2003). There are several levels of enforcement of human rights law: international, regional and domestic.

The main international mechanisms for the monitoring and enforcement of human rights law are the UN treaty and charter bodies ${ }^{7}$. When a state ratifies a treaty, it is obliged to submit periodic reports on its fulfillment of human rights standards to the relevant treaty body. For example, the Committee on Economic, Social and Cultural Rights monitors the ICESCR, while the Committee Against Torture monitors the Convention Against

Once a state has signed or acceded to a treaty, it is required to ratify it. Ratification means that the obligations of the treaty should be formally incorporated into domestic legislation (MFAT, 2003; UN, 2002).

${ }^{7}$ Charter bodies gain their mandate from the provisions contained within the UN Charter, have broad human rights mandates, address a wide audience, and take action based on majority voting. Treaty bodies are derived from provisions contained in a specific legal instrument (i.e., the Covenant on Civil and Political Rights), hold narrower mandates (i.e., the set of issues codified in the legal instrument involved), address a more limited audience (i.e., only those countries that have ratified the legal instrument in question) and base their decision-making on consensus (UN, 2007). 
Torture (CAT). The treaty body then examines the state reports, as well as the alternative 'shadow' reports provided by NGOs, and publishes its findings. The findings provide detailed recommendations for state action.

Alongside the treaty bodies are the charter bodies, which derive their existence from the UN Charter, the founding document of the UN. The main charter body is the recently formed Human Rights Council (UN, 2006). Composed of 47 representatives elected from all UN member states, the Human Rights Council will review the human rights records of all 191 UN member states every four years. As well as the Human Rights Council, the UN Charter provides for special rapporteurs. Special rapporteurs have a mandate to monitor human rights and can accept human rights complaints lodged by individuals. They are categorised by country and by human rights theme, such as violence against women or minority rights.

The findings and recommendations from the treaty bodies, the Human Rights Council and the special rapporteurs can be used by human rights advocates and the international community to lobby and put diplomatic pressure on non-compliant states. This can happen through aid embargoes, expulsion from multilateral institutions or trade sanctions (UNOHCHR, 2006). This type of diplomatic pressure is international law's main source of power as, "in the absence of enforcement mechanisms, international law matter[s] by affecting actors' perceptions, calculations, reputations, and norms" (Uvin, 2007, p. 559).

Enforcement of the international human rights framework is also supported by regional human rights conventions, commissions and courts, including the European Commission on Human Rights, the European Court of Human Rights, the Inter-American Commission on Human Rights, the Inter-American Court of Human Rights, and the African Commission on Human and Peoples' Rights (MFAT, 2003). Such regional institutions make an "invaluable contribution to protecting and promoting human rights" (MFAT, 2003, p. 69). Not only do they have the ability to interpret international law and thus influence domestic law, they can also 'translate' human rights in ways which are regionally relevant. For example, the African Charter on Human and Peoples' Rights (1981) states in its preamble that it takes account of "the virtue of the historical tradition 
and the values of African civilization which should inspire and characterise their reflection on the concept of human and peoples' rights" (AU, 1981).

Finally, international law may be incorporated into domestic legislation, as normally happens when a state ratifies an international human rights treaty (O'Byrne, 2003). States may choose to incorporate human rights directly through a Bill of Rights, a constitution or a Human Rights Act. They can also do so indirectly through different sections of the law. For example, provisions in criminal law may protect life, liberty or property, while those in labour law may protect the rights of workers (Reinsich, 2002). Once human rights are incorporated into domestic legislation they become enforceable under domestic justice systems, providing a more direct and effective means by which to address human rights violations (Alston \& Steiner, 2002). Additionally, many states have national human rights institutions; legally established independent authorities which exist to protect human rights at the domestic level. National human rights institutions have the power to make recommendations to states, to monitor the compliance of domestic law with international human rights standards, to act upon individual complaints and to promote human rights awareness through research and education. As such, they play an important role in the protection, promotion and enforcement of human rights at the domestic level (MFAT, 2003).

\section{Non-State Actors and Human Rights}

The incorporation of non-state actors into international human rights framework is an evolving area of international human rights law. The term non-state actor covers a wide range of diverse organisations including multinational corporations, international financial institutions, NGOs, private individuals and religious organisations (Alston, 2005). As non-state actors are not signatories to human rights treaties they cannot be held legally accountable for human rights violations under strict interpretations of international law. This was accepted when the $\mathrm{UN}$ and the main human rights treaties were established because during this period the state was the main provider and violator of human rights. However, in many of today's liberalised and privatised economies, nonstate actors have taken on roles formerly reserved for the state, such as the provision of 
healthcare and water. Therefore, it is often argued that they too should be responsible for the protection, respect and fulfillment of human rights (Alston, 2005; Jochnick, 1999).

How can the state-centric international human rights framework regulate these non-state actors? Alston (2005, p. 19) argues that if no effective means of regulation is found, then the international human rights framework will be rendered "irrelevant in relation to important issues". In an effort to prevent the existing system becoming irrelevant, there is currently much investigation into how non-state actors may be held legally accountable for human rights violations (Alston, 2005; Andrenopolis, Arat, \& Juviler, 2006; Clapham, 2006). As the Nuremberg Charter demonstrates, extending accountability to non-state actors does have precedent under international law $^{8}$. This is also suggested by the opening paragraphs of the UDHR itself:

Nothing in this Declaration may be interpreted as implying for any state, group or person any right to engage in any activity or to perform any act aimed at the destruction of any of the rights and freedoms set forth herin (UN, 1948).

In light of this interpretation of the legal accountability of non-state actors under international law, the UN Sub-Commission on the Promotion and Protection of Human Rights recently recognised the human rights obligations of transnational corporations:

Within their respective spheres of activity and influence, transnational corporations and other business enterprises have the obligation to promote, secure the fulfilment of, respect ... and protect human rights recognised in international as well as national level law (UN, 2003b, p. 1).

However, while it has been established that transnational corporations and other non-state actors can be legally accountable for upholding international human rights law, in practice there are no procedures for holding them accountable at the international level.

\footnotetext{
${ }^{8}$ For example, the first principle of the Nuremburg Charter states that "any person who commits an act which constitutes a crime under international law is responsible therefore and liable to punishment" (NMT, 1950, p. 1).
} 
It has been suggested the existing "human rights machinery and norms are pliant enough to be reoriented to cope with these new demands" of non-state actors (Clapham, 2006, p. 28 ). However, how this could best be done is still being debated. For example, should there be an international court for non-state actors? Or should domestic laws be strengthened and harmonised across borders (to prevent non-state actors basing themselves in those states with the least restrictive human rights laws)? (Reinsich, 2002). Until this issue is resolved, it will pose a significant constraint to the realisation of human rights.

\section{A Hierarchy of Rights?}

In 1966, the human rights contained within the UDHR were made legally binding by their translation into two covenants - the International Covenant on Civil and Political Rights (ICCPR) and the International Covenant on Economic, Social and Cultural Rights (ICESCR). While both covenants are considered to be of equal standing, human rights have traditionally been interpreted as referring to civil and political rights only, with economic, social and cultural rights generally being overlooked. This so-called 'hierarchy' of rights is a common theme in the literature on human rights and poses one of the greatest constraints to the global acceptance and relevance of human rights (Alston \& Steiner, 2002; Donnelly, 2003; Ishay, 2004). Before discussing why this hierarchy or division has endured, this section will provide a brief overview of the evolution of civil and political rights and economic, social and cultural ones.

\section{Civil and Political Rights}

Civil and political rights in the ICCPR include the rights to life, liberty and security of person, equality before the law, freedom of thought, conscience, religion and association, and freedom from torture and discrimination. They are often classed as 'negative' in that, unlike economic, social and cultural rights, they do not require a great degree of state intervention in order to ensure they are fulfilled. Rather, they focus on the things the state should not do. For example, it should not torture, discriminate, or compromise the liberty, security or lives of its citizens (Alston \& Steiner, 2002). However, labelling civil and political rights as negative or non-intervention rights is not entirely accurate, as many of these rights do in fact require state funding in order to be realised (UNOHCHR, 2006). 
For example, the right to equality before the law is predicated on the existence of a free and fair legal system and this clearly requires state intervention and funds.

Civil and political rights have their origins in the eighteenth century European Enlightenment. This was a time when many diverse factors stimulated criticism of the established order. These factors included the scientific revolution, the rise of mercantilism, maritime exploration and colonialism, the consolidation of the nation-state and the emergence of the bourgeoisie class (Ishay, 2004). Across Europe, a new discourse based on human reason and individual free choice challenged traditional religious and social hierarchies. Alongside this newfound belief in the individual developed new political and economic ideas based on 'natural rights'. Natural rights included the right to vote (for property owning males), the rule of law, private property rights, and the rights to contractual agreement and economic independence ${ }^{9}$. These new ideas were influenced by Locke's late seventeenth century Two Treatises on Government, and were expressed most clearly in both the American Declaration of Independence in 1776 and the French Declaration on the Rights of Man and of the Citizen in 1789 (Ensor $\&$ Gready, 2005).

Civil and political rights in the eighteenth century were associated with the new capitalist economic system. Indeed, the two were considered to be mutually beneficial (Ishay, 2004). As Kant argued at the time and as many continue to argue today "civil freedom can no longer be easily infringed without disadvantage to commerce" (Evans, 2005; Reiss, 1970, p. 50; WB, 2001).

\section{Economic, Social and Cultural Rights}

Economic, social and cultural rights in the ICESCR include the rights to an adequate standard of living including adequate food, clothing, housing and education; the highest

\footnotetext{
${ }^{9}$ This overview is based on the most common interpretation of the rise of civil and political rights. For an alternative, see Stammers (2005), who suggests that rather than representing a bourgeois ideology of property and capital, the eighteenth century rights debates were a manifestation of much more radical struggle against absolutist state power, meaning that rights were actually considered dangerous by the rising middle classes.
} 
attainable standard of physical and mental health; just conditions of work; social security; and participation in cultural life.

Economic, social and cultural rights are often considered to be 'positive' rights (Alston \& Steiner, 2002). They require the state to create an environment which provides or facilitates the provision of rights for its citizens. Unlike civil and political rights which demand immediate protection, economic, social and cultural rights require only progressive realisation (UNDP, 2000).

The economic, social and cultural rights contained within the ICESCR have their origins in the nineteenth century (Stammers, 2005). During this time a new set of factors, related to but different from those of the Enlightenment era, combined to cause social unrest: workers protested the poor working conditions and wages of the industrial revolution and called for the right for collective organisation; suffragettes demanded voting rights be extended to include women as well as property owning males; Chartists called for universal suffrage irrespective of property ownership; people from all sections of society campaigned for the abolishment of the slave trade; and writers such as Marx, Engels and Weber criticised the ability of the capitalist market system to provide for all members of society (Ishay, 2004; Stammers, 1999). Many of these social movements pointed to the growing economic inequalities of the nineteenth century and called for the state to take responsibility for extending the Enlightenment values of liberty and equality to all citizens, whether worker, woman or slave (Ishay, 2004).

These ideas found further expression in the twentieth century with the establishment of the International Labour Organisation (ILO), Roosevelt's New Deal and the rise of the welfare state before being incorporated into the UDHR and the ICESCR ${ }^{10}$. Like civil and political rights, economic, social and cultural rights remain associated with the historical period in which they were first articulated, meaning while civil and political rights have tended to be related to eighteenth century economic liberalism, economic, social and

\footnotetext{
${ }^{10}$ The ILO was established under the Treaty of Versailles in 1919. In the interwar years and particularly during the Great Depression of the 1930s, it was responsible for the development of minimum standards on issues such as trade unionism, forced labour, working age and hours, sickness protection, old age pensions and others, all of which are now classed as economic, social and cultural rights (Alston \& Steiner, 2002).
} 
cultural rights have been linked more closely to the nineteenth century origins of socialism (Ishay, 2004).

\section{Indivisibility}

Although the two sets of human rights have quite different origins and economic and political implications, the international human rights framework is deliberately neutral in relation to economic or political systems (UNOHCHR, 2006). As the Committee for Economic, Social and Cultural Rights (UNCESCR) states, rights may be realised "within the context of a wide variety of economic and political systems, provided only that the interdependence and indivisibility of the two sets of human rights is affirmed" (UNCESCR, 1990, p. 1). From a human rights perspective, the state is able to establish whatever regulatory and policy framework it chooses. However, the chosen framework must ensure access to essential services of acceptable quality on a non-discriminatory basis, and must deprive no one of these services solely because they are unable to pay (UNCESCR, 1990; UNOHCHR, 2006).

Despite the neutrality of the UDHR, the two sets of human rights have tended to be associated with differing political and economic systems, as discussed above (Donnelly, 2003; Gledhill, 1997; Ishay, 2004). This association reflects an important political debate over the role of the state in wealth redistribution and economic regulation (Molyneux \& Lazar, 2003). To what degree should the state intervene in the lives of its citizens, and how should it be structured to realise their rights? Should the role of the state be minimalist, should it be interventionist, or is there room for a middle way?

These issues have always been contested, but perhaps never more so than in the ideological battleground of the Cold War (Alston \& Steiner, 2002; Ishay, 2004). Broadly speaking, western aligned capitalist states emphasised the individual, viewing civil and political rights as the only significant rights and economic, social and cultural ones as tantamount to an endorsement of communism (Bell, Nathan, \& Peleg, 2001). Conversely, communist states generally prioritised economic and social rights, claiming civil and political rights were a meaningless luxury if people's basic needs for food and shelter were not met (Alston \& Steiner, 2002). These tensions meant that by the 1960 s, 
when it was time to draft a single charter to make the UDHR binding under international law, it became impossible to gain consensus among all the UN member states. Eventually, rather than settling for no legally binding charter at all, it was agreed to create two covenants which divided the rights along ideological lines - the ICCPR and the ICESCR.

Western focus on civil and political rights during the Cold War meant human rights and human rights campaigning invariably became focused on these rights; for example, on securing fair trial and freedom for prisoners of conscience, criticism of the use of torture and freedom of speech (AI, 2005). Generally, economic, social and cultural rights remained on the margins of human rights discourse ${ }^{11}$. It was not until the end of the Cold War, the perceived triumph of capitalism and liberal democracy, and the subsequent relaxation of political and ideological tensions that the west would consider openly affirming economic, social and cultural rights again (Fukuyama, 1989). The most dramatic move in this direction took place at the World Conference on Human Rights in Vienna in 1993. At the conference, 172 states signed the Vienna Declaration and Programme of Action which explicitly reaffirmed the principles of indivisibility and interdependence of rights:

All human rights are universal, indivisible, interdependent, and interrelated. The international community must treat human rights globally in a fair and equal manner, on the same footing, and with the same emphasis. While the significance of national and regional particularities and various historical, cultural and religious backgrounds must be borne in mind, it is the duty of states, regardless of their political, economic and cultural systems, to promote and protect all human rights and fundamental freedoms

- Paragraph 5, Vienna Declaration and Programme of Action (UN, 1993).

\footnotetext{
${ }^{11}$ Although interestingly, and not without difficulty, some economic, social and cultural rights were negotiated into the later human rights treaties (Alston \& Steiner, 2002). For example, the Convention on the Elimination of Discrimination Against Women (CEDAW) of 1979 illustrates "the complex relationships among diverse phenomena that bear on women's rights" by linking patterns of authority and discrimination, both public and private, with economic dependence and key social issues such as access to education and health (Alston \& Steiner, 2002, p. 159).
} 
While today there is official recognition of the indivisibility and interdependence of both sides of the human rights framework, states continually refuse to grant economic, social and cultural rights the same respect as they do civil and political rights, and fail to ensure these rights within their own constitutions and legislative frameworks (Alston \& Steiner, 2002). As the UN Committee on Economic, Social and Cultural Rights argues, "despite the rhetoric, violations of civil and political rights continue to be treated as though they were far more serious, and more patently intolerable, than massive and direct denials of economic, social and cultural rights" (A. R. Chapman, 1996, p. 37).

\section{Cultural Relativism and Human Rights}

Cultural relativism is another constraint to the success of the international human rights framework $^{12}$. The cultural relativist tradition argues there are no universal values; instead, that values are socially constructed within particular cultural settings and are therefore relative to the cultural standards from which they derive (Bell, Nathan, \& Peleg, 2001; Parekh, 1999). Cultural relativists criticise the assumption of universalism, an inherent aspect of the international human rights framework. They suggest that rather than being universal, today's human rights, particularly today's civil and political rights (to which this critique is most commonly applied), are the product of a specific period of western history, the eighteenth century Enlightenment. Human rights are therefore not applicable to different cultures and different value systems and are nothing more than a new imperialism that is "dictating Anglo-American values to everyone else" (Bell, Nathan, \& Peleg, 2001, p. 5). Cultural relativists also consider human rights to be individualistic, focusing on the rights held by the individual rather than the duties the individual holds towards his or her community. This view, often held by those from nonwestern cultures, is considered out of place in societies in which communal values and group harmony are viewed as the basis of individual wellbeing (Sen, 1998).

The American Anthropological Association's (AAA) 1947 statement on the then draft UDHR is a good example of this argument and is a view which dominated

\footnotetext{
${ }^{12}$ For the purposes of this thesis, culture is understood as the beliefs, values, and behaviours of a community (Rao \& Walton, 2004).
} 
anthropology's response to human rights for the most part of the twentieth century. The AAA stated:

Standards and values are relative to the culture from which they derive so that any attempt to formulate postulates that grow out of the beliefs or moral codes of one culture must to that extent detract from the applicability of any Declaration on Human Rights to mankind as a whole (AAA, 1947, p. 539).

The AAA's perspective on human rights and cultural relativism was part of a broader criticism of the west's history of colonial subjugation and the associated 'white man's burden' to 'civilise' non-western cultures (Merry, 2001). In this context, the cultural relativist perspective rightly questioned the dominant modernist assumption that western culture was the height of civilisation. It emphasised that non-western views were as valuable as western ones. While this aspect of cultural relativism is laudable, the cultural relativist perspective has tended to be appropriated over the years by states wanting to escape criticism of their human rights records. This can be seen in the 'Asian values' debate of the 1990s, in which repressive regimes constructed a discourse of pan-Asian values which they claimed were fundamentally incompatible to many aspects of the UDHR (Sen, 2004).

Universalist counter-arguments to cultural relativism are usually based on either normative or formalist positions. The normative argument, which is articulated by the UDHR itself, is that human rights are derived from the inherent dignity of humanity and are therefore applicable to every person from every culture (UN, 1948). The formalist position argues even if human rights did evolve primarily in the west, the fact that today most states have ratified and agreed to be bound by international human rights law demonstrates universal acceptance of human rights (Alston \& Steiner, 2002; Donnelly, 1999). Universalists also question the cultural relativist claim that human rights are essentially individualistic by pointing to Article 29 of the UDHR. This article emphasises the duties an individual has towards his or her community and says rights must always be exercised with respect for the rights of others. At the time of drafting, Article 29 was widely considered to be a crucial aspect of the international human rights 
framework, one which would ensure a balance between individual freedom and social order (Donnelly, 2003; NZLC, 2006).

For Parekh (1999, p. 139), "if universal values are to enjoy widespread support ... democratic validation and are to be free of ethnocentric biases, they should arise out of an open and uncoerced cross-cultural dialogue". When one considers the process by which the UDHR was created, it is evident efforts were made to foster cross-cultural dialogue and to consider multiple cultural perspectives. The UDHR drafting body, the Commission on Human Rights, included members from Latin America and Asia as well as the major powers (NZLC, 2006). Additionally, before drafting the UDHR, the United Nations Educational, Scientific and Cultural Organisation (UNESCO) surveyed 150 intellectuals from around the world on the philosophical foundations of human rights. From this survey UNESCO concluded there are common convictions about basic human values, irrespective of cultural and religious differences (Lauren, 2003). These common convictions, according to UNESCO, obliged the UN to "declare, not only to all governments, but also to their peoples, the rights which have now become the vital ends of human effort everywhere" (Lauren, 2003, p. 215).

The debate between cultural relativism and universalism has traditionally been polarised between two forms of absolutism. However, in recent years there have been attempts to move beyond this polarity, particularly within anthropology (AAA, 1998; Merry, 2001; Wilson, 1997b). Contemporary processes of globalisation have led to recognition that cultures are not the static systems that a cultural relativist viewpoint assumes they are. Rather, they are dynamic and interactive, with the ability to change, interact with and borrow from one another. Cultures are also not homogenous but are full of tensions, contradictions and internal struggles over meaning and power. These tensions impact on issues of cultural identity and tradition and determine who speaks for this tradition and why (Appadurai, 2004; Merry, 2001; Parekh, 1999). This point is made strongly by Tongan writer and sociologist Epeili Hau'ofa:

It is the privileged who can tell the poor to preserve their traditions. But their perceptions of which traits of traditional culture to preserve are increasingly 
divergent from those of the poor, because in the final analysis it is the poor who have to live out the traditional culture; the privileged can merely talk about it, and they are in a position to be selective about what traits they use or more correctly urge others to observe (1987, p, 7).

Additionally, it is accepted that while as humans we share universal experiences and values, these are interpreted differently and according to different priorities in different and evolving cultural contexts (Parekh, 1999). Today, more nuanced ideas such as cultural transformation, actor-oriented perspectives and the vernacularisation of human rights offer a means by which to translate human rights across different cultures and a way to move beyond the cultural relativism - universalism polarity (An-Na'im, 2002; Merry, 2005; Nyamu-Musembi, 2002). They are an aspect of human rights practice which will be discussed in greater detail in Chapter Six.

\section{Conclusion}

The international human rights framework has evolved over the past sixty years to incorporate treaties and declarations which were not even considered when the UDHR was first written. Today, it continues to change in response to issues which constrain the realisation of human rights, issues such as the role of non-state actors, the contested relationship between civil and political rights and economic, social and cultural ones, and the ongoing debate between universalism and cultural relativism. However, while it is always evolving, the principles which underpin the international human rights framework remain the same today as they did in 1948 - those of accountability, participation, universality and indivisibility. It is these principles which have led to recent recognition of the relationship between human rights and development and the potential benefits of viewing development and poverty alleviation from a human rights perspective. As the following chapter will demonstrate, this recent recognition is part of a broader history of alternative development which dates back to the 1960s. 


\section{Chapter Four: The History of Human Rights and Development}

\section{Introduction}

Today's rights-based approaches to development are more than just another development fad. In fact, they are part of a long history of alternative ways of thinking about and doing development. In this respect, human rights can be viewed as having had "a continuous relationship to development throughout its history", even if this relationship has only recently been made explicit (Ensor \& Gready, 2005, p. 16). This chapter provides a history of the connections between human rights and development, as well as analysis of the specific contemporary factors which have led to the recent shift towards rights-based approaches to development in global development policy.

\section{The Rise of Rights}

\section{The Dawn of the Development Era}

The signing of the UDHR in 1948 signalled the beginning of the modern human rights movement. It also coincided with the emergence of the modern development era, with Harry Truman's address the following year first establishing the concepts of development and underdevelopment (Ensor \& Gready, 2005):

We must embark on a bold new program for making the benefits of our scientific advances and industrial progress available for the improvement and growth of underdeveloped areas... What we envisage is a program of development based on the concept of democratic fair dealing (Truman, 1949, p. 1).

As Truman's address demonstrates, development was understood as both a process and a goal, an understanding which continues to apply today. As a process, development implies efforts to, in Truman's words, improve and grow underdeveloped areas. Once improvement and growth is achieved, a state will have attained the goal or condition of 
being 'developed' - a condition which has been attempted and defined in many different ways over the past six decades (O’Brien \& Williams, 2004) ${ }^{13}$.

The concepts of universal human rights and development were both responses to the changing post-World War Two world, a world of decolonisation, incipient Cold War tensions and increasing global inequalities. Both human rights and development embodied the idealistic belief that through coordinated efforts by the newly formed international community, human wellbeing not only could but should be improved. And both quickly became entangled in the realist motives of Cold War geopolitics. As the previous chapter demonstrated, human rights became split along ideological lines. So too did development, becoming the means by which both communist and capitalist states bolstered ideological support among the newly formed nations and among those suffering from the post-war economic decline (Ensor \& Gready, 2005). In the west, it was commonly believed, as then NZ Minister of Foreign Affairs F.W Doidge noted, that "to checkmate communism, it is necessary to lift the standard of living of the people" in the 'underdeveloped' countries (NZ Parliament, 1950, p. 339). The most effective way to lift living standards and alleviate poverty was considered to be through an intensive process of state-driven modernisation. Through modernisation, underdeveloped countries would be able to catch up to the west. Likened to the transition of the Europe from feudalism to capitalism, modernisation theory came to dominate development economics from the 1950s to the early 1970s. It was heavily influenced by economists such as W.W Rostow, whose The Stages of Economic Growth (1960) emphasised the macro-economic determinants of what he considered a transition from 'backwardness' to 'modernity', a state characterised by high economic growth which was measured in terms of Gross National Product (GNP) (O'Brien \& Williams, 2004).

\section{Human Rights and Alternatives to Modernisation Theory}

Modernisation theory was not without its critics, many of whom questioned the assumption that macro-economic intervention and economic growth alone would improve

\footnotetext{
${ }^{13}$ As this chapter demonstrates, development was and remains an "ill-defined and contested term" (O'Brien $\&$ Williams, 2004, p. 254). For a detailed discussion of its various meanings, see Development in Practice $17(4 \& 5)$.
} 
living standards and alleviate poverty (O'Brien \& Williams, 2004). They argued that a focus on economic variables ignored the equally important social and cultural dimensions of development, and noted that even where economic growth was achieved, it was not equally shared and did not necessarily 'trickle down' to improve the living standards of the poorest in society (Ensor \& Gready, 2005).

It is within these early criticisms of modernisation theory that the first recognition of the relationship between human rights and development can be seen (Filmer-Wilson, 2005). For example, in 1959, the International Commission of Jurists (ICJ) called for a reaffirmation of the indivisibility of the two sets of human rights and stressed that development should mean the fulfilment of human rights (Ensor \& Gready, 2005). Similarly, at the drafting of the two human rights Covenants in 1966 (the ICCPR and the ICESCR), African states, many of whom had successfully used rights and citizenship struggles as a means to gain independence, emphasised the importance of understanding development within a human rights framework (Cornwall \& Nyamu-Musembi, 2004b). Likewise, in a review of the first official UN 'development decade' (1960-1970) there was criticism that human rights priorities were being disregarded by development (Ensor \& Gready, 2005). And in the 1969 UN Declaration on Social Progress and Development, the relationship between the two was made even more explicit:

Social progress and development shall be founded on respect for dignity and value of the human person and shall ensure the promotion of human rights and social justice

- Article Two, Declaration on Social Progress and Development (UN, 1969).

In the 1970s criticism of modernisation theory intensified, and with it came calls for human rights and development to be more closely connected (Ensor \& Gready, 2005). Some, such as those of the dependency school, questioned the wider global power and class structures which perpetuated poverty and inequality, suggesting it was in the interests of elites (in the developed and the developing world) to maintain underdevelopment and dependency among the poor (A. Thomas, 2000). Dependency theory was very influential on the many recently decolonised developing states during 
this period. Bolstered by their numerical majority within the UN, the recent success of the OPEC oil embargo, and the UN Conference on Trade and Development (UNCTAD), these states lobbied for an international system of trade, finance, development and investment which would be fairer on the developing world (Uvin, 2007) ${ }^{14}$. Their efforts led to the Declaration for the Establishment of a New International Economic Order (NIEO) in 1974, discussion of which dominated development debates during the 1970s, though with few concrete results (O'Brien \& Williams, 2004). One important aspect of the NIEO was its demand that development be viewed as a human right because doing so would give legal as well as ethical impetus for the redistribution of global wealth (Ensor $\&$ Gready, 2005). This was not to happen during the heyday of the NIEO, but as will be discussed further below, sustained lobbying by developing states did eventually gave rise to the 1986 Declaration on the Right to Development (DRD).

Another alternative to modernisation theory that developed during the 1970s was the basic needs approach (O'Brien \& Williams, 2004). This approach, supported by the ILO and World Bank alike, called for development to focus on agriculture and the rural sector rather than solely on industrialisation. It also emphasised the importance of the immediate fulfilment of basic needs such as health and education, and repudiated the idea that wealth would automatically trickle down to the poorest in society. Instead, the basic needs approach advocated for policies of wealth redistribution (O'Brien \& Williams, 2004). The realisation of human rights was considered an important aspect of the basic needs approach because, as the Director General of the ILO commented in 1976, human rights themselves "contribute to the attainment of other goals" such as rising living standards (as cited in Alston, 1981, p. 102).

\footnotetext{
${ }^{14}$ Despite NIEO lobbying, inequities in the international trade and economic systems continue to constrain developing countries today. In 2006 UNCTAD argued that a key reason for growing inequality is the fact that the international trade system is inherently biased towards developed countries (for example, agricultural subsidies for developed world farmers, protectionist policies for the developed world while the developing world is encouraged to liberalise). These biases mean that across developing countries, the terms of trade of exported commodities compared to imported manufactures has declined drastically over the past thirty years, with the 1975-85 average level 30\% higher than the 2005 average (UNCTAD, 2006). As Oxfam argues, if trade could be made more truly free, and also more fair, allowing developing countries to increase their share of world exports by just $5 \%$, "this would generate some US $\$ 350$ billion in additional income - seven times as much as they receive in aid" (as cited in NZAID, 2007).
} 
The ICJ also maintained its pro-human rights stance during the 1970s, commenting in 1978:

Development should not be conceived of or understood simply in terms of economic growth, nor as an increase in per capita income, but should necessarily include those qualitative elements, which human rights constitute and which provide an essential dimension (ICJ, 1981, p. 27).

And again in 1981 at its conference on Development, Human Rights and the Rule of Law the ICJ stated:

The satisfaction of basic needs would be permanently achievable only with structural change at all levels, local, national and international, that would enable those concerned to identify their own needs, mobilise their own resources and shape their own future in their own terms. Development should, therefore, be seen as a global concept including equal emphasis on civil and political rights and economic, social and cultural rights (ICJ, 1981, p. 224).

During this era there were also moves within the UN to move development away from a focus on growth and towards the fulfilment of human rights. In its 1979 report, the Commission on Human Rights confirmed the theoretical existence of the right to development, a right first claimed in 1972 by the NIEO aligned developing states at the third meeting of UNCTAD (Alston, 1981). The Commission also included a definition of development which was considered to represent a general consensus across UN member states at the time:

The central purpose of development is the realisation of the potentialities of the human person in harmony with the community; the human person is the subject not the object of development; both material and non-material needs must be satisfied; respect for human rights is fundamental; the opportunity for full participation must be accorded; the principles of equality and non-discrimination 
must be respected; and a degree of individual and collective self-reliance must be achieved (UNCTAD, as cited in Alston, 1981, p. 102).

\section{A Return to Growth: the Neoliberal Development Model}

Criticisms and alternatives to modernisation theory were set back with the 1979 oil shock and the ensuing financial crises among developing states (O'Brien \& Williams, 2004). Unable to maintain their debt repayments to the Bretton Woods financial institutions, developing states were encouraged to curtail public spending and stimulate economic growth by following strict structural adjustment policies (SAPs). SAPs aimed to quickly integrate developing economies more closely into the international market. They included the privatisation of basic social services, the liberalisation of trade through the removal of import tariffs and production subsidies, and the deregulation of domestic labour laws in order to encourage foreign investment. During the 1980s, the SAP formula was a prerequisite for loans from the Bretton Woods financial institutions and became a feature of what became known as neoliberal development. Like earlier modernisation theory, neoliberal development focused on economic growth as the primary means of poverty alleviation. However, unlike modernisation theory, the early neoliberal model did not consider the state to be an important facilitator of development. Rather, many of the functions of the state were left to the presumed impartiality and efficiency of the market (A. Thomas, 2000).

Neoliberalism was, and is, not without its critics. And again, it is within this criticism that articulation of the relationship between human rights and development emerges (Ensor \& Gready, 2005). Echoing earlier critics of modernisation threory, those critical of neoliberalism pointed to mounting evidence against the claim that economic growth will inevitably trickle down to widespread poverty alleviation. They suggested that the reverse is in fact true, that economic growth is more likely if basic social needs are first met, and that these basic social needs are best met by the state rather than the profitdriven market (O'Brien \& Williams, 2004; UNDP, 1990). These critics also questioned the assumption of market impartiality and efficiency, when markets, as human constructs, 
are distorted by unequal power relations (A. Thomas, 2000) ${ }^{15}$. Criticism was also levelled at the way the speed of transition towards open, market based economies caused significant adjustment costs to local economies - such as widespread job losses - without ensuring adequate social safety nets were in place to support those who had lost their livelihoods.

Very early criticisms of SAPs can be seen in UNICEF's Adjustment with a Human Face (Cornia, Jolly, \& Stewart, 1987) which advocated people-centred rather than growthcentred development, in Robert Chambers' (1983) work on participatory approaches to development, and in the work of Amartya Sen (1981). Sen's concept of entitlements, those things a person has control over or command of, made an important contribution to the growing body of literature and opinion linking human rights and development (ODI, 2001). Sen argued entitlements are attained through rights, and, in his landmark study on famine, demonstrated that famine and starvation are less about lack of food and more about a lack of civil and political rights among the marginalised, which limits their access to resources (Sen, 1981).

In 1986 two major events gave further momentum to the convergence of human rights and development. The first was the establishment of the United Nations Committee on Economic, Social and Cultural Rights (UNCESCR). UNCESCR provided a platform for high-level advocacy for the long neglected, development-orientated economic, social and cultural rights and argued they could be a tool with which the poor could achieve their basic needs (Filmer-Wilson, 2005). The second major event was the Declaration on the Right to Development (DRD). The DRD was the product of over a decade of campaigning by developing states. It was notable because by claiming development as a human right, it turned development and wealth redistribution from an act of charity into one of legal obligation (L. H. Piron, 2002; Uvin, 2007) ${ }^{16}$. In doing so, it reiterated some

\footnotetext{
15 See footnote 14. The developing world continues to attempt to address the unequal power relations which govern the international trade and economic system, but, as the collapse of the most recent Doha round of trade negotiations demonstrates, this process is continually thwarted by developed states (Oxfam, 2007b).

16 The Declaration on the Right to Development was based on four main arguments:

(i) The human person is at the centre of development;
} 
of the concerns of the by then largely defunct NIEO movement, particularly those around how international economic and trade systems can either facilitate or constrain development. The DRD emphasised international accountability for the creation of fairer systems:

States have the primary responsibility for the creation of national and international conditions favourable to the realisation of the right to development - Article 3 (1), Declaration on the Right to Development (UN, 1986).

And:

States have the duty to take steps, individually and collectively, to formulate international development policies with a view to facilitating the full realisation of the right to development

- Article 4 (1), Declaration on the Right to Development (UN, 1986).

Unfortunately the DRD was never supported by developed states and has rarely been taken up by movements promoting social change (L. H. Piron, 2002; Uvin, 2007) ${ }^{17}$. This is primarily because of its controversial demands for collective responsibility for the creation of favourable conditions for development, which, as the ICJ had argued in 1981, implied the need for structural change at all levels. It was also unpopular due to its operational vagueness, with state and non-state critics alike arguing it was without clear duty-bearer obligations, justiciability, and, as with all international human rights law, effective enforcement mechanisms (Uvin, 2007). However, while it may have lacked practical influence, the DRD did play an important role, creating an international model for development cooperation and raising international awareness of the relationship

(ii) The process of development should be respectful of all human rights. Development should in particular respect the right of participation;

(iii) Development should promote social justice; and

(iv) States have the primary responsibility for realising the Right to Development at the national level, but also through appropriate international policies and international co-operation (L. H. Piron, 2002, p. 5).

${ }^{17}$ See Piron (2002) for an overview of voting patterns by developed states on the Right to Development. 
between human rights and development, an awareness which would later be manifested in rights-based approaches to development.

\section{The Rise of Rights}

Despite some high-level recognition, focus on the relationship between human rights and development had remained fairly marginal from the 1950s to the 1980s. However, during the 1990s, human rights moved from the margins of development policy to the very centre. This shift was influenced by several factors, including the end of the Cold War, the rise of good governance, the evolution of the NGO and women's rights movements, and the reform of the UN. Coupled with continued criticism of neoliberal models of trade and development and the ongoing search for more effective ways to alleviate poverty, these factors eventually resulted in the rise of rights-based approaches to development.

By 1990 the Cold War was over, the old communist states had collapsed and there was a renewal of confidence in liberal democracy. However, the development community was under criticism. A decade of neoliberal reform had led to high social costs for many in the developing world, particularly those in Latin America and sub-Saharan Africa (UNDP, 1990). Poverty was still widespread and inequality had increased, leading the 1980s to become known as the "lost decade" of development (O'Brien \& Williams, 2004, p. 271) $)^{18}$. Responding to this criticism, the United Nations Development Programme (UNDP) proposed an alternative way to measure and define development. In its inaugural Human Development Report (HDR), The Concept and Measurement of Human Development (1990), UNDP sought to change the focus of development from growth to the reduction of poverty and the fulfilment of human potential. UNDP argued that "the real wealth of a nation is its people. And the purpose of development is to create an enabling environment for people to enjoy, long, healthy, creative lives" (UNDP, 1990, p. 9). In order to measure this new and multifaceted understanding of development, UNDP

\footnotetext{
${ }^{18}$ As the Human Development Report of 1992 demonstrated, the gap between the rich and the poor had widened immensely during the 1980s: while in 1980 the richest $20 \%$ of the world's population earned 45.1 times as much as the poorest $20 \%$, by 1989 this had increased to 59.1 times as much (UNDP, 1992). For information on the achievements of five decades of development see the 1998 Human Development Report (UNDP, 1998).
} 
proposed a Human Development Index (HDI). Alongside the traditional measurement of GNP as an indicator of a nation's development, the HDI measured indicators of life expectancy and education.

Just as UNDP was attempting to change the way people thought about development, another of the central development agencies, the World Bank, was also rethinking its approach. During the 1990s, the World Bank began to recognise the importance of focusing on poverty alleviation and targeting development to the most poor and marginalised, a focus which has resulted in today's Poverty Reduction Strategy Papers (PRSPs) (Molyneux \& Lazar, 2003). More recently, the World Bank's document Economic Growth in the 1990s: Learning from a Decade of Reform (2005) has emphasised the need for budget support, a more careful and selective approach to reform, and a general move towards 'bringing the state back in' to the development process, in direct opposition to early neoliberalism's calls to reduce state involvement. According to some, the World Bank's new thinking represents "the extent to which the thinking of the development policy community has been transformed" over the past decade (Rodrik, 2006, p. 1).

While UNDP and the World Bank - two of the most influential development agencies were reconsidering the means and ends of development, changes were happening in the world of human rights. The relaxation of ideological tensions that came with the end of the Cold War meant states were more comfortable acknowledging the indivisibility and interdependence of both sides of the international human rights framework: civil and political rights and economic, social and cultural ones (Filmer-Wilson, 2005). As Chapter Three described, this was demonstrated by 1993's World Conference in Human Rights in Vienna at which 172 states reaffirmed the universalism, indivisibility, and interdependence of all human rights. The Vienna Declaration also emphasised the importance of the earlier DRD and claimed "development and respect for human rights and fundamental freedoms are interdependent and mutually reinforcing" (paragraph 8, Vienna Declaration and Programme of Action, UN 1993). Although their status as declarations rather than treaties means neither the Vienna Declaration nor the DRD are legally binding under international law, for many their very existence reflected changing 
global norms, with changes in discourse being the first crucial step towards practical change (Uvin, 2007).

Not long after the Vienna Declaration and its reaffirmation of indivisibility, the rhetoric of good governance entered development discourse, and with it came some, but not all, human rights (Minogue, 2002; Molyneux \& Lazar, 2003). Good governance emerged out of the post-Cold War optimism surrounding liberal democracy, as well the recognition that successful neoliberal development requires the state to play a greater role than had been previously allowed. However, while good governance allows the state to play a greater role, this role is generally limited to the facilitation of the free market. For example, in good governance terms, the state should ensure a stable regulatory environment, sound institutions, secure contractual and private property rights, and accountability and transparency (O'Brien \& Williams, 2004; Stiglitz, 2003). Echoing eighteenth century ideas about the connections between the free market and democracy, good governance policies often emphasise the role of civil and political rights in supporting economic liberalisation (Evans, 2005). Critics of good governance argue that it is used to "blame southern governments for their own underdevelopment" and that it ignores the wider structural causes of poverty and inequality (Ensor \& Gready, 2005, p. 39). They also note that good governance's focus on civil and political rights not only undermines the rhetoric of indivisibility proclaimed at Vienna, but also that there is an inherent tension between the promotion of economic liberalisation on the one hand, and the realisation of economic, social and cultural rights on the other (Donnelly, 1999; Minogue, 2002; Uvin, 2007). Comments by UNCESCR typify some of the earliest criticisms of this tension:

The flurry of many states romantically to embrace the market as the ultimate solution to all of society's ills, and the corresponding rush to denationalise and leave economics, politics and social matters to the whims of the private sector...will inevitably have an impact upon the full realisation of economic, social and cultural rights (UNCESCR, 1992, paragraph 98). 
It was through good governance that the promotion of human rights, if only in the form of civil and political rights, first properly entered mainstream development policy. However, it was international NGOs who were responsible for broadening the focus beyond good governance's civil and political rights to include economic, social and cultural ones. As Molyneux and Lazar (2006, p. 3) identify, during the 1990s there was a conceptual shift across a range international NGOs in which they moved from being primarily "needs based and service driven" towards a more strategic approach in which "rights issues were increasingly incorporated into their work".

This was largely because NGOs recognised the need to address not only the symptoms but also the underlying causes of poverty, including political marginalisation of the poor and inequalities within global trade and economic systems (Ensor \& Gready, 2005). This recognition led many international NGOs to look to the human rights field for inspiration (Pettit \& Wheeler, 2005). They realised framing poverty as a denial of human rights, both civil and political, and economic, social and cultural, allowed scope for national and international accountability and legal redress, something lacking in traditional development (Hausermann, 1998a). Many international NGOs incorporated rights language into their policies during this period, including Save the Children, Oxfam, and Action Aid. Through participation in the various UN conferences on both human rights and development that took place during the 1990s, most notably at the World Social Development Summit at Copenhagen in 1995, these NGOs were able to push their newfound interest in human rights onto the international agenda (Cornwall \& NyamuMusembi, 2004a) ${ }^{19}$. In this way they were able to influence the policy of international donors, including the British, Swedish, Norwegian, Swiss, and Danish development agencies. By doing this, NGOs brought a broader conception of human rights to the heart of development ${ }^{20}$.

\footnotetext{
${ }^{19}$ Conferences included: the World Conference on Human Rights in Vienna (1993); the International Conference on Population and Development in Cairo (1994); the World Summit on Social Development in Copenhagen (1995); Beijing Women's Conference (1995); the World Food Summit (1996); Vienna +5; Cairo + 5; and, Beijing + 5.

${ }^{20}$ See, for example, DFID's early research report A Human Rights Approach to Development (1998) and its policy document Realising Rights for Poor People (2000).
} 
The emerging links between human rights and development were also influenced by the struggles of the women's rights movement during the 1990s. The women's rights movement had long seen the logical connection between women's lived experiences of human rights abuses, such as discrimination and political marginalisation, and poverty. At conferences such as the Beijing Women's Conference in 1995 these connections were made explicit, and it was recognised that women's rights are an essential basis for sustainable human development (UNDAW, 1995). The women's rights movement has been instrumental not only in upholding existing human rights covered in special instruments such as CEDAW, but also in creating new ones, such as the campaigns during the 1990s to have gender-based violence recognised as a human rights violation. By highlighting the fact legal change does not automatically translate into the realisation of human rights in day to day life, the women's rights movement foreshadowed the methods which today characterise rights-based approaches to development: legal and state advocacy for law reform and accountability, combined with community action focused on changing people's behaviours and empowering citizens to claim their human rights (VeneKlasen, 2004).

The final influence on the convergence of human rights and development came, appropriately given its history, from within the UN itself. Despite being founded upon respect for human rights, during its first forty years of existence the UN did not play a leading role in their promotion and defence (Jonsson, 2005). As discussed above, this was largely because it was constrained by the ideological split between its member states. However, the post-Cold War era opened up space for recognition of the indivisibility of human rights, allowing them to become a central part of discussions and conferences on development. This meant "the collective message of all the UN summits and conferences of the 1990s may be summed up as a call for greater recognition of human rights in development" (UNOHCHR, 2007, p. 1). The UN's renewed focus on human rights was given greater impetus in 1997 when then Secretary General Kofi Annan announced a programme of UN reform. Central to this reform process was the call for a human rights perspective to be incorporated into all areas of UN activity (Filmer-Wilson, 2005). This meant in its Millennium Declaration of 2000, the UN General Assembly could 
unanimously support the central role of all human rights in creating a "peaceful, prosperous and just world"(UN, 2000, Article 1) ${ }^{21}$.

Within the UN's development agency, UNDP, the incorporation of human rights into development began in 1998 with the policy document Integrating Human Rights with Sustainable Human Development. This policy recognised the connections between human rights and development and argued that "poverty is a human rights violation, and freedom from poverty is an integral and inalienable human right" (UNDP, 1998, p. 1). Two years later UNDP followed this policy with the publication of the $2000 \mathrm{HDR}$ entitled Human Rights and Human Development. Unlike the 1990 HDR which only implicitly made the connection between human rights and development, the 2000 HDR was explicitly focused on the relationship between the two. Its findings, including that "a broad vision of human rights must be entrenched to achieve sustainable human development" and the "two concepts make up a self-reinforcing virtuous circle", point to the degree discussions of the relationship between human rights and development, which for decades had remained on the periphery, had finally entered the development mainstream (UNDP, 2000, p. iii).

\section{Conclusion}

Human rights and development were both founded in the post-World War Two era and shared the goal of realising human wellbeing. As this chapter has demonstrated, concern for human rights has often appeared within critical or alternative approaches to mainstream development and as such, current discourse on human rights and development cannot be dismissed as simply another development fad. However, it was not until after the Cold War that recognition of the connection between human rights and development gained the momentum necessary to create a shift towards rights-based

\footnotetext{
${ }^{21}$ Alongside the Millennium Declaration sit the eight Millennium Development Goals (MDGs), the first example of an internationally agreed upon framework for development. While the eight MDGs do not explicitly mention human rights, they are grounded within the human rights framework and are supported by the Millennium Human Rights Goals. For an interesting discussion on the relationship between human rights and development and the MDGs, see Maxwell (2005) and Archer (2005). See Appendix One for the Millennium Human Rights Goals and examples of the overlap between the MDGs and specific human rights treaties and declarations.
} 
approaches to development in global development policy. The following chapter will look at the conceptual underpinnings of the relationship between human rights and development before exploring how the global development community understands and uses rights-based approaches, as well as some of the challenges of doing so. 


\section{Chapter Five: Human Rights and Development at the Global Level}

\section{Introduction}

This chapter draws from the literature on human rights and development in order to understand the theoretical and practical relationship between the two. The first section looks at how this relationship is understood and at the benefits of viewing development through a human rights lens. The second examines how human rights are being used for development by the global development community, focusing on rights-based approaches to development. The final section discusses the main conceptual, political, cultural and operational challenges surrounding the use of these new approaches.

\section{Understanding Human Rights and Development}

The promotion of human development and the fulfilment of human rights share, in many ways, a common motivation, and reflect a fundamental commitment to promoting the freedom, wellbeing and dignity of individuals in all societies (UNDP, 2000, p. 19).

According to UNDP (2000), the goals of human freedom, wellbeing and dignity are common to both human rights and development. In human development terms, these goals are expressed as a desire to enhance an individual's capabilities and choices so they have the opportunity to "lead a life of respect and value" (UNDP, 2000, p. 2). In human rights terms, they are understood as everyone being entitled to social arrangements which protect them from abuse and which ensure a minimum standard of human wellbeing and dignity (UNOHCHR, 2006).

At its simplest, the relationship between human rights and development is evident in the fact that poverty, or the denial of the choices and opportunities for a tolerable life, is both the antithesis of human development and is a violation of Article 25 of the UDHR: 
Everyone has the right to a standard of living adequate for the health and wellbeing of himself and of his family, including food, clothing, housing, medical care and necessary social services (UN, 1948).

The basic human rights necessary for an adequate standard of living are similar to many of the development targets found in the policy documents of the global development community, for example, the Millennium Development Goals (MDGs). However, today it is widely recognised that poverty means more than a denial of the basic material needs mentioned in Article 25 (Chambers, 2005; Sen, 1992; UNDP, 2002). Within development circles poverty is now seen as a multidimensional phenomenon which encompasses denials of "freedom from fear and violence, social belonging, cultural identity... and the ability to live a life with respect and dignity" (UNHRC, 2006, p. 9). Exclusion from political participation is also now seen as an aspect of poverty, which is important because "reducing poverty depends as much on whether poor people have political power as on their opportunities for economic progress" (UNDP, 2002, p. i).

Likewise for human rights, poverty alleviation also has political implications beyond those expressed in Article 25. From a human rights perspective, poverty is caused not only by specific rights violations, but also by violations of the human rights principles of accountability, participation, universality, and indivisibility (Petitti \& Meyer-Bisch, 1998). For example, violation of the principle of accountability can lead to corruption, which then undermines efforts to reduce poverty (DFID, 1997). Violation of the principle of participation, whether due to poverty or discrimination, means those who live in poverty are doubly marginalised as they have "the least access to the power needed to shape policies which may eradicate poverty" (AI, 2007, p. 1). Violation of the principle of universality leaves some groups within society (such as women, children, indigenous peoples or sexual minorities) insufficiently protected under national law, meaning they can in turn be more vulnerable to poverty (Hausermann, 1998a). Finally, violation of the principle of indivisibility can mean while people may have their basic material needs met, they have little chance to participate in or shape political life, or conversely, it can mean while people have ample civil liberties, they are unable, due to a lack of access to basic needs, to utilise them (Filmer-Wilson, 2005). For Hausermann (1998a, p. 138), the 
relationship between development, human rights and poverty alleviation is therefore circular and mutually re-enforcing:

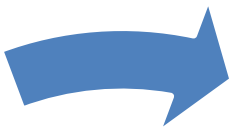

Realisation of

Human Rights

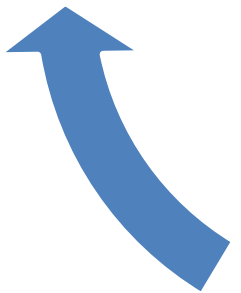

Human

Development

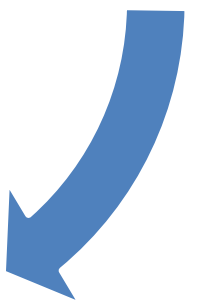

Poverty

Alleviation

Figure 1: The Relationship Between Human Rights, Human Development and Poverty Alleviation

These links mean that viewing development and poverty alleviation through a human rights lens can bring numerous benefits to existing development practice (Hausermann, 1998a; Robinson, 2005; UNDP, 2000). The main benefit stems from the human rights principle of accountability and the legal basis of the international human rights framework. Other benefits come from the human rights principles of participation, universality and indivisibility.

\section{Accountability}

Viewing development and poverty alleviation from a human rights perspective means that rather than being seen as a human condition, poverty is seen as a violation of internationally agreed upon and legally binding human rights. This turns poverty alleviation from an act of charity into one of legal accountability. It also means poverty is analysed in terms of the power relationships between rights-holders and duty-bearers, and leads to questions such as whose rights are being violated? Who benefits from this violation? And who is accountable for it? (Ball, 2005; Robinson, 2002). 
The accountability principle applies at both the national and international level. At the national level, the main human rights duty-bearer is the state and the rights-holders are its citizens. At this level, human rights can be used to empower rights-holding citizens to clearly identify state or duty-bearer accountability for the failure to uphold specific human rights standards (Filmer-Wilson, 2005). As the differences between the following two paragraphs on children's healthcare demonstrate, this clear demarcation of accountability adds power to claims for social justice and state assistance (CID, 2005, p. $44)^{22}$ :

The standards of care are unacceptably low, leading to poor nutrition and distress among most children. We call for swift action to deal with this problem.

And:

The standards of health care violate three articles of international rights law which have been ratified by the concerned government. This is in spite of the fact that the government, as legal duty-bearer, has undertaken to ensure full adoption of these articles. The awareness of the government cannot be doubted as the issue was explicitly mentioned in the proceedings of the Committee of the Rights of the Child, and clear steps were recommended. We therefore call upon the government to fulfil its legal obligations and commitments to this group of rightsholders.

Compared to the first paragraph, the second views the issues through a human rights lens. In doing so, it clearly delineates accountability, and also refers to clear steps the state can take to fulfil its human rights obligations. As discussed in Chapter Three, these steps are elaborated upon in the findings of the UN treaty bodies (such as the Committee on the Rights of the Child, the Committee on the Elimination of Racial Discrimination), as well

\footnotetext{
${ }^{22}$ These paragraphs are purely fictional and are used simply to demonstrate the power of framing problems in human rights terms. They do not relate to any real State.
} 
as in the findings of the various special rapporteurs (such as the special rapporteur for health).

From a human rights perspective, the state is the primary human rights duty-bearer. However, the principle of accountability also encourages analysis of responsibility for poverty alleviation and development at the international level (UNOHCHR, 2006). As the paragraphs below demonstrate, a focus on accountability allows us to examine donor motivations for aid, as well as the underlying structural causes of human rights violations.

Until the Millennium Declaration and the MDGs, there were few internationally agreed upon standards and accountability mechanisms for development. Bilateral development was, and arguably continues to be in spite of the MDGs, conducted on an arbitrary basis. The common denominator in the provision of bilateral development assistance was almost "exclusively that of national self-interest on the part of the donor" (HRCA, 1995, pp. 4-5). By contrast, the international human rights framework offers the global development community, developing states, and local development practitioners a common set of development processes and goals which are grounded in clear and legally binding economic, social, cultural, civil and political rights (Jonsson, 2005). This means improving the quality of life enjoyed by individuals becomes the main purpose of development, rather than political expediency or donor economic self-interest (Hausermann, 1998a; Laure-Helene Piron, 2005).

Additionally, a human rights focus on accountability draws attention to the wider political and economic structures which prevent states from fulfilling their human rights obligations (Ball, 2005; J. Chapman, 2005; Smaller, 2005; VeneKlasen, 2004). Article 28 of the UDHR says, "everyone is entitled to a social and international order in which the rights and freedoms set forth in this Declaration can be fully realised". An international order in which political power is shared fairly between states and in which trade is open and fair would go a long way to reducing the resource constraints which hinder the ability of developing state to realise their human rights obligations (Cornwall \& Nyamu-Musembi, 2004a; Falk, 2000; Hausermann, 1998a). Using human rights and the international human rights framework as a tool of analysis and a set of development 
processes and goals has the potential to reveal and then address the international power imbalances which perpetuate poverty and underdevelopment (Hausermann, 1998a; Smaller, 2005) ${ }^{23}$. As the UN Committee on Economic, Social and Cultural Rights argues:

Although human rights are not a panacea, they can help to equalise the distribution and exercise of power within and between societies - Paragraph 6, statement on Poverty and the ICESCR (UNCESCR, 2001).

\section{Participation}

Closely connected to the principle of accountability is that of participation. Since the early 1980s development practitioners have recognised the importance of stakeholder participation and inclusion in all aspects of the development process. Participation and inclusion are also important principles of the international human rights framework and are included in numerous human rights treaties and declarations including the UDHR, the CRC and the ICCPR. The most explicit expression of these principles and their relationship to development can be seen in Article 2 (1) of the DRD, which states "the human person is the central subject of development and should be the active participant and beneficiary of the right to development" (UN, 1986). Within the development field, participation was originally conceptualised as a transformative process by which power relationships would be analysed and development beneficiaries would become the subjects rather than the objects of development (Chambers, 2005). However, once 'mainstreamed', participation became less about empowerment and more a tool with which to make development projects more efficient (Cornwall \& Nyamu-Musembi, 2004b). By defining participation as both a human right in itself and also as a fundamental principle of development, a human rights perspective "sharpens the political edges of participation in the wake of the instrumentalism produced by mainstreaming" (Cornwall \& Nyamu-Musembi, 2004b, p. 4). In doing so, the participation principle encourages development projects to make rights-holders aware of and able to claim their legal rights. At its most political, participation also encourages rights-holders to analyse

\footnotetext{
${ }^{23}$ For an extensive discussion on how human rights can be used to analyse trade liberalisation, see Smaller (2005).
} 
the barriers which prevent the realisation of their rights. This in turn can be an empowering process for those whose voices and claims are normally marginalised (VeneKlasen, 2004).

\section{Universality}

The human rights principle of universality implies that everyone should have equal access to human rights. When applied to development, universality, alongside the related concepts of equality and non-discrimination, means the focus must be on the individuals and groups who may normally miss out on state services or development, such as the most marginalised or excluded within society (Hausermann, 1998a). Like accountability, universality also means that the immediate and structural institutional, political, economic and social factors which may lead to exclusion or discrimination must be analysed, and, as described further below, the appropriate duty-bearers targeted (Hausermann, 1998a; Moser \& Norten, 2001; Robinson, 2005). In this way, applying a human rights lens to development moves interventions from simple 'band aid' solutions which merely address the symptoms of poverty, to more sustainable ones which identify the underlying reasons for human rights not being universally fulfilled (Ball, 2005; Ensor \& Gready, 2005).

\section{Indivisibility}

Indivisibility implies that both sides of the international human rights framework - civil and political rights, and economic, social and cultural rights - are of equal value. Indivisibility strengthens the emphasis development places on the multidimensional nature of poverty and wellbeing, reminding us that in ordinary life, poverty encompasses all types of human rights violations:

The poor, denied access both to health care and to justice, deprived both of economic security and political power, are acutely aware of the indivisibility of rights. The rights to food, water, health, education, housing, personal security, justice and dignity itself are, for the poor, as equal and inter-dependent as they are elusive (Robinson, 2000, p. 1). 
In practice, a focus on indivisibility, like that of universality, moves development from "discrete projects in particular areas (silos) to looking at...the context of broader social change processes, which promotes links across programs and strategies" (J. Chapman, 2005, p. 2). As discussed in Chapter Three however, indivisibility does not mean it is impermissible to prioritise human rights in the case of resource constraints. Rather, it acknowledges that while prioritisation is inevitable, efforts must always be made to prioritise according to the principles of non-discrimination, equality and participation (Hunt, Osmani, \& Nowak, 2004).

\section{Using Human Rights for Development: Rights-Based Approaches}

Recognition of the benefits of using human rights standards and principles to analyse and address poverty has resulted in a shift towards human rights in global development policy. This shift is most evident in the proliferation of rights-based approaches to development (hereafter, rights-based approaches) over the past decade (Eyben, 2003). While there is no one rights-based approach, there are common elements which distinguish these approaches from other ways of doing and thinking about development. In general, rights-based approaches offer:

A conceptual framework for the process of human development that is normatively based on international human rights principles and standards, and operationally directed to promoting and protecting human rights (UNOHCHR, 2006, p. 15).

This section will focus on the type of projects typical of rights-based approaches, and the way human rights can be used as tools for stakeholder analysis and programme design ${ }^{24}$.

\section{Duty-Bearers and Rights-Holders}

Essentially, rights-based approaches focus on both strengthening the accountability of duty-bearers to fulfil their human rights obligations, and on supporting the ability of

\footnotetext{
${ }^{24}$ For examples of how multilateral institutions, international NGOs and government donor agencies are using rights-based approaches, see Appendix Two.
} 
rights-holders to claim their rights. The focus on both duty-bearers and rights-holders is a key feature of rights-based approaches because while human right may exist in law, they are often not realised in everyday life (J. Chapman, 2005; VeneKlasen, 2004). This may be due to resource or capacity constraints on the part of the state, deliberate budgetary prioritising of areas other than those which fulfil human rights (such as military expenditure), or the impact of non-state actors and global economic systems (Ljungman, 2005). Additionally, it may be that while there are moves at the duty-bearer level to realise human rights, there is cultural or political resistance at the community level. Women's rights provide an example of this resistance, as while the concept may be generally accepted within government policy, underlying patriarchal attitudes within the community may prevent these rights being realised (J. Chapman, 2005).

The way rights-based approaches can be used is demonstrated in figure two (Ljungman, 2005, p. 8):

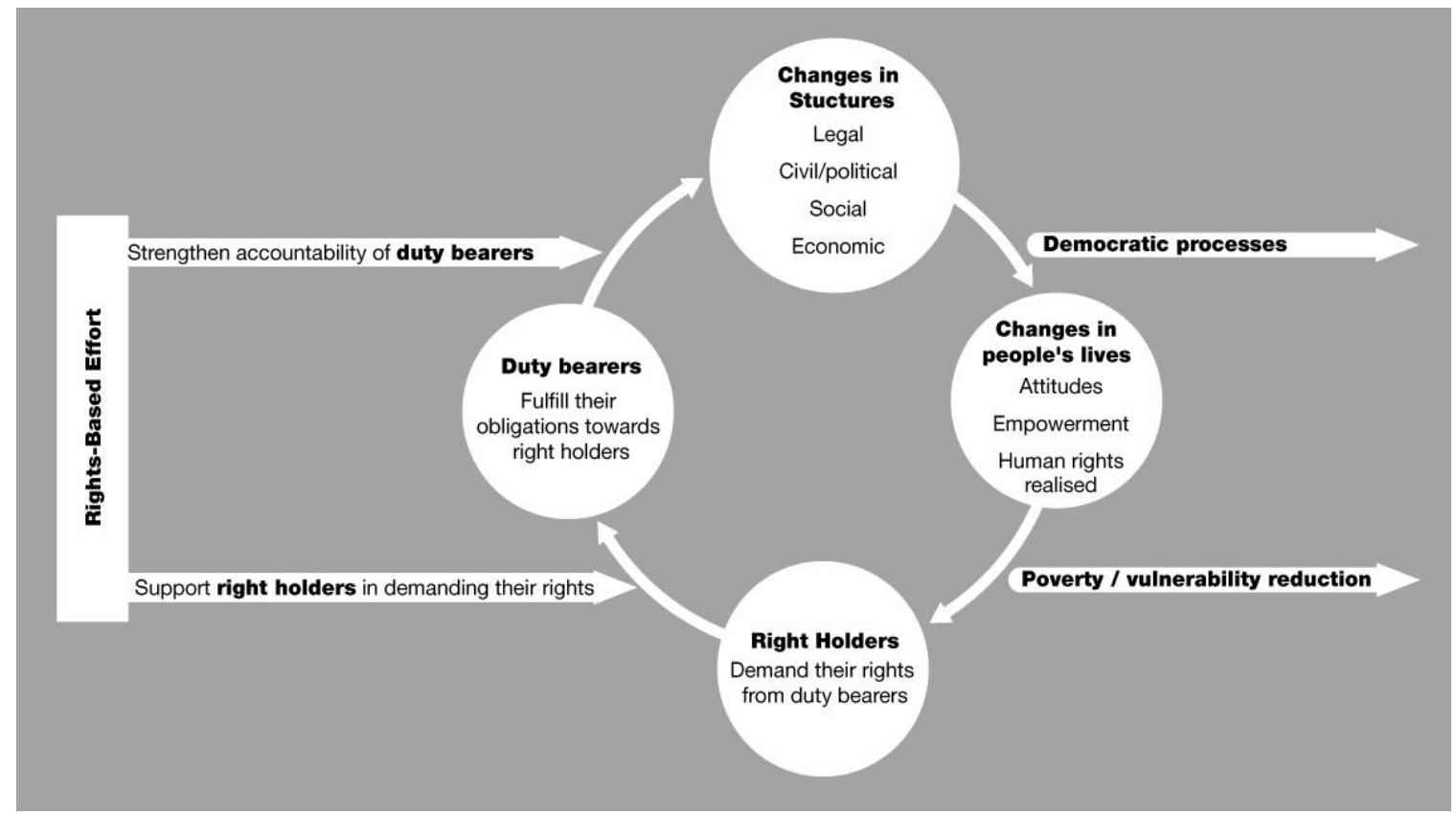

Figure 2: Using Rights-Based Approaches

Projects to strengthen the accountability of duty-bearers may include those which promote (Filmer-Wilson, 2005; L.H Piron \& O’Neil, 2005): 
- macroeconomic, legal, policy or budgetary measures to remove inequalities in status and entitlements and to harmonise laws with international human rights treaty standards;

- public sector capacity building, human rights training and human rights mainstreaming within policy;

- accountability mechanisms such as national human rights institutions, the formal judicial system and informal indigenous justice systems;

- measures to rectify structural discrimination, for example affirmative action for women or ethnic minorities;

- non-state actor adherence to international human rights norms and voluntary codes of conduct;

- participatory democracy.

Projects to support the ability of rights-holders to claim their rights may include those which (Filmer-Wilson, 2005; L.H Piron \& O’Neil, 2005):

- work with local NGOs to support human rights education and communication campaigns to promote attitudinal and behavioural change;

- encourage rights-holders to claim their rights;

- analyse budgets and policies from a human rights perspective;

- build relationships and negotiate between rights-holders and duty-bearers; and,

- encourage human rights and social impact analysis of trade agreements;

- promote rights-holder participation in local and central government processes.

\section{Human Rights Analysis}

As noted above, the most important aspect of rights-based approaches is their focus on accountability. Using human rights to analyse development and poverty issues allows the identification of the accountable duty-bearers, affected rights-holders and of possible programming interventions. Jonsson (2005, pp. 53-57) provides a five step framework for this type of human rights analysis:

1) Causality Analysis: the causes of the problem are identified in terms of the human rights violations they represent, resulting in a list of the rights which are being 
violated, the major causes of these violations, and the main actors involved. For example, if the problem is low numbers of girls receiving basic education (a problem which clearly has many subsequent social impacts), the primary right that is being violated is Article 26 of the UDHR: "everyone has the right to education, education shall be free" (UN, 1948). The major causes may be social, cultural, and economic, and the main actors are the children, parents, teachers, local and national governments.

2) Pattern Analysis: the relevant rights-holders and duty-bearers are identified on the basis of the causality analysis. In the case of girls' education, the rights-holders would be girls, while the duty-bearers would be parents, teachers, and local and national governments. Then, the actions needed in order for the right to be fulfilled are identified according to the accountability of each duty-bearer. For example, parents may need to allow their girls to go to school, teachers may need to ensure children stay in school and establish parent-teacher associations to encourage parents to value and participate in their girls' education, district governments may need to provide more schools and provide more school materials, while the national government may need to legislate for free and compulsory basic education, create policy to exempt poor families from paying school fees, and ensure adequate salaries for teachers.

3) Capacity Analysis: this step builds from the previous one in order to ascertain why the right is not being realised. It starts from the assumption that either rights-holders do not have the capacity to claim the right, or duty-bearers lack the capacity to fulfil them. Obviously, in some cases, there could be capacity gaps on both the rightsholder and duty-bearer sides. Jonsson (2005) defines capacity as a combination of responsibility, authority, access and control of resources, and ability to access and communicate information. Using the example of girls' education, the capacity of parents may be limited by lack of resources and information (about rights or education, for example), that of teachers may be limited by lack of authority and authority, and that of local and national governments by lack of responsibility, resources and communicative ability.

4) Identification of Candidate Actions: these are actions which will increase the capacity duty-bearers to fulfil the right in question. For example, with regard to 
parents as duty-bearers, actions which could help improve parental willingness to send girls to school could be the establishment of a parent-teacher association which could provide information and support to parents about education and rights, and which could encourage community involvement in education and school management.

5) Programme Design: actions are then prioritised and selected across all duty-bearers and turned into a comprehensive programme which works with both duty-bearers and rights-holders from the local level to the national.

\section{Challenges}

It is much easier to refer to a human rights approach in policy statements than to use it in practice (Hausermann, 1998b, p. 3).

Tsikata (2004) argues that it is difficult to disagree with the benefits rights-based approaches can potentially bring to existing development practice. Indeed, they are benefits which have long been fought for by those interested in alternative development: provision of an accountable framework for human-centred development; empowerment, participation, non-discrimination; and attention to the underlying causes rather than merely the effects of poverty. Rather than questioning these benefits, the main criticisms of rights-based approaches focus on the challenges of turning these theoretical benefits into practice. The challenges presented here have been analysed according to the four interrelated categories described in Chapter Two: conceptual, political, cultural and operational. They have been identified by development practitioners and academics alike, and relate primarily to the use of rights-based approaches by the global development community. However, as the following chapter will demonstrate, some of these challenges are also relevant at the local level.

\section{Conceptual}

Donnelly (1999) has questioned the conceptual relationship between human rights and development which forms the basis for rights-based approaches. As he comments: 
Human rights and ... human development 'are inextricably linked' only if development is defined to make this relationship tautological ... human development simply redefines human rights, along with democracy, peace, and justice, as subsets of development ... neither most ordinary people nor governments use the term in this way (Donnelly, 1999, p. 611).

As Donnelly criticises, the reality that neither ordinary people nor governments understand human rights and development in this way poses a huge conceptual challenge for rights-based approaches that will require much education and debate if it is to be overcome. Like Donnelly, Uvin (2004) is also critical of the way human rights and development have been linked. He questions whether rights-based approaches as they are currently understood and used by the global development community really offer anything new; whether they really go beyond what he calls the "thinly disguised repackaging of old wine in new bottles" (Uvin, 2004, p. 50). He is particularly critical of the way the potential strength of rights-based approaches, their ability to analyse power relationships and address the structural causes of poverty, is "obfuscated by a lot of the easy and self-serving rhetoric that agencies produce", in which verbal "sleights of hand" are used to redefine both human rights and development so it seems "human rights are what ... development agencies have been doing all along" (Uvin, 2007, pp. 599-600).

Uvin argues if human rights are simply neoliberal development repackaged in this way, then the essential difference between rights-based and the more traditional needs-based development becomes blurred. He believes when fully realised, rights-based approaches should do more than simply provide a service or resource as traditional needs-based development characteristically did. Rather, they should provide a social contract for development within which "the interactions between citizens, states, and corporations are structured" and which allows analysis of how these interactions impact on the most marginalised and discriminated against in society (Uvin, 2007, p. 600).

Uvin and Donnelly's criticisms demonstrate that there is some doubt around the conceptual underpinnings of rights-based approaches. These doubts are heightened by the lack of definition surrounding such approaches. This lack of definition means rights- 
based approaches are at risk of being diluted into little more than an "a la carte menu of possibilities", considered by donors, practitioners and beneficiaries alike as just another development fad which has little chance of social transformation (Vieria de Mello, 2003, p. 1). Indeed, in reviews of the way rights-based approaches have been understood and used in the policy papers of the global development community, commentators have noted that there are "plural rights-based approaches, with different starting points and rather different implications for development practice" (Cornwall \& Nyamu-Musembi, 2004a, p. 1415).

There have been numerous frameworks developed to categorise these different 'starting points ${ }^{25}$. For example, Nguyen (2002, as cited in Ensor \& Gready, 2005, p. 24) identifies four main starting points for understanding the relationship between human rights and development:

1. successful development leads to the respect for human rights;

2. respect for human rights contributes to sustainable development;

3. the realisation of human rights is one of the goals of development;

4. the realisation of human rights is the goal of development.

Nguyen's analysis implies the way an organisation understands the relationship between human rights and development clearly influences how human rights are then incorporated into its development programming. If organisations start with the belief that human rights are simply a by-product of successful development, then the language of human rights may be used merely to legitimate rather than transform existing development practices (Ensor \& Gready, 2005; Uvin, 2007). For example, the World Bank (1998, p. 3) starts from the assumption that "the advancement of an interconnected set of human rights is impossible without development" (emphasis in original). Understanding the relationship between human rights and development in this way does not require the World Bank to transform how it does development, although recent moves within the

\footnotetext{
${ }^{25}$ See, for example, Uvin (2004), Cornwall \& Nyamu-Musembi (2004a) and, Piron \& O’Neil (2005).
} 
Bank suggest it is indeed moving beyond this understanding to incorporate human rights more fully into its approaches to poverty alleviation (L.H Piron \& O’Neil, 2005).

If the starting point is that human rights lead to more efficient or sustainable development, then human rights may be integrated as tools for situation analysis, or as indicators for project monitoring and evaluation (Cornwall \& Nyamu-Musembi, 2004a). If, as in Nguyen's level three, human rights are considered to be just one of several development goals, then it is likely organisations will use them as a condition of development, or will include discrete human rights projects within their programming, most often focusing on civil and political rights and good governance (L.H Piron \& O’Neil, 2005).

Finally, if the starting point is that the realisation of human rights is considered to be the goal of development, as they are with agencies such as Oxfam and DFID, then human rights are used to redefine the entire development paradigm. At this level of integration, human rights standards and principles are integrated into every aspect of development. When understood in this way, rights-based approaches can transform power relationships between rights-holders and duty-bearers and can serve as a means of "legitimising a more progressive, radical even, approach to development" (Cornwall \& Nyamu-Musembi, 2004a, p. 46).

\section{Political}

As described above, rights-based approaches have the potential to analyse and challenge unequal power relations both within and between states, an inherently political process which "takes into consideration power, struggle and a vision of a better society as key factors in development" (J. Chapman, 2005, p. 6). Yet alongside the above conceptual challenges, the ability of rights-based approaches to fulfil their transformative potential faces significant political ones. Political challenges arise from the fact that analysis of the structures which perpetuate poverty requires developed states to acknowledge their part in these structures. While this is something government donor agencies may be willing to do, it is something their foreign affairs and trade counterparts may be uncomfortable with (Uvin, 2007). Indeed, lack of coherence between development policy and other policy 
agendas has been identified as a significant challenge to the ability of rights-based approaches to fulfil their transformative potential (L.H Piron \& O’Neil, 2005).

Some critics argue that in order to avoid this politically challenging aspect, government donor agencies have tended to interpret rights-based approaches from a state-centric perspective, focusing on the relatively safe issue of state accountability and continuing to overlook the broader structural factors which may prevent a state from fulfilling its domestic human rights obligations (Cornwall \& Nyamu-Musembi, 2004a; Uvin, 2007). When rights-based approaches are depoliticised in this way, they bypass questions of wealth redistribution and actually undermine rather than support earlier efforts by the DRD to create conditions favourable to the realisation of the right to development (L. H. Piron, 2002; UN, 1986; Uvin, 2007). Without the international dimension, rights-based approaches risk simply become another tool of good governance, which focuses on "accountability, transparency and the role of citizen participation in demanding their rights" rather than government and international responsibility for fulfilling them (Mohan \& Holland, 2001, pp. 182-183). If they focus primarily on these aspects of human rights framework and ignore issues of international accountability and economic, social and cultural rights, critics argue that the potential of rights-based approaches to "challenge the structures which create underdevelopment" will be compromised (Mohan \& Holland, 2001, p. 195).

The political challenges surrounding rights-based approaches mean that to date, there has been "little evidence that the structural violence and injustice of global power systems are being truly challenged by the philosophy of equal rights now mouthed by power itself' (Slim, 2002, p. 4). Like Slim, Uvin (2004, 2007, p. 603) is also concerned that rightsbased approaches are being mouthed by the wrong people, that they constitute a "voluntary act by people in New York, Washington, London, or Geneva - smart and well intentioned, most of them, but not exactly those in great need of overthrowing the established order" rather than being fought for "by the masses in whose name it is adopted”. For both Slim (2002) and Uvin (2004, 2007), if rights-based approaches are going to fulfil their potential, they will need to take root at the local level, and among 
those international NGOs who work closely with their local partners in developing countries.

\section{Cultural}

Chapter Three demonstrated that issues of culture and human rights are often cause for debate. So too are issues of culture and development itself. Traditionally, if development has considered culture at all, it has seen it as a barrier to economic growth (Harrison \& Huntington, 2000; Rao \& Walton, 2004). However, in line with the broader post-Cold War revaluation of development as a whole, and also influenced by the more nuanced approaches to culture which will be discussed in Chapter Six, there is now a general consensus among the global development community that culture does indeed matter to development. How it matters though is widely debated (Douglas, 2004; Rao \& Walton, 2004). For Sen (2004), culture matters for many different reasons, including that cultural factors influence economic behaviour, political participation, a society’s social capital and, most importantly for the current discussion, that culture influences value formation and evolution (Putnam, 1993). Yet, when it comes to rights-based development, the consensus that culture matters, though identified as a challenge, has been largely neglected in the policy papers of the global development community (Ensor, 2005; L.H Piron \& O’Neil, 2005). Many policies seem to start with the assumption that human rights are generally accepted and that what is necessary is simply to assist rights-holders in the claiming of these rights (Ensor, 2005). However, this assumption overlooks the reality that in many non-western communities, human rights are perceived as threatening to established patterns of life (Parekh, 1999). This makes applying rights-based approaches within non-western communities very challenging. It is an issue which will be explored in greater detail in the following chapter as it is particularly relevant to the work of local NGOs in developing countries.

\section{Operational}

A key operational challenge identified in the literature on rights-based approaches is that

they fundamentally change the way development organisations operate. When taken to their logical end point, rights-based approaches mean the normative principles and standards of the human rights framework are applied to every aspect of a development 
organisation's work, including its projects and goals, its relationships with partner organisations and those with local communities (Jones, 2005; VeneKlasen, 2004). Additionally, rights-based approaches require organisations to have a comprehensive understanding of the international human rights framework, knowledge traditional development practitioners do not usually have (Jones, 2005). Also, as demonstrated above, the political aspect of rights-based approaches can also be challenging for development organisations. This is particularly true for many local and international NGOs, for whom "claiming to be apolitical has been a survival strategy", in terms of securing donor funding, remaining operational under repressive domestic conditions or maintaining solidarity with other civil society organisations (J. Chapman, 2005, p. 33; VeneKlasen, 2004). Finally, the multiple definitions of rights-based approaches and the evolving literature on their implementation means for many development organisations, rights-based approaches generate "as much confusion as excitement" and "while most development people have got their hearts around a rights-based approach, they have yet to get their heads around it" (Slim, 2002, p. 2).

Another important operational challenge to rights-based approaches involves the adequacy and accessibility of local legal systems. As discussed above, the legal accountability that the international human rights framework brings to development is one of the main benefits of rights-based approaches. However, international enforcement of human rights law is difficult, while within many developing states, the legal mechanisms for upholding and protecting human rights are often inadequate. As Ljungman (2005) notes, although states may have signed human rights treaties, they may not have ratified them, meaning the standards may not be incorporated into domestic legislation. Additionally, even where there is coherence between international human rights law and domestic legislation, policy makers may not be educated in human rights and may make policies which unintentionally undermine them. Finally, existing policies may be out of date with more recently ratified human rights treaties. Even where legal systems are adequate, they may be physically or economically inaccessible to those who most need them (Cornwall \& Nyamu-Musembi, 2004a). 


\section{Conclusion}

For human rights to become meaningful in people's daily lives there must be a fundamental change in power relationships at both the local and global levels (J. Chapman, 2005). One of the main benefits of viewing development from a human rights perspective is that it becomes grounded in international law and thus has the potential to challenge and change these power relationships. The shift towards rights-based approaches within donor policy demonstrates how this idea has started to impact on the way the global development community understands and practices development. But as the above challenges suggest, translating the theoretical benefits of human rights rhetoric from policy into real world impacts is neither an easy nor an automatic process. The following chapter will investigate if this global rhetoric is influencing local realities by looking at how local NGOs use human rights for development, and at some of the challenges they face in doing so. 


\section{Chapter Six: Human Rights and Development at the Local Level}

Rights-talk in Washington or Paris might be used piously as new words for the same old liturgy in the cathedrals of international trade and development ... But from another place (a slum or the scene of a rigged election) and spoken from another voice (that of a poor man or a woman land rights lawyer) the same words or rights-talk could function prophetically as a demand for redress to change and challenge power (Slim, 2002, p. 3).

\section{Introduction}

As Slim (2002) and others argue, it is when human rights and rights-based approaches are translated from global rhetoric into local reality that they have the power to create social change (VeneKlasen, 2004). However, while there is much discussion of the way human rights are incorporated into the policy papers of the global development community, there is less known about how they are being used for development at the local level (Ensor \& Gready, 2005; Gaventa \& Jones, 2002; Molyneux \& Lazar, 2003; Pettit \& Wheeler, 2005). This is despite the fact that supporting rights-holders to claim their rights is an integral aspect of rights-based approaches and is a process which for many donor agencies involves the use local NGOs. Indeed, as this chapter will demonstrate, it is a process which is best facilitated by local NGOs (Molyneux \& Lazar, 2003; L.H Piron \& O’Neil, 2005). How then do these local human rights and development NGOs understand the relationship between human rights and development? Do they view development through a human rights lens? Does the rights-talk used in the "cathedrals of international trade and development" impact on their day to day work (Slim, 2002, p. 3)? And what factors may challenge the use of human rights for development at this local level?

To explore these questions, this chapter begins by situating the role of local NGOs within the broader context of development. It then discusses the important role they play when it comes to 'translating' international ideas to the local level, and how this role is 
particularly important when it comes to human rights. Finally, it reviews case studies of NGOs working with human rights and development in order to ascertain how human rights and development are being understood and used in different contexts, and to identify challenges to the use of human rights for development at the local level ${ }^{26}$.

\section{Local NGOs in Developing Countries}

\section{Historical Context}

During the colonial period, local NGOs in developing countries were usually restricted to service delivery and welfare provision, with any broader political role being strongly discouraged by colonial authorities (Boli \& Thomas, 1999). However, in the independence era many local NGOs did become politicised through their involvement in independence movements. This political role was furthered with post-colonialism, when many NGOs evolved and diversified in response to local and global development themes and local concerns, including those of women's rights, indigenous rights, environmental and health issues (Ahmed \& Potter, 2006).

From the early 1990s onwards, local NGOs, like their international counterparts, played an increasingly important role as agents of development and received increasing amounts of direct donor support (Eade, 2000). This new role was influenced by neoliberal development policy, in which privatisation of state services led to a focus on the non-state sector for service delivery (Ahmed \& Potter, 2006; Whaites, 2000). Within this ideological climate, channelling donor funds through local and international NGOs was considered to be a more efficient means of reaching the poor than the direct funding of recipient states which had previously been the norm. In part to justify this transfer of funding from the state to the non-state and NGO sector, donors established the rhetoric of civil society, arguing that support for civil society was fundamental to the establishment of democracy in a post-Cold War world (Ahmed \& Potter, 2006; Whaites, 2000). Yet

\footnotetext{
${ }^{26}$ Case studies were drawn from the following qualitative interview and questionnaire based research:

- IDS's "Linking Rights and Participation" project (2004) and "Sustainable Livelihoods in Southern Africa" project (2003);

- UNDP's “Lessons Learned From Rights-Based Approaches" project (2005); and,

- Molyneux and Lazar's case study on Latin American NGOs (2003).
} 
precisely as they were being heralded by donors as the new face of neoliberal development, NGOs were recognising the limits of service delivery to affect long-term structural change. As Commins (2000, p. 70) comments, many NGOs feared they were becoming little more than "the delivery agency for a global soup kitchen, handing out meagre comfort amidst harsh economic changes and complex political emergencies". They worried they were propping up the very neoliberal development models so many of them criticised. Worse still, local and international NGOs alike found their work constrained by donor funding requirements, as few government donors were willing to support projects which advocated for structural change, preferring instead to support the less politically controversial provision of basic services (Eade, 2000; Korten, 1990).

\section{Contemporary Context}

Today, local and international NGOs are still faced with this conflict between donor priorities and the need for long-term structural change. However, donor attitudes towards NGOs have become much more "complex, ambiguous and controversial" than they were during the 1980s and 1990s (Lewis \& Opoku-Mensah, 2006, p. 669). As Chapter Four discussed, donors are increasingly recognising the limits of the weak state model of development that was preferred by early neoliberalism (Rodrik, 2006). The World Bank (1997, p. 25) itself acknowledged the importance of the state for development as early as 1997, noting in its World Development Report that "state dominated development has failed, but so will stateless development. Development without an effective state is impossible". This recognition has resulted in increased bilateral engagement between donors and recipient states, with good governance and the PRSPs an example of this new focus. The refocus on bilateral aid relationships has meant while NGOs continue to play an important role in development, they no longer receive quite the acclaim they did during the 1990s (Anderson \& Rieff, 2005; Tvedt, 2006).

\section{Human Rights, Culture and Local NGOs}

\section{Local NGOs: Global Rhetoric, Local Realities}

While the place of NGOs within development may have changed, in one respect their role has remained vital. Local NGOs have consistently functioned as intermediaries, 
translating ideas generated by the global development community into local contexts (Merry, 2005). Some criticise this role, arguing that due to their reliance on donor funding, local NGOs are little more than contemporary manifestations of nineteenth century missionary movements, spreading a western version of wellbeing and truth (Anderson \& Rieff, 2005). Others suggest that local NGOs have more agency than this view allows (Hilhorst, 2003; Tvedt, 1998; Wallace, Bornstein, \& Chapman, 2006). They agree that local NGOs work within development systems and are guided by development theories which "are not determined by the internal characteristics of different cultures" (Tvedt, 1998, p. 229). Yet, they argue that local NGOs translate these systems and theories into specific cultural contexts, rather than simply applying them uncritically. In doing so, local NGOs work in a space of "cross-cultural communication" (Tvedt, 1998, p. 229). In this space, they facilitate debate on what constitutes development at the local level, and translate ideas from the global to the local and back again.

\section{Human Rights: Global Rhetoric, Local Realities}

The boundaries of cultural systems are leaky and ... traffic and osmosis are the norm, not the exception (Appadurai, 2004, p. 61).

Human rights have been criticised for spreading a particularly western version of wellbeing which disregards cultural difference and privileges the rights of the individual over those of the community (AAA, 1947). As Chapter Three demonstrated, this cultural relativist view of human rights is countered by the normative and formalist arguments for universalism. Universalism views human rights as either derived from humanity itself, or as legitimised by their almost universal acceptance within the state system.

Until recently, the cultural relativist - universalist divide dominated human rights discourse. However, today there are more nuanced interpretations of human rights which attempt to find a middle ground between the two extremes. Many of these recent interpretations have come from the anthropology field and have been influenced by social constructivist views of culture (Englehart, 2003; Merry, 2001; Wilson, 1997b). They acknowledge that human rights offer basic standards for human behaviour and 
interaction, but argue they are able to be "created, re-created and instanciated by human actors in particular socio-historical settings and conditions" (Stammers, 1999, p. 980). This means that rather than undermining non-western cultures, human rights can in fact be applied in ways which interact and resonate with existing cultural values and beliefs (Leonard, 2006) ${ }^{27}$. These more recent interpretations of human rights also argue that rather than simply being a static product of a specific time and place (the west circa 1948), human rights are in fact dynamic, evolving in response to changing social norms, emerging struggles and new types of violations. This argument is supported by evidence of the many treaties and declarations which have been added to the international human rights framework over the past sixty years, including those on children, women, indigenous people and development, and by the renewed interest in economic, social and cultural rights as a response to their violation by new, non-state actors such as transnational corporations (Mitchell \& Wilson, 2003). Indeed some commentators recognise that in the face of emerging moral, political and social issues, the international human rights framework is characterised less by concrete universals and more by a process of socially constructed continuity and change (Forsythe, 2000).

These views of human rights relate to recent rethinking, particularly within anthropology, on the nature of culture itself (AAA, 1998; Appadurai, 2004; Merry, 2001; Wilson, 1997b). Traditional anthropological thought viewed culture as something autonomous and homogenous, a view which allowed ideas such as cultural relativism to flourish (Wilson, 1997a). However, as Mitchell \& Wilson (2003, p. 9) comment, in today's world of unprecedented cultural and economic globalisation, it is nearly impossible for cultures to exist autonomously and therefore culture is increasingly understood in terms of "interconnections, networks and movements of people, ideas and things". Additionally, where culture was once considered to be relatively homogenous, today it is generally recognised that within every culture there are a many subcultures, contradictions and "contested attributes" (Rao \& Walton, 2004, p. 4). These contested attributes may reflect internal struggles over resources and power. They can mean that what is deemed to constitute traditional culture may change according to the interests of those who define

\footnotetext{
${ }^{27}$ It is important to note that cultural beliefs and values may be quite different from cultural practices, which can at times undermine beliefs and values (NZLC, 2006).
} 
and benefit from it (Hau'ofa, 1987; Parekh, 1999) ${ }^{28}$. This recent recognition that cultures are neither autonomous nor homogenous has allowed debate on culture and human rights to move beyond the conventional cultural relativist - universalist divide towards a more nuanced middle ground in which "the local and the global touch, but need not always collide" (Downey, 2003, p. 310).

There are several examples of this new thinking about human rights and culture. NyamuMusembi (2002, p. 1), drawing on the work of Giddens (1984), writes about "actororiented perspectives" on human rights. In general, actor-oriented perspectives begin from the premise that people's lives are constrained by the political, social and cultural structures that surround them. However, rather than being static, these structures are essentially a construct which people have the ability to influence and change (NyamuMusembi, 2002). In relation to human rights, actor-oriented perspectives address the interplay between the global structure that is the international human rights framework, and the meaningful construction of these human rights by people acting within specific local contexts (Nyamu-Musembi, 2002). They suggest the formal recognition of human rights by the international community means little unless these rights are seized from below, and for them to be seized from below they must be viewed as relevant to local social, political and economic struggles.

An-Na'im's (2002) work on the cultural transformation of human rights is another example of this new thinking. Like Nyamu-Musembi, An-Na'im believes that rather than simply being imposed from above, human rights must be made meaningful at the local level. However, rather than relating human rights to local struggles, he suggests human rights need to be sanctioned and internalised by local cultures (An-Na'im, 2002). In practice, cultural transformation can be facilitated by identifying the lack of cultural

\footnotetext{
${ }^{28}$ An example of how tradition can change according to the interests of those who define it can be seen in the contested role of women in public life. Contemporary male leaders often claim that traditionally, Pacific women were involved solely in 'domestic' issues, with little external influence. But as the Pacific Women's Programme for Action from the Beijing Women's Conference in 1995 states, this is a highly selective interpretation of tradition:

"Women traditionally played an important and vital role in the household, in productive activities, and in community management. Through more than a century of exposure to colonial and other influences, women have been marginalised from the mainstream of government planning and decision-making" (UNESCAP, 1995, p. 1).
} 
support for a particular human right and then identifying ways this right may be legitimised in terms of existing cultural values, beliefs and processes of change. AnNa'im's approach emphasises that as humans we do share universal experiences and values (an assertion supported by numerous ethnographic studies of different cultures), but these experiences and values may be interpreted and expressed differently in different contexts (An-Na'im, 2002; Downey, 2003; Josephides, 2003; Parekh, 1999).

Like An-Na'im and Nyamu-Musembi, anthropologist Sally Engle Merry (Merry, 2005, p. 1) also argues "in order for human rights ideas to be effective ... they need to be translated into local terms and situated within local contexts of meaning". She calls this process "vernacularisation" (Merry, 2005, p. 219). Having documented the work of independence and women's rights activists working in many different cultures, Merry notes the most effective examples of vernacularisation involve framing human rights with images, symbols, narratives, and religious and secular language drawn from the local culture. An example of vernacularisation or cultural transformation can be seen in the Manual for Women's Human Rights Education in Muslim Societies developed by Muslim women from a variety of different cultures (Nyamu-Musembi, 2002, p. 9). The manual covers a range of rights situations such as those within the family, rights to education and employment, and rights to political participation. It is interactive, its exercises combining conventional human rights language with excerpts from the Qur'an, Shari'a rules, idioms, stories and personal experiences. Because it has translated human rights in this way and made them resonate with Muslim values and beliefs, the manual has been very successful (Nyamu-Musembi, 2002).

These new approaches to understanding human rights argue that for global human rights norms to become meaningful in people's day to day struggles, they need to be related to local contexts and cultural values. Of course, as An-Na'im, Merry and Nyamu-Musembi acknowledge, this process is not without its challenges, for example, as discussed above, who is to decide what these local cultural values are? And what happens when local values or cultural practices completely contradict international human rights law? Echoing participatory development, all these approaches suggest discussion is the best way to negotiate the "babble of competing ideas, resistance and accommodation" which 
results from the interaction of global norms with local realities (Englehart, 2003, p. x). As Sen (2004, p. 42) explains, "value formation is an interactive process, and the culture of talking and listening can play a significant part in making these interactions possible". It is through talking and listening that people can engage and participate in the construction of all cultural values, including human rights, allowing them to be claimed and owned by local communities rather than simply imposed from above.

\section{Local NGOs: Translating Human Rights}

The rights embodied in UN conventions and declarations often seem remote from the daily lives of those who most stand to benefit from them, namely, the excluded and the poor (Molyneux \& Lazar, 2003, p. 2).

Local NGOs are particularly valuable actors when it comes to the inter- and cross-cultural translation of human rights. Firstly, their intermediary position between global ideas and local contexts allows them to make connections between formal human rights frameworks and what "makes rights become substantive in terms of people's actual experiences" (Englehart, 2003; Pettit \& Wheeler, 2005, p. 6). Secondly, local NGOs are able to take local experiences and 'frame' them in international human rights language (Merry, 2005; Molyneux \& Lazar, 2003). In fact, this is one of the most crucial roles local NGOs play. By framing local experiences in international terms, they can help the most socially marginalised bypass "the larger political life of a society which offers them no place in its conception of the good" and to find support and redress in international norms (Gledhill, 1997, p. 106). Finally, NGOs have a history of human rights construction and advocacy. Chapter Three described how social movements, of which NGOs are one manifestation, were crucial in the creation and construction of the rights now codified in the UDHR. Whether campaigning for the rights of workers, women, slaves or indigenous peoples, part of the essence of social movements is that they "construct claims for human rights as part of their challenge to the status quo" (Stammers, 1999, p. 998). This role is particularly important under contemporary social and economic conditions in which the influence of the state, the primary human rights duty-bearer, is being challenged by non-state actors such as transnational corporations. 
As Stammers (1999, p. 1007) argues, given this contemporary reality, it is essential social movements and NGOs move into the space vacated by the state in order to "extend popular understanding of human rights as challenges to extant relations and structures of power".

\section{Local NGOs and Rights-Based Approaches}

Interventions must be more sensitive to historical context and local practices and needs, and less beholden to the agendas created in New York, London or Geneva (Mitchell \& Wilson, p. 13).

The above section demonstrates why local NGOs are in an ideal position to use human rights for development and to realise the potential of rights-based approaches (Molyneux \& Lazar, 2003). However, "very little is known about ... how rights languages are actually used in situated struggles, by different individuals and groups, and to what effect" (Gaventa \& Jones, 2002, p. i). This section will draw from case studies on local NGOs, human rights and development in order to gain an insight into how concepts of human rights, development and rights-based approaches are understood and used at the local level. Despite the fact that each case study reflects a specific local context and a unique blend of historical, political, social and cultural factors, it was possible to identify common themes. These themes will be presented according to the ways local NGOs understand human rights, development and the relationship between the two, and then how they use human rights for development. In the last section, the focus will shift to the main conceptual, political, cultural and operational challenges of using human rights for development at the local level.

\section{Understanding Human Rights and Development}

Among the global development community there is a general consensus on the shared goals of human rights and development, and this general consensus was also evident in the local NGO case studies. For example, representatives from Zimbabwean NGOs said human rights and development are essentially about "enhancing the inherent dignity of each person ... sending the message that every human matters, rich or poor, urban or 
rural, male or female" (Makanje, Shaba, \& Win, 2004, p. 21). For both development and human rights, representatives noted the goal is "to ensure a good life for everyone" which means "all material needs are met, there is freedom to choose in every sphere for one's life, freedom from oppression...freedom to participate" (Makanje, Shaba, \& Win, 2004, p. 21). Similarly, in India, many of the local NGO representatives interviewed implicitly noted the overlapping goals of human rights and human development, stating their work was based on both claims for social justice and on "political transformation through people's empowerment" (NCAS, 2004, p. 13). The shared goals of social justice, development and human rights was clearly demonstrated in the slogans of one Indian NGO representing former bonded labourers and Adivasis, which asserted "We are not animals, but human beings...we are not here to beg, but to demand justice" (NCAS, 2004, p. 13).

Representatives from the Latin-American NGOs surveyed by Molyneux and Lazar (2003) also tended to support the connection between human rights and development. Women's groups in particular considered their work with development to be an "extension and development of their long-standing commitment to the promotion of rights" (Molyneux \& Lazar, 2003, p. 45). Several representatives interviewed in this Latin-American case study also noted the empowering potential of linking human rights with development. For example, the director of a Peruvian children's rights network said:

Seeing a person not only as a person with needs, but as a person with rights, allows people to see themselves as citizens (Molyneux \& Lazar, 2003, p. 47).

This argument was echoed by another representative from a Bolivian women's rights organisation:

We're working on helping women to understand that there is protection for them, through universal norms. This helps them to feel more secure and less isolated. They realise that there are other countries where women are fighting for the same thing, and that we are all in the same situation (Molyneux \& Lazar, 2003, p. 46). 


\section{Rights versus Development}

However, despite similar goals, many local NGO representatives commented on the differences between 'rights' and 'development' work in practice, with debates over the relevance and importance of each being a feature of several of the case studies. While this difference was acknowledged in some of the global literature (although not in the policy papers) on rights-based approaches, it was more marked at the local NGO level (Ensor \& Gready, 2005). Representatives from human rights NGOs considered their work to be more important than traditional service delivery or basic needs development because, rather than simply treating symptoms of problems, it attempted to address their underlying causes (Jasis \& Garcia, 2004; Lumbantobing \& Zulminarni, 2004; VeneKlasen, 2004). Representatives of NGOs involved in development on the other hand tended to characterise their work as of more immediate relevance to local populations (Banerjee, 2005; Makanje, Shaba, \& Win, 2004).

An demonstration of this gap can be seen in comments made in the Zimbabwe case study. For example, Zimbabwean civil society activist Deprose Muchena noted a typical response to recent constitutional debate in Zimbabwe was "does a hungry person eat a constitution? What does this document have to do with the price of mealie-meal?" (Makanje, Shaba, \& Win, 2004, p. 22). He added that local NGOs working on issues of constitutional rights were often castigated by those in power, for "engaging in idle debate while the nation starved" (Makanje, Shaba, \& Win, 2004, p. 22). Markanje, Shaba \& Win (2004) also observed that the perceived irrelevance of human rights also exists at the community level, explaining that if given the choice, rural women in Zimbabwe would prefer a practical workshop on gardening to one on human rights, which would be seen as a luxury. These observations were echoed elsewhere too. For example, in the Philippines, the Centre for Community Journalism, a local NGO, found it was difficult to engage poor and marginalised people, for whom "struggle for basic survival often precedes engagement in civic action that can be very time intensive" (Banerjee, 2005, p. 324). One way local NGOs in India overcame this challenge was to offer a tangible service - for example education - in order to gain acceptance and entry into a community, and from there discussed human rights issues (Banerjee, 2005). 
As one Zimbabwean NGO representative commented, "our organisation does development. We don't do those rights things" (Makanje, Shaba, \& Win, 2004, p. 13). The following table demonstrates the perceived differences between development and "those rights things" as explained by NGOs in Zimbabwe (Makanje, Shaba, \& Win, 2004, pp. 13-14):

\begin{tabular}{|c|c|}
\hline Development Organisations & Human Rights Organisations \\
\hline Use practical projects & Talk about human rights \\
\hline Deal with socio-economic problems & Deal with political problems \\
\hline Work in and with rural and poor communities & $\begin{array}{c}\text { Work at the national or central government } \\
\text { level on policy or legislation }\end{array}$ \\
\hline Allow stakeholders to participate in projects & Allow little stakeholder participation \\
\hline Have a good relationship with government & $\begin{array}{c}\text { Have a confrontational relationship with } \\
\text { government }\end{array}$ \\
\hline Use participatory methodologies & $\begin{array}{c}\text { Do not use participatory methodologies, } \\
\text { instead use complicated legal language }\end{array}$ \\
\hline Results are visible and measurable & Results are difficult to see and measure \\
\hline
\end{tabular}

Table 3: Perceived Differences Between Development and Human Rights Organisations

The distinction between human rights and development organisations was echoed elsewhere. Carmina Perez, an activist with a human rights group in Mexico, commented that there is little dialogue between the human rights and development communities there (Jasis \& Garcia, 2004). She added that often, local development NGOs will work "without understanding the relationship between fighting for decent housing, and the right to decent housing" (Jasis \& Garcia, 2004, p. 23). Similarly, authors of the Indonesian case study noted there was generally little recognition by development practitioners of how human rights can be used to engage critical awareness (Lumbantobing \& Zulminarni, 2004). 


\section{Using Human Rights for Development}

Throughout the case studies local human rights and development NGOs used human rights in a variety of creative ways at both the rights-holder and duty-bearer level. In Zimbabwe, for example, Mankanje, Shaba and Win (2004) describe how local NGOs provided human rights education through drama and song, used human rights for advocacy, worked with communities to empower them to claim their rights from the state, or worked on law reform and litigation at the national level. In Brazil, human rights were used with success in struggles for rural land ownership and urban housing, and were closely tied to citizenship rights through the establishment of participatory democracy (Junior, Antunes, \& Romano, 2004). For many of the NGOs in Molyneux and Lazar's (2003) Latin-American case study, it was critical for human rights be used as a tool for personal empowerment, because without this aspect, wider social change would not take place. An important first step for personal empowerment was to educate people about the relevance of human rights in their everyday lives, or, as a Bolivian representative noted, making them part of "daily life, [of the] personal emotional environment, work environment and human relations"(Molyneux \& Lazar, 2003, p. 51).

\section{Rights-Based Approaches?}

Representatives from most case study NGOs were aware of the concept of rights-based approaches, but did not describe their work in such terms (Lumbantobing \& Zulminarni, 2004; NCAS, 2004; Toyo, 2004). While representatives from human rights NGOs did tend to view their from a human rights perspective, those working in community development tended to use human rights as one of many tools of analysis and practice, often using them to complement existing initiatives or in the form of educational or advocacy projects. For example, although women's groups in the North west of Nigeria were apparently "entirely unaffected by the prevailing rhetoric of rights-based approaches as canvassed by the mainstream", they were still incorporating human rights campaigning into many of their development projects (Toyo, 2004, p. 33). In Indonesia, although NGOs were aware of rights-based approaches, the approaches they used in the field were "frequently not based on a particular concept or theory, but on their field experience as advocates and individuals" (Lumbantobing \& Zulminarni, 2004, p. 32). 
Where local development NGOs were more aware, usually because of donor influence, of rights-based approaches and did categorise their work in such terms, the way they then used such approaches varied considerably. Characteristically, these organisations used human rights as a lens through which they viewed all their work, but while some focused on community level empowerment, others worked at the national level to lobby governments and promote law reform (Junior, Antunes, \& Romano, 2004; NyamuMusembi \& Musyoki, 2004). In the Kenyan case study, Nyamu-Musembi and Musyoki (2004, pp. 6-7) identified five ways in which development NGOs used rights-based approaches:

1. re-orientating the focus of their programming around the attainment of specific rights or the empowerment of a particular group of marginalised or vulnerable people;

2. explicitly applying the international human rights framework to all their work;

3. enabling communities to engage with government (thus giving effect to the right and principle of participation);

4. helping partner organisations to develop more participatory and legitimate internal governance structures so issues of inequality and poverty are addressed; and,

5. building alliances and networking with civil society groups working in the area of human rights.

The multiple ways in which local development NGOs use rights-based approaches are inevitable given the similarly diverse understanding and use of rights-based approaches at the global level. To a certain extent, these multiple understandings and practices reflect the fact rights-based approaches are new and evolving. They also suggest that such approaches must be grounded in local contexts in order to succeed, rather than being imposed according to a formula from above.

\section{Challenges}

This section presents the challenges of using human rights for development, as identified in the NGO case studies. Once again, challenges are presented according to four interrelated categories: conceptual, political, cultural and operational. 


\section{Conceptual}

The local NGOs in the case studies generally agreed on the overlap which exists between the goals of human rights and those of development. However, while this is easy to agree on in theory, many of the case studies demonstrated that in practice there remains a divide between organisations traditionally considered to be human rights-based and those viewed as development-based. This divide poses a significant challenge to the concept of rights-based development, particularly as it means local communities themselves can consider human rights an unnecessary luxury rather than a means by which to claim economic and social justice. It clearly reflects the enduring perception of human rights as synonymous with civil and political rights. As Chapters Three and Four explained, Cold War ideological differences meant that until recently, this perception dominated the human rights field. It is a perception that has also influenced the way some donors, such as those from government and some multilateral institutions, have incorporated human rights into development, as the language of good governance demonstrates and as Donnelly (1999) and Uvin (2007) both criticise. However, while the global human rights and development communities have now reaffirmed, rhetorically at least, the inherent indivisibility of the international human rights framework, it will evidently take time, discussion and education for these perceptions to change at the local level.

\section{Political}

For their proponents, part of the strength of rights-based approaches comes from their ability to re-politicise development, refocusing it on the underlying local and global structural and power imbalances which perpetuate poverty and inequality. However, as some case studies demonstrate, the political nature of human rights can cause challenges for local NGOs, and these challenges limit the ability of human rights and rights-based approaches to fulfil their transformative potential. For example, in both Zimbabwe and Kenya, local NGOs traditionally involved in development voiced concern about expanding into human rights as they were seen as dangerously confrontational, a concern of particular salience given the political circumstances of both countries (Makanje, Shaba, \& Win, 2004; Nyamu-Musembi \& Musyoki, 2004). In Zimbabwe, organisations working in human rights often confined their work to the perceived safe areas of legal 
literacy on family law or children's rights, rather than extending into overt criticism of the state or of the international economic system (Makanje, Shaba, \& Win, 2004).

The idea that human rights are inherently political again relates to the dominant perception that human rights refer primarily to civil and political rights while development is service-based and apolitical. In both the Zimabwean and Kenyan case studies the authors noted the political context is crucial to the use of rights-based approaches, for if those in power are fearful of losing control, they will "depoliticise development on the one hand, and demonise rights on the other", with often negative consequences for those working in human rights (Makanje, Shaba, \& Win, 2004, p. 21).

Other case studies revealed another, different consequence of human rights being 'too political', this time in relation to donors rather than the state. In India, for example, local NGOs were uncomfortable with referring to human rights because "the use of rights as an entitlement and their assertion of political empowerment" is threatening to local NGOs reliant on foreign donors (NCAS, 2004, p. 3).

Additionally, several of the case studies suggested that local NGOs are sceptical about today's rights-based approaches because they believe they represent a de-politicisation of the language of human rights. For example, commenting on the findings of its study of local Indian NGOs, the National Centre for Advocacy Studies (NCAS) (2004, p. 23) observed that "the promotion of human rights by multiple actors often confuses people about the real intentions behind the human rights agenda", a particularly pertinent point given the fact human rights have often been used in conjunction with programmes of good governance and economic liberalisation. NCAS respondents further commented that if rights-based approaches are to achieve their potential, there must be sustained support for "socio-political process and capacity building at the grassroots level", without which, human rights and rights-based approaches may merely continue the tradition of top-down, donor-driven development (NCAS, 2004, p. 23). 


\section{Cultural}

In many of the case studies local resistance to human rights was commonly cited as a challenge to the use of rights-based approaches. Most local NGO representatives believed the way to overcome the perception that human rights constitute external interference is by contextualising them according to local struggles and cultural values. Implicitly echoing the contemporary social constructivist and anthropological approaches to human rights described in Chapter Six, local NGO representatives in India for example commented that although the discourse of rights is universal, their meaning is "derived by proponents in a particular context" (NCAS, 2004, p. 15). Likewise, the Mexico case study findings suggested "there is not one human rights agenda, there are several, every concrete reality determines a different agenda" (Jasis \& Garcia, 2004, p. 23), while the Indonesian case study emphasised "the socio-political dynamics in a country will mark the form, contents and strategy in any struggle for rights" (Lumbantobing \& Zulminarni, 2004, p. 32). In practice, this contextualisation of human rights language often requires local NGOs to start with local struggles, and then to relate these struggles to the international human rights framework. In Kenya, a representative elaborated on this point, commenting:

The notion that a rights-based approach is about telling people about rights is mistaken. It's more effective to start letting people identify and analyse their problems and then come up with their solutions ... it's about facilitating a discovery of the root causes, and then facilitating the search for solutions (Nyamu-Musembi \& Musyoki, 2004, p. 15).

Likewise, a Nigerian NGO representative emphasised:

Rights in practice [are] about people's daily struggles and not about abstract notions or concepts which do not link people's experiences with the things they know and can act upon (Toyo, 2004, p. 33). 
Toyo (2004) also emphasises the need for inner cultural acceptance of human rights. This is a process local Nigerian NGOs have helped foster through local debates and discussions which strengthen "counter-discourses and ... carry greater legitimacy than 'outside' pressure" (Toyo, 2004, p. 12). This is a process akin to An-Na'im's (2002) concept of the cultural transformation of human rights. An example of such local contextualisation of human rights can be seen in the work of local NGOs in the largely Islamic north-west of Nigeria. There, the Shari'a legal system operates in tandem with the state-based one, so women's rights NGOs frame their discussions of human rights by appealing to the rights and entitlements found in Islamic law (Toyo, 2004). Using the Shari'a system as an entry point for discussion of women's participation in decision making allows NGOs to relate local values to the global ones found in CEDAW and other international human rights documents.

However, as noted in the discussion on social constructivist approaches to human rights, the process of debate over local cultural values and struggles can in itself involve tension. A Bolivian NGO representative noted:

Not everything that is cultural is good...'culture' is often used to justify violence and discrimination, not only against women, but also against other social groups that have been marginalised throughout history. If this is culture, it has to be changed (Molyneux \& Lazar, 2003, p. 91).

\section{Operational}

A commonly cited operational challenge to the use of human rights for development was lack of public knowledge of human rights. This can mean either misconceptions about human rights or no knowledge whatsoever. For example, in a Ugandan study on local NGOs using human rights for development, almost a quarter of local NGOs identified public ignorance about human rights as a key challenge to the successful use of human rights (Okille, 2005, p. 106). Equally, in Brazil it was observed that rights education is always a complex challenge, but it "becomes more complex when we work with populations with low levels of education" (Junior, Antunes, \& Romano, 2004, p. 42). Such lack of knowledge means for many local NGOs, it is necessary to begin with basic 
human rights awareness raising before moving on to strategies to assist rights-holders to claim their rights (Toyo, 2004).

Another operational challenge was the adequacy and accessibility of legal systems. For example, NCAS (2004, p. 24) in India argued that "the rights-based approach has severe limitations in places where the state itself does not have the ... administrative capacity to fulfil rights". Similarly, Latin-American NGO representatives said that problems of access to legal services, and corrupt and inefficient judiciaries posed a challenge the successful use of human rights for development (Molyneux \& Lazar, 2003).

A final operational challenge identified by many local NGO representatives is the difficulty of monitoring and evaluating human rights projects, particularly those focused on rights-holder education, empowerment and advocacy. Despite the global literature acknowledging these types of projects to be an inherent part of rights-based approaches, several local NGOs commented that attempting to follow such approaches led to difficulties with donors (Junior, Antunes, \& Romano, 2004; Nyamu-Musembi \& Musyoki, 2004). This is because donor budgeting and planning systems do not generally allow for flexible, longer-term projects which have what may often be considered to be intangible outputs and outcomes. As a local Brazilian NGO commented, "despite the supposed consensus that this is a priority, the majority of donors don't want to invest in this part of the work; they do not want us to work at a slower pace on projects" (Junior, Antunes, \& Romano, 2004, p. 42).

\section{Conclusion}

This chapter has demonstrated the vital role local NGOs play in development, and how this role becomes even more important when it comes to using human rights for development. The unique position of many local NGOs allows them to translate ideas from the local to the global and back again, framing local struggles in global terms and translating global terms into local contexts. Apart from those explicitly involved in human rights, few of the case study NGOs viewed all their work from a human rights perspective or consciously adopted rights-based approaches. However, all NGOs used human rights in some way in their work, reflecting the global trend towards human rights 
and demonstrating that rights-talk can indeed be used to empower and create change beyond the global rhetoric. Nevertheless, the case studies also revealed significant challenges to the use of human rights for development at the local level. Many of these challenges echoed those discussed in the global literature on rights-based approaches: the lack of knowledge about human rights; doubts surrounding the adequacy and accessibility of legal systems; and scepticism surrounding the top-down advocacy of rights by donors. However, some of the major challenges identified were not widely considered in the global literature and policy documents. These included the challenges surrounding local cultural resistance to human rights and the division between human rights and development organisations. The following two chapters will focus on Fiji, to ascertain whether the themes and challenges identified in the NGO case studies are reflected in the experiences of local NGOs there. 


\section{Chapter Seven: Rights, Politics and Power in Fiji}

\section{Introduction}

For global human rights and development ideas to be successfully applied at the local level, it is essential to consider the historical, political, social and economic specificities of the community in question. Therefore, this chapter discusses these factors as they apply to Fiji, the fieldwork location. It begins with a history of Fiji and a discussion of its contemporary political situation. It then looks at the main human development and human rights issues Fiji faces, and provides an overview of the NGO community there.

\section{History}

Fiji became independent in 1970, after nearly a century of British rule. Until 1987, the archipelago of over 300 islands (100 of which are inhabited) remained relatively stable. However, since then it has been through four general elections, four coups, three constitutions and at least a dozen governments and regimes (Naidu, 2007a). The past twenty years of instability are the result of Fiji's pre-colonial situation as well as the continuing influence of British colonial structures and institutions in the post-colonial era (Ratuva, 2007). These factors will be explored below.

\section{Pre-Colonial Fiji}

Melanesian migrants began to settle Fiji, Tonga and Samoa some 3000 years ago. Settlers in the eastern maritime provinces and outer islands of Fiji remained relatively isolated from the rest of the country, maintaining contact with Tonga and Samoa and developing the highly stratified political, social and cultural patterns which are similar to those of Polynesia (Lal, 1992). The hinterlands of Fiji's two main islands and the small western islands continued to receive waves of Melanesian migrants, giving this part of the country a more socially flexible Melanesian character ${ }^{29}$. By the early nineteenth century, the strongest eastern confederacies (clan groupings) were involved in "a byzantine struggle for political supremacy" over Fiji (Lal, 1992, p. 5). As with the rest of

\footnotetext{
${ }^{29}$ The Polynesian/Melanesian distinction within Fiji has been challenged by some. See, for example, N. Thomas (1989). See Lawson (1990) for more discussion on the uniformity or lack thereof of 'traditional' Fijian society.
} 
the Pacific, these internal power struggles were complicated with the arrival of Europeans, who settled mostly in the east of Fiji and introduced a cash economy, trade in natural resources, cotton plantations, religion and new diseases. From the mid-nineteenth century onwards, various attempts were made to establish a Fijian-wide government (Lal, 1992). However, internal rivalries and settler opposition meant none of these attempts proved successful (Routledge, 1985). Eventually even Ratu Seru Cakobau, the driving force behind the creation of a government, was to admit ceding Fiji to Britain was the best way forward:

If matters remain as they are, Fiji will become like a piece of driftwood in the sea, and be picked up by the first passer-by ... of one thing I am assured, that if we do not cede Fiji, the white stalkers on the beach, the cormorants, will open their maws and swallow us (Derrick, 1950, p. 248).

\section{Colonial Fiji}

Fiji was ceded to the British on the tenth of October, 1874. When the first British governor Sir Arthur Gordon arrived, it was a "colony in acute distress" (Lal, 2003, p. 12). A measles epidemic had killed around forty thousand indigenous Fijians, much of the best land was being claimed by settlers and cotton plantations were struggling due to the collapse of the previous decade's cotton boom. Governor Gordon believed he had a "divine mission to make the [Fiji] islands the exception to the dismal history of colonialism" (MacNaught, 1982, p. 2). This meant, at least superficially, that the guiding objective for policy during the colonial period became the maintenance of indigenous Fijian interests (Lawson, 1990). In practice, this resulted in indigenous Fijian customs, land and heritage gaining paramouncy over any other claims, such as those by European settlers in their demand for Fijian land, or later, those by indentured Indian labourers and their descendents. Governor Gordon made around 84 percent of land in Fiji the inalienable property of mataqali (family groups), confiscating only around ten percent for the other settlers (France, 1969) ${ }^{30}$. He also established the Great Council of Chiefs

\footnotetext{
${ }^{30}$ In 1940 this system of land ownership was formalised through the creation of the Native Land Trust Board. Until 1940, individual mataqali had independently negotiated the leasing of their land to settlers with varying terms from contract to contract. Fearing that short term cash gains for long term leases could threaten future generations' access to land, leading chief Ratu Sukuna persuaded mataqali to relinquish
} 
(GCC), a ruling body made up of chiefs from the eastern confederacies. The GCC benefited from and upheld the system of indirect British rule and formalised the dominance of the eastern confederacies (Naidu, 2007a; Ratuva, 2007). It also became the arbiter of Fijian tradition. However, the prevalence of eastern chiefs within the GCC meant the rigid view of Fijian tradition they imposed did not reflect the social and political complexity and fluidity of Fiji's pre-colonial past, in which chiefly leadership was contestable rather than entrenched (Lal, 1992; Lawson, 1990; Routledge, 1985).

During the colonial period, Fiji became economically and socially divided along racial lines, with "whites on top and dark skinned people at the bottom" (Naidu, 2007a, p. 25). Chiefs and those with lighter skin made up a middle layer of this racial hierarchy. European settlers dominated the economy, establishing businesses, working for government and running the plantations and mills of the sugar industry (Lal, 1992). Governor Gordon was reluctant to allow indigenous Fijians to work on the plantations, believing that doing so would mean the abandonment of "all hope, not only of the improvement but of the preservation of the race" (Lal, 1983, p. 7). Instead, indentured Melanesians, Gilbertese and then Indians provided the necessary labour, often working in inhumane conditions ${ }^{31}$. To achieve his goal of improving and preserving the indigenous Fijian race and way of life and to facilitate the system of indirect rule, Governor Gordon implemented policies and legislation which restricted indigenous Fijians to communal and subsistence living in their villages (Ratuva, 2007). These policies were supported by many of the chiefs whose power and authority they strengthened (Lal, 1992; Lawson, 1990). They resulted in Fiji becoming the only colony in which indigenous land, institutions and traditions (however selective) were so well protected (Lal, 1992) ${ }^{32}$. However, they also led to a divided and "dualistic" economic and social system, in which

individual control over land in favour of a centralised, non-governmental system of land leasing and administration which continues to this day (France, 1969).

${ }^{31}$ Some 60, 965 Indian labourers were brought to Fiji under the indentured labour scheme which ran from 1879- 1916 (Lal, 2004 ). With the end of the scheme, Into-Fijians were free to settle and work in Fiji, with many becoming tenants farmers, leasing land from either indigenous Fijian mataqali or from the Colonial Sugar Refinery (Khan \& Barr, 2003).

32 'Atu Bain (1988, p. 136) argues that Gordon's policies towards the indigenous Fijians actually masked an "array of legislative measures which ably defended the interests of plantation capital". They were also selective in that they choose to ignore aspects of Fijian tradition that did not accord with the colonial mentality - for example, aspects of indigenous Fijian pre-Christian belief were outlawed (Lal, 1992). 
Europeans and the indentured labourers contributed to the cash economy while Fijians remained isolated within their subsistence structures (Naidu, 2007a). This division was reflected in politics. Europeans gained a much greater share of seats than their numbers warranted, while indigenous Fijian commoners and Indo-Fijians had far fewer opportunities for political participation ${ }^{33}$. As the colonial period continued, these economic, political and social inequities were challenged by the Indo-Fijians, whose numbers, cultural diversity and strength grew considerably after indenture and with the arrival of free migrants from India. The increasing numbers of Indo-Fijians left indigenous Fijians fearful and led many, particularly those of the chiefly aristocracy who benefited from it, to favour the political and social status quo. As the first secretary for Indian Affairs J.R Pearson noted in 1928, "Indo-Fijians were impatient for change, Europeans were resistant to it, and Fijians too willing to side with the Europeans in order to restrain the Indo-Fijians"(Lal, 1992).

\section{Post-Colonial Fiji}

The British had never attempted to create a sense of nationhood or common citizenship among the two main communities in Fiji (indigenous Fijians and Indo-Fijians) and the racial divide which characterised colonial Fijian society continued and indeed intensified in the post-colonial era (Robertson, 2005). With independence and the implementation of parliamentary democracy in 1970, ethnicity became "the principle vehicle of political participation" in Fiji (Lal, 2003, p. 336). The independence constitution entrenched chiefly power and the mataqali system of land ownership. It also established a complicated communal voting system which "encouraged ethnic politics and sought to ensure that the government ... was in the hands of the ethnic Fijian chiefs and their [European] business allies" (Naidu, 2007a, p. 26). The two main post-independence political parties were the Alliance Party and the National Federation Party (NFP). The Alliance Party was formed in 1966 and, though it overtly promoted a multiracial Fiji, in reality it became the means by which the eastern chiefly establishment maintained political dominance into the post-colonial period (Lawson, 1990; Ratuva, 2007). It

\footnotetext{
${ }^{33}$ Europeans, constituting only two percent of the population, had the same number of representatives as Indo-Fijians (who gained franchise as early as 1929), while Fijian 'commoners' were represented by their chiefs, not gaining franchise until 1965 (Naidu, 2007a).
} 
successfully positioned itself as the natural representative of indigenous Fijians and was supported by indigenous Fijians and European settlers alike, particularly those from the business community. The second main post-independence party, the NFP, was formed in the early 1960s and originated out of Indo-Fijian cane-grower unions. It was predominantly supported by Indo-Fijians who resented the racial, economic and political privileges of the European minority.

As Ratu Sir Kamisese Mara, Fiji's first prime minister noted, in post-colonial Fiji, race had become a "fact of life" (Lal, 2003, p. 336). However, while racial divisions remained important during the 1970s and early 1980s, class divisions also started to impact on life in Fiji. By the 1960s the British had recognised that restricting indigenous Fijians to the villages was hindering their economic and social development (Lal, 1992). Shortly before independence these restrictions were lifted, and in the post-colonial era, indigenous Fijians began to migrate to urban centres, where they often lived, studied and worked side by side with Indo-Fijians. Greater economic mobility, also the result of affirmative action policies directed towards indigenous Fijians during the 1970s, meant socio-economic status or class, rather than just race or ethnicity, began to be a signifier of difference in the post-colonial era (Naidu, 2007a).

Race and class issues created the conditions for Fiji's first coup (Robertson, 2005). However, as Ratuva (2007, p. 10) notes, "differences in culture do not necessarily lead to conflict; conflict occurs when difference are politicised and used as a means of achieving particular economic, political, or personal objectives". Throughout Fiji's colonial and post-colonial history, cultural difference had been politicised, but never more so than in the lead up to the 1987 coup and its aftermath. On May 14, Lieutenant Colonel Sitiveni Rabuka overthrew the recently formed and newly elected, multiethnic Fiji Labour Party (FLP) - NFP coalition and reinstated the defeated Alliance Party ${ }^{34}$. He claimed to be acting to uphold indigenous Fijian rights in the face of the 'pro-Indo-Fijian' FLP's electoral success. However, the coup was not just about the threat of Indo-Fijian domination. It also had much to do with intra-indigenous Fijian conflict (Sanday, 1989).

\footnotetext{
${ }^{34}$ The Fiji Labour Party was formed by the Fiji Trade Union Congress after a wage freeze which was considered to be one of many anti-worker policies implemented by the Alliance Party.
} 
The FLP's indigenous Fijian leader Timoci Bavadra was openly critical of the hold the chiefly establishment had over the people of Fiji. Although he did not want to alienate the chiefs, Bavadra did want indigenous Fijians to recognise the difference between their traditional and their political obligations:

The chiefly system is a time-honoured and sacred institution of the taukei [indigenous people]...but we also believe that a system of modern democracy is one which is quite separate from it. The individual's democratic right to vote in our political system does not mean that he has to vote for a chief. It is an absolutely free choice (Bavadra, 1987, as cited in Lal, 1992, p. 263).

The FLP campaign had also focused on the previously neglected areas of poverty and inequality, arguing that while leaders had used their personal power to amass personal wealth, the average indigenous Fijian was becoming "more and more backward" (Bavadra, 1987, as cited in Lal, 1992, p. 263). Bavadra's challenge to the established economic, social and racial order was compounded by his position as a middle-rank chief from the west of Fiji, a fact which further discomforted the eastern chiefs who already felt their traditional authority being eroded by modern life (Lal, 1992; Lawson, 1990).

Coup supporters masked the complex interplay of economic, social and intra-indigenous Fijian conflicts which led to the first 1987 coup, framing it instead as the defence of the indigenous Fijian race against the threat of Indo-Fijian political domination ${ }^{35}$. In doing so, they appealed to what Lawson (1990, p. 797) calls the "myth" of Fijian cultural homogeneity, a myth based neither on historical nor contemporary reality yet one which has developed into a "powerful rhetorical device to serve the political interests of the chiefly establishment". The second coup of 1987 came after discussions between Bavadra and the reinstated Alliance Party leader Ratu Mara led to agreement on some form of unity government. Rabuka and the ethno-nationalists of the taukei movement

\footnotetext{
${ }^{35}$ The claim of political domination has been widely contested. While 19 of the coalition parliamentarians were Indo-Fijians compared to 7 who were indigenous Fijian, within the 52 seat House of Representatives, Indo-Fijians held only 22 seats (Lal, 1992).
} 
were not part of these discussions ${ }^{36}$. They acted to prevent any further compromises by suspending the 1970 constitution and effectively taking control of parliament. Over the following months, FLP and NLP leaders and supporters were detained and suffered human rights abuses at the hands of the military, and many Indo-Fijians left Fiji (Bedford, 1989; Naidu, 2007a) ${ }^{37}$.

Rabuka and his allies decreed a new constitution in 1990. This constitution dealt a "severe blow to the task of nation-building in a racially divided society" (Lal, 1992, p. 325). It further entrenched indigenous Fijian power by reserving for indigenous Fijians key government positions and basing voting on racially determined electorates. It allowed the GCC to choose the president, and then allowed the president to choose the upper house of parliament from nominees chosen by the GCC (Lal, 1992). It also privileged indigenous Fijians from rural areas over their urban counterparts, allocating them 30 out of the 37 indigenous Fijian seats despite the fact that by this stage, 40 percent of indigenous Fijians had migrated to urban areas (Lal, 2003). Finally, it required indigenous Fijian candidates to be registered on the Vola Ni Kawa Bula (register of native births) of the constituency in which they were standing. This meant provincial and regional rivalries began to dominate politics, undermining to some extent the careful construction of Fijian cultural homogeneity, “opening up pre-colonial social cleavages", and resulting in the proliferation of indigenous Fijian political parties (Lal, 2003, p. 338; Robertson, 1998).

Political fragmentation and economic stagnation characterised Rabuka's rule during the 1990s, with corruption becoming widespread and the National Bank of Fiji collapsing (Cole, 1989; Grynberg, Munro, \& White, 2002; Sutherland, 1989). Economic inequalities also increased during this period. Rabuka's post-1987 affirmative action policies for indigenous Fijians aimed to close the gap between indigenous Fijians and their Indo-Fijian counterparts (Sutherland, 1989). However, these policies benefited a minority of indigenous Fijians, resulting in the emergence of an aspiring and urbanised

\footnotetext{
${ }^{36}$ Ethno-nationalism refers to political and ideological mobilisation around an ethno-communal identity, as opposed to civic-nationalism which refers to mobilisation around the collective identity of the state (Ratuva, 2007).

${ }^{37}$ Between 1987 and 1999 Fiji lost around ten percent of its Indo-Fijian population (Naidu, 2007a).
} 
indigenous Fijian middle-class but failing to reach the poorest Fijians (Naidu, 2007a). At the same time, labour market and taxation reforms increased general poverty (Lal, 2003). Rising poverty and inequality was compounded by the expiry and non-renewal of sugar cane farm leases towards the end of the 1990s. This left poor and landless Indo-Fijian farmers with little choice but to move into squatter settlements in urban and peri-urban areas in order to seek new employment (Naidu, 2007a).

In 1996, a constitutional review led to the creation of the new, more equitable 1997 Constitution. This constitution included a power-sharing arrangement and a Bill of Rights. It also recognised the place of all ethnic groups in Fijian society ${ }^{38}$. However, while the Constitutional Review Commission recommended an end to race-based political representation, the 1997 Constitution continued the tradition of communally allocated seats and the power of the GCC. Despite this, in 1999 the multi-ethnic People's Coalition managed to come to power, ousting Rabuka. The People's Coalition was comprised of the FLP, the Fijian Association Party and a variety of minority parties and was led by the Indo-Fijian Mahendra Chaudry. It began to implement substantial policy changes, including the end of Rabuka's economic reforms and government service cuts, the increase in welfare funds, and the withdrawal of the controversial VAT on food items consumed by the poor (Naidu, 2007a). However, as in 1987, the ethno-nationalist taukei movement resisted the new government on the grounds it was anti-Fijian (Ratuva, 2007). One year after the election, a small group from the military's Counter Revolutionary Warfare Unit, led by George Speight and supported by unnamed backers, staged another coup. Speight held the government hostage inside Parliament for 56 days. During this period, harassment of and violence towards rural and urban Indo-Fijians and their farms and businesses was widespread, and large numbers of poor Indo-Fijian farmers fled their homes to seek refuge on the outskirts of the western town of Lautoka (Naidu, 2007a).

Eventually, the hostage crisis was resolved by an accord between Speight and the military. The military Commodore Voreqe Bainimarama abrogated the constitution and

\footnotetext{
${ }^{38}$ The power-sharing provision of the 1997 Constitution entitled all parties with over ten percent of seats in parliament to cabinet portfolios.
} 
appointed an interim government ${ }^{39}$. This interim government was led by former businessman Lasenia Qarase, whom Bainimarama believed would support a multiracial government of "national unity" (Fraenkel, 2007, p. 423). However, Qarase was influenced by the nationalist movement and prior to the 2001 election formed the Soqosoqo Duavata ni Lewenivanua (SDL) party. The SDL came into power amidst allegations of vote rigging and vote buying amongst the rural indigenous Fijian community. Qarase refused to accept the power-sharing requirements of the 1997 Constitution, denying the other major party (FLP) a place in a multi-party government and opting instead to form a coalition with Speight's nationalist Conservative Matanitu Vanua Party (CMV). The SDL - CMV coalition maintained power until 2006. This period was a time of moderate economic growth but increasing unemployment and continuing poverty (Naidu, 2007a). It was also a period of increasing tension between the military and the government. Commodore Bainimarama was particularly intent on bringing those involved in the 2000 coup to justice as his life had been threatened during the post-coup mutiny. However, Qarase's government granted early release to several of those who had been convicted as coup supporters and gave ministerial positions to several others who though not convicted, had been implicated in the coup. Qarase was also reluctant to support the ongoing coup investigation and attempted to remove Bainimarama from power for his reluctance to forgive and forget (Naidu, 2007a). Additionally, Bainimarama opposed three bills the Qarase government was intent on passing: the Promotion of Reconciliation, Tolerance and Unity Bill; the I Qoliqoli Bill; and the Land Tribunal Bill ${ }^{40}$. Bainimarama and others viewed these Bills as being promoted by "an element of the ethnic Fijian middle class to enrich themselves at the expense of the wider community" (Naidu, 2007a, p. 33).

\section{Contemporary Fiji}

By the 2006 election the military was actively campaigning against the government. In the wake of the election, Qarase had acted in accordance with the 1997 Constitution,

\footnotetext{
${ }^{39}$ The 1997 Constitution was reinstated after the landmark Republic of Fiji v Chandrika Prasad case of 2001 which found that it had been unlawfully abrogated in the aftermath of the 2000 coup.

${ }^{40}$ The Reconciliation Bill aimed to end investigations into the 2000 coup and to give amnesty to coup perpetrators, the Qoliqoli Bill gave exclusive domain of fishing areas to customary owners, while the Land Tribunal Bill allocated F\$500 000 to customary land owners to buy back freehold land they felt had been taken without acceptable compensation.
} 
inviting the FLP to join the incumbent SDL in a multi-party government. However, this was a fragile coalition which had started to collapse due to internal tensions within both parties long before the December 2006 coup (Fraenkel, 2007). Following the election, Bainimarama's threats of military intervention to 'clean up' the nationalist dominated Qarase government intensified, and Qarase responded by attempting to undermine and remove him from power. After an unsuccessful attempt by the New Zealand government to prevent a coup, Bainimarama overthrew the Qarase government on the fifth of December, 2006 in what the media described as yet another example of Fiji's endemic “coup culture” (Gregory, 2007, p. 10).

Bainimarama's actions demonstrate the central role the military has come to play in Fijian politics and society ${ }^{41}$. Since the 1987 coup, this role has involved restoring 'order' if politicians seem to be acting against what the military considers to be the public interest. As Fiji's history demonstrates, issues of public interest in Fiji are all related to those which have shaped Fijian politics and society for at least the past hundred years race, class and the concerns which flow from them. These are issues which underpin the 2006 coup. However, Bainimarama appears to view them from a completely different perspective to his predecessors Rabuka and Speight, and in doing so has "turned Fiji politics upside down" (Fraenkel, 2007, p. 422; Tarte, 2007). The 1987 and 2000 coups were about overthrowing reformist, leftist governments and returning economic and political power to a certain section of indigenous Fijian society in the name of indigenous paramouncy (Tarte, 2007). With his 2006 coup, Bainimarama's self-stated motives and actions have been quite different. He argues that the Qarase government:

Did not adhere to the fundamental principles of good governance, transparency and equal citizen rights...after the elections it flouted the rule of law and condoned nepotism and corruption. It very alarmingly sought to consolidate its political survival by engaging in and promoting divisive and racial policies,

\footnotetext{
${ }^{41}$ The Royal Fiji Military Force (RFMF) is almost completely made up of indigenous Fijians and has close ties to the chiefly elite. Almost every Fijian family has a son, brother or uncle in the RFMF, and the remittances sent home from UN-employed Fijian peacekeepers contribute a huge amount to the Fijian economy (Naidu, 2007a).
} 
practices and laws. It breached the trust that was entrusted to it by the Royal Fiji Military Force (Bainimarama, 2007, p. 1).

Bainimarama claims to want to move Fiji towards a multiracial democracy by replacing the current race-based political system with a common role (McDonald, 2007). The language he uses to describe these proposed changes to the voting system is reminiscent of that used by Timoci Bavadra in the lead up to the 1987 election:

Fijians live in a democracy with a mentality that belongs to the Fijian chiefly system. They decide for us who to vote for, [or] our church ministers decide for us who to vote for...The common role is the way to go, it takes away the race card (Bainimarama, 1997, as quoted in McDonald, 2007, p. 5).

In the wake of the coup, Bainimarama has been publicly critical of what he views as the Methodist church's role in "sowing the seeds of racial hatred" (McDonald, 2007, p. 5) He has also criticised the chiefly establishment, suspending the GCC and making allegations of corruption against some chiefs. Additionally, his multi-racial interim administration has established the Independent Commission Against Corruption to investigate and 'clean up' the government and its statutory bodies and corporations; has repealed the Qarase government's proposed VAT increase and halted plans to privatise water; is reassessing race-based affirmative action polices; and is reviewing the land issue, including the role of the Native Land Trust Board (ECREA, 2006). Although Bainimarama claims not to have abrogated the 1997 Constitution, the legality of this claim and of the current interim administration is contested (Madraiwiwi, 2007). And while he has positioned himself and the military as upholding the rule of law, justice and multiracial democracy, this has been undermined by an intolerance of dissent and a failure to condemn soldiers for their ongoing intimidation and abuse of human rights activists and others critical of the current regime (Naidu, 2007a).

Responses to this coup have varied. Some of those who were backers of the 2000 coup have come out in support of democracy and the rule of law, while some of the victims of 1987 and 2000 have defended the takeover (Fraenkel, 2007). Some ordinary citizens 
have been supportive of the coup, often because the presence of the military on the streets has led to a decrease in violent crime (Madraiwiwi, 2007). Within the NGO community, responses have been equally diverse, as will be discussed further below. The military, long a stalwart of indigenous paramouncy, has mostly supported Bainimarama, representing a change in the "personalities, values and attitudes of senior military officers over the last 20 years" and also suggesting a degree of support within some elements of indigenous-Fijian community (Naidu, 2007a, p. 33). However, the international community, especially Australia and New Zealand, have been very critical of Bainimarama, and as in 1987, Fiji has been suspended from the Commonwealth.

\section{Human Development in Fiji}

The past twenty years of political instability have had a detrimental impact on the Fijian economy, particularly on the tourism industry (Naidu, 2007a). This has led to an increase in poverty and inequality (Barr, 2003; UNDP, 1997). The negative economic and developmental impacts of political instability have been further exacerbated by recent moves to end preferential trade agreements and liberalise two of Fiji's main sources of income, the sugar and garment industries (Coates, 2007) ${ }^{42}$. These industries support, directly and indirectly, some 300000 people (out of a population of around 860000 ) and so their decline has and will continue to have a huge impact on poverty and inequality within Fiji (NZAID, 2005). Additionally, the expiry and non-renewal of land leases has left many rural Indo-Fijians without land or livelihood, and has led to a rise in urban migration and an associated increase in the number of people living in squatter settlements (Naidu, 2007a).

Today, the poverty line in Fiji is around FJ $\$ 35$ per adult per week. Poverty is not absolute, but means it is difficult for people to meet their basic needs. As such, Fiji is considered a mid-range developing country. The key human development indicators (life expectancy, education and GDP per capita) give Fiji a ranking of $90^{\text {th }}$ out of the 177

\footnotetext{
${ }^{42}$ For analysis of the impacts on development of the Economic Partnership Agreement currently being negotiated between the EU and Pacific Islands nations, see Oxfam (2006). For background to free trade in the Pacific see Kelsey (2004).
} 
countries in the most recent UNDP Human Development Report (UNDP, 2006) ${ }^{43}$. In 2003 the national incidence of poverty was around 34 percent, although some have suggested it is as high as 50 percent (Narsey, 2007; NZAID, 2005). In Fiji, poverty statistics, like most other aspects of society and politics, have usually been viewed from a racial perspective. Traditionally, poverty has been considered greatest within the rural indigenous Fijian community, and affirmative action policies have been designed accordingly. However, the most recent poverty figures demonstrate it is now rural IndoFijians who face the greatest hardship (Narsey, 2007):

\begin{tabular}{|c|c|}
\hline Ethnic Group & $\begin{array}{c}\text { Percentage Living } \\
\text { in Poverty }\end{array}$ \\
\hline Rural Indo-Fijians & $47 \%$ \\
\hline Rural Others & $45 \%$ \\
\hline Rural Indigenous Fijians & $39 \%$ \\
\hline Urban Indo-Fijians & $26 \%$ \\
\hline Urban Indigenous Fijians & $23 \%$ \\
\hline Urban Others & $12 \%$ \\
\hline
\end{tabular}

Table 4: Poverty in Fiji by Ethic Group

Narsey (2007, p. 1) notes that although the incidence of poverty is higher (36 percent) for all Indo-Fijians compared to all indigenous Fijians (33 percent), indigenous Fijians are now the majority in terms of population. This means that when considered from a population wide perspective, indigenous Fijians have the largest share of poor people (at 53 percent) while Fiji-Indians have a slightly smaller share (44 percent).

As with poverty, inequality is increasing in Fiji. The findings of the 2002-2003 Household Income and Expenditure Survey reveal approximately 21.8 percent of Fiji's households received some 50 percent of the wealth, while the remaining 78.2 percent received the other 50 percent (NZAID, 2005). This inequality is greater within rather than between ethnic groups (NZAID, 2005). Finally, unemployment in Fiji is currently

\footnotetext{
${ }^{43}$ Life expectancy is 68 years, combined primary, secondary and tertiary education enrollment is 74.7 percent, and GDP per person (US\$PPP) is \$6066 (UNDP, 2006).
} 
around 27 percent, and away from urban centres there is little income earning opportunity (Narsey, 2007).

\section{Human Rights in Fiji}

Like poverty, human rights have often been seen from a racial perspective in Fiji. Madraiwiwi (2006, p. 50) describes how among traditional leaders and nationalists, there is a "profound scepticism, even suspicion" about the compatibility of traditional indigenous Fijian values with human rights, and a perception that human rights pose a threat to these values. As in many non-western societies, within traditional indigenous Fijian society the rights and values of the group were prioritised over those of the individual and dissent was suppressed (Madraiwiwi, 2006) ${ }^{44}$. Human rights, particularly civil and political rights, are therefore seen as a threat to this established order. Increasingly, this is a view also being espoused by the churches (particularly the dominant Methodist church), who have an enormously influential and powerful role within indigenous Fijian society (Jalal, 2005). However, as Madraiwiwi (2006) argues, the values of human dignity and wellbeing that form the basis of human rights are echoed in many cultural and religious traditions in Fiji, and it is by focusing on these shared values that a degree of harmonisation is possible (see also NZLC, 2006).

Resistance to human rights within Fiji is echoed elsewhere in the Pacific (NZLC, 2006). Despite this, human rights are an important aspect of the Pacific Plan, the Pacific Island Forum's framework for strengthening cooperation and integration across the region. The vision of the Pacific Plan is one in which the "cultures, traditions and religious beliefs are valued, honoured and developed" and the region is respected "for its defence and promotion of human rights" (PIF, 2004, p. 1). This recognition of the central place of human rights is significant and is supported by a list of initiatives with which to strengthen human rights across the region. These include judicial training, education, measures to reduce poverty, strengthening of traditional justice mechanisms,

\footnotetext{
${ }^{44}$ Although, as mentioned above, pre-colonial Fijian society was by no means homogenous, and there were in reality a variety of different social systems, some of which tolerated more dissent than others (Lawson, 1990).
} 
investigating the basis for harmonisation of human rights with custom, and supporting the ratification of international human rights treaties (NZLC, 2006).

Fiji has ratified three of the seven major international human rights treaties: the Convention on the Elimination of Racial Discrimination (1973); the Convention on the Rights of the Child (1993); and the Convention on the Elimination of All Forms of Discrimination Against Women (1995). It also has a Bill of Rights and a Social Justice Chapter within the 1997 Constitution and these cover most of the human rights from the ICCPR and ICESCR ${ }^{45}$. Although Fiji is not a signatory to the two Covenants themselves, it has signed the UDHR which includes all the Covenant rights and which has become customary international law. Fiji is also the only Pacific Island nation to have a Human Rights Commission (Jalal, 2005). This was established under the 1997 Constitution and exists to educate (the public, the public sector and the judiciary), to protect and to advise on human rights in Fiji. It can also litigate on human rights issues, take unresolved cases to court and advocate for changes to policy and law where these contradict constitutional or international human rights obligations (FHRC \& NZHRC, 2006).

As with many Pacific Island nations, Fiji lacks resources and this constrains its ability to fulfil human rights (FHRC \& NZHRC, 2006). The relatively high per capita costs of meeting its public service, judicial, security, social welfare, education, health and regional and diplomatic obligations pose significant challenges, and in Fiji, these are further exacerbated by political instability and, as described above, recent moves towards trade liberalisation.

\section{Civil and Political Rights}

Civil and political rights are included in Fiji's constitutional Bill of Rights. The most pressing civil and political rights issues currently facing Fiji stem from the so-called 'coup culture' in which in the name of national interest it is considered justifiable to overthrow democratically elected governments and repress civil liberties, such as the

\footnotetext{
${ }^{45}$ The Social Justice chapter requires the government to provide education, housing and opportunities within commerce, the public service, the military and the police force for disadvantaged members from any community.
} 
right to freedom of expression, the right to a fair trial, and the right to freedom from cruel and degrading treatment (Jalal, 2005). Coups have also impacted on Fiji's judicial system, meaning the independence and impartiality of the judiciary has been compromised (Madraiwiwi, 2007). Racial discrimination is another significant human rights issue within Fiji, and, as its history demonstrates, has been both a cause and symptom of civil and political unrest. Balancing indigenous rights with the rights of all of its citizens is a real challenge and one which could be aided by the doctrine of human rights, based as they are on common humanity rather than the interests of one particular group $^{46}$. Another significant civil and political rights challenge in Fiji is discrimination against women and children, which results in a low number of women participating in political and economic life and a high incidence of gender-based violence and child abuse (Jalal, 2005; NZAID, 2005). Discrimination against sexual minorities is also common in Fiji and is driven in large part by the Methodist church, which has made statements calling for gays to be stoned to death and has organised public marches denouncing gay marriage (Jalal, 2005).

\section{Economic, Social and Cultural Rights}

From a human rights perspective, Fiji's high rate of poverty itself represents a violation of the economic, social and cultural rights enshrined within the UDHR, and also those rights contained in the Social Justice chapter of the 1997 Constitution. The most pressing problems relating to economic, social and cultural rights in Fiji are those which stem from the high rate of poverty. One of the most obvious ones is the impact of poverty on education, with around 66 percent of students dropping out of school early due to difficulties in paying school fees or to provide additional income for their families (NZAID, 2005). This then constrains their ability to find well-paid work. Another problem stemming from poverty is the increase in peri-urban squatter settlements which often lack sanitation, electricity and water (NZAID, 2005). These squatter settlements are in part due to the rise in urban migration, which in turn is a result of the expiry of land leases and the collapsing sugar and garment industries, factors for which successive governments have been inadequately prepared (NZAID, 2005). Associated with the rise

\footnotetext{
${ }^{46}$ For a discussion on how indigenous rights can be used to compliment human rights in the Fijian context, see Khan (2007).
} 
in urban migration is the rise in commercial sexual exploitation of children, child labour and street children (Ali, 2006; Barr, 2006). The near total lack of social welfare services in Fiji exacerbates poverty, with many of the poor being single parent (often femaleheaded) households, the elderly, those living with sickness, and the disabled (Barr, 2003). The lack of adequate social welfare provisions for these people constitutes a violation of human rights, given Article 25 of the UDHR requires signatory states to provide the "necessary social services, and the right to security in the event of unemployment, sickness, disability, widowhood, old age or other lack of livelihood in circumstances beyond his control". Finally, many of those who are poor in Fiji are actually working $\left(\right.$ NZAID, 2005) ${ }^{47}$. However, as there is no national minimum wage in Fiji, those who work are often still unable to meet their basic needs (ILO, 2007). This is itself a violation of Article 23 of the UDHR which makes remuneration allowing existence with human dignity a human right.

\section{The NGO Community in Fiji}

Numerous NGOs existed in Fiji during the colonial and immediate post-colonial period. Most focused on service delivery, although some, including the YWCA, were heavily involved in advocacy (George, 2004) ${ }^{48}$. After the 1987 coup, new NGOs were established and some existing ones moved into a more politicised role. As one Fijian NGO representative commented, "since 1987 there has been a quick self-education. NGOs have galvanised themselves into becoming more rights-based rather than welfarebased" (WAC). Today, Fiji has a diverse and vibrant NGO community. It includes a range of advocacy, human rights and social justice NGOs, as well as those based on the more traditional service delivery model of development. Fiji is also home to several regional NGO associations, including the umbrella NGO, the Pacific Islands Association of NGOs (PIANGO).

\footnotetext{
${ }^{47}$ NZAID (2005, p. 18) notes that "83 percent of heads of poor households work but are earning wages below the (Fiji) poverty line". These poorly paid workers come mostly from copra and sugar plantations, garment factories, and the retail, security guard and lower-end clerical sectors.

${ }^{48}$ See George (2004) for an interesting comparison between the advocacy strategies of the YWCA and those of two of today's prominent women's groups, FWRM and FWCC. George suggests today's climate of neoliberalism and donor-reliance constrains the ability of women's groups to address wider structural concerns such as the links between trade, economics and development, and means they focus on the 'safer' areas of legal reform and violence against women. See Emberson-Bain (1995), Ram (1995) and Slatter (1995) for more on the impacts of economic development on Pacific women.
} 
NGOs in Fiji, like others in the Pacific, face the constraints of working in a very small community and with limited funds. They also work under out of date legislation which requires them to be registered as charitable organisations and thus curtails their advocacy role (Hill, 1994; Jalal, 2005). This latter constraint was highlighted in 2001 when the Citizens' Constitutional Forum (CCF), a prominent Fijian NGO, was deregistered after it and other NGOs criticised the abrogation of the 1997 Constitution and supported litigation for its reinstatement. De-registration made it very difficult for $\mathrm{CCF}$ to secure donor funding, and forced it to become a not-for-profit company (Jalal, 2005).

Despite these constraints, relationships within the Fijian NGO community have usually been friendly, and NGOs have a history of working together on issues as diverse as women's rights, poverty, trade and racial discrimination. For example, in 2002 many key Fijian NGOs came together under the banner of the 'NGO Coalition on Human Rights' to submit a shadow report to the UN Committee for the Elimination of All Forms of Racial Discrimination, while currently several NGOs work together under the umbrella group the Pacific Network on Globalisation (PANG) on trade and development issues affecting the Pacific.

Although relationships between Fijian NGOs have traditionally been good, the current political situation has caused much tension and this was evident during my fieldwork there. This is due to the way NGOs have responded to the 2006 coup. The three previous coups were overtly racist and served to benefit a minority of Fijians, and so a more or less unified NGO response was possible. However, this coup is unique in that it offers a non-racial and egalitarian agenda (Tarte, 2007). Therefore, the NGO response has been fractured, with some agreeing with the ends (if not the means), and others believing a coup can never be justified, no matter what the ends. To simplify it somewhat, there is evidence of a split between those NGOs who work from a human rights platform, and those whose work is more development or social justice orientated (Naidu, 2007b). This split relates to the divide or hierarchy which continues to exist between civil and political rights, and economic, social and cultural ones. The human rights NGOs in Fiji have been fiercely critical of the 2006 coup for its violation of the 
civil and political rights enshrined in both the Fijian Constitution and the UDHR (Chetty, 2007). This criticism resulted in several prominent human rights activists suffering abuse from the military over the Christmas period in 2006. The NGOs who campaign more from an economic, social and cultural rights platform tend to agree with the civil and political rights-oriented NGOs that the coup was illegal. However, they have been less critical of Bainimarama and the interim administration (ECREA, 2006). This is because they believe the policies of the overthrown Qarase government were racist (for example, with its affirmative action policies based on race rather than need) and that they undermined basic economic, social and cultural rights (for example, considering rising the VAT from 12.5 to 15 percent and the privatisation of water). Their community-based work has given these social justice/development NGOs direct experience with the impacts these policies have on the poor and marginalised. In Bainimarama and the interim administration, they see the opportunity to restructure Fijian society along more socially just and non-racist lines (ECREA, 2006; Naidu, 2007b; Tarte, 2007). This position has meant that unlike the staunch human rights critics of the coup, these NGOs have been willing to engage with the interim administration.

The split within the NGO community has been exacerbated by the 'pro-coup' position taken by the Fiji Human Rights Commission (FHRC). In the aftermath of the coup, FHRC director Shaista Shameem published a report exonerating the coup on legal and constitutional grounds (Shameem, 2006). This report revealed the apparently pro-coup stance of the commission and meant many of those who had suffered abuses of their human rights at the hands of the military were reluctant to report them to the FHRC, going to NGOs instead. It also led the isolation of the FHRC from the rest of Fijian civil society (Naidu, 2007b). There are two reasons for Shameem's response. In June 2006 the FHRC published a report by an independent consultant into the Qarase government's race-based affirmative action policies (FHRC, 2006). This report was highly critical of the policies, commenting they were both discriminatory and based on a selective and politicised interpretation of poverty statistics. It led to tension between Shameem and the Qarase government and this tension was heightened by questionable practices during the 2006 election, including maladministration of voter registration, the printing of too many ballot papers for some constituencies and allegations of vote rigging (Naidu, 2007b). 
These issues were publicly debated during my fieldwork in Fiji, and people were very open about discussing them during their interviews. The impression I gained was even though this divide was impacting on people's personal and professional relationships, there was a desire to move beyond it.

\section{Conclusion}

Fiji's contemporary political, social and economic situation is a product of its precolonial and colonial past. Expiring land leases and neoliberal policy reforms have combined with the traditionally contested issues of race and class to contribute to the recent power struggles and political instability, and together these factors have led to the increasing poverty and inequality which characterises the country today. While the vibrant NGO community in Fiji works at various levels and across various sectors in order to address these problems, it too has been affected by recent instability and uncertainty. This meant during the fieldwork in Fiji, there was a noticeable and much debated split within the NGO community. This split, and the issues it arose from, is the result of the particular Fijian context but is also reflective of tensions around human rights that occur universally, as Chapter Six demonstrated. The following chapter will look closely at how these and other issues affect the use of human rights for development by local NGOs in Fiji. 


\section{Chapter Eight: Human Rights, Development and Fijian NGOs}

\section{Introduction}

As with Chapter Six, this chapter looks at if and how the shift towards human rights in global development policy is reflected in the work of local NGOs. It presents the findings from interviews with eleven representatives from seven Fijian NGOs. As the overview below describes, three of the NGOs interviewed are typical 'development' NGOs - community-based and focusing on promoting equality and tackling poverty by various means (such as advocacy, service delivery and education). Two are explicitly rights-based development NGOs, and two are primarily human rights NGOs, chosen for the insight they could provide into the challenges that may arise from promoting human rights at the local level and the way they interact with development ideas. Following the NGO overview, the first section of this chapter presents the findings according to the way the NGO representatives understand the relationship between human rights and development and rights-based approaches. The second section looks at how they use these concepts in their work. The final section focuses on the challenges to the use of human rights for development at the local level, presenting these challenges according to the four interrelated categories used previously: conceptual, political, cultural and operational.

\section{Overview of NGOs Interviewed in Fiji}

\section{CCF}

The Citizens' Constitutional Forum (CCF) is a human rights organisation which was established in 1991 in response to the military's imposition of the 1990 Constitution. Its goal is "to build a nation in which Fiji's people live together in equality, justice and peace, respecting the rule of law, under a Constitution that guarantees democracy and human rights" (CCF, 2007, p. 1). It achieves this goal through community education and national level advocacy on a broad range or constitutional and human rights, including: minority rights, democracy and the rule of law, housing and resource rights, workers rights, and religion and rights. 


\section{FWRM}

The second human rights organisation, the Fiji Women's Rights Movement (FWRM), began in 1986. Its purpose is "to work towards the elimination of all forms of discrimination against women, promote the equality of women, and support democracy and human rights in all areas in Fiji and the Pacific Island region" (FWRM, 2007a, p. 1). Like CCF, it works at both the community level where it educates for attitudinal change, and at the national level where it advocates for legal and policy reform.

\section{ECREA}

The Ecumenical Centre for Research, Education and Advocacy (ECREA) was founded in 1990. It is a community-based social justice and advocacy organisation which aims to "address the social, religious, economic and political issues that confront Fiji" (ECREA, 2007a, p. 1). ECREA's work involves community empowerment, research, and advocacy on economic, social justice and religious issues.

\section{PCDF}

Partners in Community Development Fiji (PCDF) was established in 1978. As a community development organisation, it aims "to empower people to make informed decisions" and it works "in partnership with communities to achieve equitable, holistic and sustainable livelihoods" (PCDF, 2007, p. 1). Its work is driven by community needs and involves education (on health, the environment, conflict and disaster management), and service delivery (including youth drop in centres, and school and hospital building).

\section{WAC}

Women's Action for Change (WAC) is a community-based feminist collective. It began in 1993 and aims to "create safe spaces where individuals and groups, particularly marginalised and vulnerable people, can gain strength and confidence to build a just society" (WAC, 2006, p. 1). Like ECREA, WAC works both in and with communities (providing education through theatre, working with minority groups and running community empowerment workshops on restorative justice, peacebuilding and conflict prevention) and also does advocacy at the national level on these issues.

\section{RRRT}

The Regional Rights Resource Team (RRRT) was set up in 1995 as a rights-based development organisation which aims to "demonstrate the linkages between democracy, 
good governance and human rights and their impact on development and the alleviation of poverty" (RRRT, 2007, p. 1). It works at the community level to educate and train people in human rights, as well as working at the national level to provide policy advice and support to government departments and to advocate for human rights.

\section{$S C F$}

The final organisation, Save the Children Fiji (SCF) started life as a traditional development/service-delivery organisation focusing on children. In 2004 it joined the International Save the Children Alliance and adopted a child-rights based approach, using the Convention on the Rights of the Child as a framework to guide all its work. Today, it combines both service delivery and rights advocacy, working at the community level to educate people about child rights, and at the government level to advocate for them.

\section{Understanding Human Rights and Development}

This section presents the responses to the following interview questions:

- How do you define development and human rights?

- Do you think there is a relationship between the two?

- Are you aware of rights-based approaches to development?

- What do these mean to you?

All NGO representatives defined development as some kind of positive change and human rights in terms of the international human rights framework. However, when it came to more specific definitions, particularly definitions of the relationship between human rights and development, there were differences. These differences often related to the different philosophies or areas of work of the individual NGOs, and also to whether they were engaged primarily with human rights, with development, or were attempting a combination of both in the form of rights-based approaches.

The two human rights organisations - Citizens' Constitutional Forum (CCF) and Fiji Women's Rights Movement (FWRM) - both view development through a human rights lens. Since its establishment, CCF has been active in constitutional issues and was instrumental in the enactment of the 1997 Constitution and subsequent struggles to uphold it. CCF believes that "the people of Fiji need to re-imagine themselves as citizens 
of a nation, ahead of their ethnic interests and categories" and appeals to the constitution as a means by which to do so (CCF, 2007, p. 1). For the CCF representative:

Development is holistic and includes the economic, social and cultural aspirations of people as well as the effective exercise of their civil and political rights ... Rights and responsibilities are an important aspect of development: a 'developed' society must include active citizens, be accountable.

Because of its constitutional focus, CCF defines human rights primarily in terms of constitutional rights - the civil, political, economic, social and cultural rights in the Bill of Rights and the Social Justice Chapter of the 1997 Constitution. However, it does look to the international human rights framework when this is useful or relevant. For example, as the previous chapter noted, CCF and others from the NGO Coalition on Human Rights presented a critical shadow report on Fiji's adherence to the Convention on the Elimination of Racial Discrimination (CERD) to the UN in 2002.

The second human rights organisation interviewed, FWRM, was established to "engage politically with the state on behalf of Fiji's women" (George, 2004, p. 11). It aims to remove discrimination against women through institutional reform and attitudinal change, and has a vision of a Fiji in which "the principles of feminism, democracy, good governance, multiculturalism and human rights prevail" (FWRM, 2007b, p. 12). Although it also works on the constitutional Bill of Rights, FWRM's main focus is the international human rights framework, particularly those aspects which focus on women's rights, such as CEDAW and the CRC. For the FWRM representative, development is an inherent aspect of women's rights and is tied to FWRM's women's rights philosophy:

The kind of work we do is about empowering women to make conscious and informed decisions not only about their personal development but about national development, how they can contribute to nation building economically, politically and socially, as well as their own personal development ... so, development is 
about bringing about positive change, and because we are a feminist organisation, it is about using feminist analysis and principles.

The FWRM representative went on to say that human rights and development are interconnected:

You cannot have development without the fulfilment and protection of human rights ... it's a kind of chicken and egg situation.

Unlike FWRM and CCF, the next three NGOs - the Ecumenical Centre for Research, Education and Advocacy (ECREA), Women's Action for Change (WAC) and Partners in Community Development Fiji (PCDF) - are community-based development NGOs rather than human rights organisations. This means they tended to understand the relationship between human rights and development in a different way to the human rights NGOs. While ECREA, WAC and PCDF all agreed on the conceptual relationship between human rights and development, human rights tended to be just one among many important principles guiding their work. For example, ECREA works from a Christian social justice perspective and so believes development is about building "respect, social harmony, and contentment for all" (ECREA, 2007b, p. 1). While human rights are part of this concept, they are not the defining element because what comes first is social justice:

Our motto is 'to build a just, compassionate and inclusive society', and social justice I suppose is as much a biblical concept, it goes back to biblical times, and so I think that it really includes human rights, but at the same time, we stress different rights at different times.

Like FWRM, ECREA emphasises that any sense of empowerment that comes from development and human rights must move beyond the personal to also include the political: 
Empowerment really does depend on people becoming aware, not just in a personal way.

WAC is a feminist organisation which works primarily at the community level. Its goal is to "create safe spaces where individuals and groups, particularly marginalised people can gain strength and resilience to build their own strategies" (WAC, 2006, p. 1). Underpinning this goal is a feminist perspective which determines how WAC defines development and human rights:

Rising from our feminist perspective, the notion that you are trying to work towards ... equality, where not only the basic rights are fulfilled, but where we live in a community where there is genuine and meaningful participation by all...for us, that is what development ultimately means.

We don't form all of our work around the concept of human rights alone ... before we define human rights, we define what our work is in the context of feminism, and for us that definition is about recognising oppression of both men and women from a patriarchal system.

Like WAC, PCDF works with communities in order to "empower people to make informed decisions...and to achieve equitable, holistic and sustainable livelihoods" (PCDF, 2007, p. 1). For one PCDF representative, development is "change to something better and human rights are what one has, your freedom, they are universal, you are born with them" (PCDF 1). While all the PCDF representatives agreed there is an overlap between human rights and development, PCDF itself does not direct its community development towards the fulfilment of human rights. Rather, human rights are one aspect of its education and awareness raising projects.

The final two NGOs interviewed - Regional Rights Resource Team (RRRT) and Save the Children Fiji (SCF) - both consciously apply rights-based approaches to their development work. RRRT's vision is for a "socially just and equitable Pacific based on the principles of good governance, democracy and human rights" (RRRT, 2004, p. 1). As 
a UNDP project, RRRT was established on a rights-based model and this clearly influences the way in which it defines development and expresses the relationship between human rights and development:

The two are intertwined, I mean, development is the fulfilment of human rights isn't it? So, the rights to education, to employment ... once those rights are fulfilled, then development can take place.

SCF also follows a rights-based approach and like RRRT this determines its understanding of development and the relationship between human rights and development. Child rights, as enshrined in the CRC, inform every aspect of SCF's work:

Awareness on child rights is ongoing for us and is the underlying thing for all of our projects, we always come back to children's rights, and how they relate to particular issues (SCF 2).

Because child rights are at the heart of SCF's understanding and use of development projects, they view the relationship between human rights and development as overlapping. As an SCF representative said:

What I have learned over the past three years is that the issues you're addressing are always interrelated (SCF 2).

\section{Rights versus Development}

A recurring theme throughout the interviews was the differences between human rights NGOs and development ones, a difference which can make the conceptual relationship between human rights and development difficult to practice. This difference is something also noted in the NGO case studies discussed in Chapter Six, but was particularly obvious during the fieldwork in Fiji because of the way different NGOs had responded, or were perceived to have responded, to the December 2006 coup. As with the NGO case studies, some NGO representatives in Fiji characterised human rights NGOs as being politically engaged and development NGOs as remaining relatively apolitical. For example, the 
RRRT representative noted most Fijian NGOs "are still on a service delivery, charitable modality", while the CCF representative commented:

Development is associated by aid donors more with service delivery, is apolitical.

Among those NGOs whose work is consciously involved in human rights, there was the perception that NGOs involved in community development tended to "pick and choose" (RRRT) their rights, ignoring abuses of civil and political rights. As the RRRT representative went on to say:

The basic principles of human rights that ... follow from indivisibility, those things aren’t well understood amongst civil society here.

Likewise, the FWRM discussed a 'gap' between human rights and development NGOs:

I think that it is a big problem that there is a gap. I think that for many traditional development NGOs ... it's almost as if they are saying that with people like us, advocacy organisations who are generally focusing on civil and political rights, they think that we are working on theoretical things, that we're not dealing with bread and butter issues, and that is where the tension comes in.

Indeed, those NGOs whose work is less advocacy and more community focused did think human rights NGOs tended to overlook the 'bread and butter' economic, social and cultural rights. For example, a PCDF representative said:

Most of the time when people talk about rights they don't talk about things like that ... most focus on CEDAW and CRC and things like that, no one really looks at the social ones (PCDF 1).

Yet, this representative continued to comment that it was when they learnt about economic, social and cultural rights people actually became interested, as they are what really matter to people: 
They say, 'Now we know, we know why we should know these things' (PCDF1).

The idea that it is economic, social and cultural rights that are meaningful to people was echoed by numerous other representatives from a variety of NGOs:

After the coup, we didn't just monitor civil and political rights, we monitored economic, social and cultural rights as well, because I think at the end of the day, if people do turn around and chase out the government, they will do so because of the economic rights (RRRT).

Civil and political rights do not mean much to the majority of people living in poverty. Civil and political rights become more meaningful when a country is able to develop and sustain ordinary peoples' economic, social and cultural rights, like the rights to basic necessities of life, like food, shelter etc (CCF).

When you're talking about survival, civil and political rights actually anger women, because you're talking about situations where you are fighting for the lives of your children (WAC).

Just as the RRRT representative argued that development NGOs tended to "pick and choose" their rights, thus undermining the principle of indivisibility, an ECREA representative argued that some human rights NGOs focus on human rights only in "the narrow sense of civil and political rights":

If we're going to talk about human rights, it needs to be in totality we need to take a balanced view of rights ... why are we going to get all upset about twenty or so human rights activists getting mistreated when we have thousands upon thousands of people who are living in squatter settlements, what about the right to housing? ... How is it that we've got $60 \%$ of our population earning wages below the poverty line? What about the right to work for a just wage? And nobody says 
anything about that? ... Why are we talking about civil and political rights and not about economic and social rights you know? It is very much the American way ${ }^{49}$.

However, while there is considerable debate within the NGO community in Fiji on these issues, heightened of course in the current political context, one SCF representative did not view the gap between human rights and development NGOs as a problem:

I never saw it as a split before, I saw it as strength of our NGO community, because you have different people working in different areas and using different models to address different community needs, so I never saw it as a split until all this started around December (SCF 2).

Even those who are critical of the split or gap do recognise it is impossible to work on all rights at one time, that, as the FWRM representative noted, "everyone has a role [but] there are overlaps and you cannot live without the other". Likewise, the RRRT representative argued that while day to day reality means you have to focus on particular rights, one must never forget the principle of indivisibility:

You can specialise ... but they [rights] all feed off each other, so, if women don't have equal rights, you can't put that aside for the right to water or livelihood because they're all so intertwined.

For the WAC representative, working from a feminist perspective allows existing divides between human rights and development, and civil and political rights and economic, social and cultural ones to be crossed:

Here, people have divided, I don't think people have been very successful at working across the divides ... this is where the feminist approach is very important, because it stresses indivisibility, it comes down to the lived in body, which means that you have to look at all rights, and that changes the way you

\footnotetext{
${ }^{49}$ The United States of America has not signed the Covenant on Economic, Social and Cultural Rights.
} 
work as an organisation, if you are focused on that, you will always be looking at economic, social and cultural rights, and civil and political ones, you won't prioritise.

\section{Rights-Based Approaches?}

As in the NGO case studies surveyed in Chapter Six, all NGO representatives were aware of and influenced by the global policy shift which has resulted in human rights playing an increasingly important role in development at the global level. This was usually because of their donors, and because, as the WAC representative noted, human rights and rightsbased approaches are "the current language of development". However, while they were aware of the language, few of the NGO representatives explicitly use such rights-based approaches in their day to day work.

The two NGOs who do consciously use rights-based approaches, RRRT and SCF, are closely linked to international organisations (UNDP and the International Save the Children Alliance) which have themselves moved in this direction and have encouraged their partners to do the same. For RRRT, a rights-based approach involves working with both rights-holders and duty-bearers to strengthen their ability to claim and fulfil rights, while for SCF it involves transforming the CRC into "a concrete strategy for child focused development ... utilising the principles of the CRC to plan and manage programmes [with] the overall goal of improving the position of children and building societies that acknowledge and respect the rights of the child" (SC, 2002, p. 3).

While none of the other NGOs consciously use rights-based approaches or view their work from a human rights perspective, all were aware of these approaches because of the work of their international partners and donors:

A few years ago donors said to us 'so you are working from a rights-based approach' and we said 'huh?' and they explained what they meant and we said, 'well, yes, that's what we do' (FWRM). 
Two NGOs implied that adopting rights-talk could be a strategic way to secure donor funding:

There is a lot of focus on it ... and most NGOs around will use a rights-based approach, or say they do - it's the current language of development (WAC).

For us to do our work effectively, it's about funds. And some people sell themselves better, and we're one of the ones that sell ourselves well (FWRM).

As described above, ECREA, WAC and PCDF categorise their approaches primarily according to their underlying philosophies of social justice, feminism and community empowerment respectively. One NGO implied that being labelled with specific approaches or categories was restrictive, but at the same time terms such as 'rights-based' could also be of strategic importance for networking with other NGOs:

I would say that WAC is working from a human rights perspective, but also a feminist, peacebuilding and non-violence one ... we don't like to be pigeonholed. These are concepts that inform our work, they are useful to hang our work on and link us to other organisations (WAC).

\section{Using Human Rights for Development}

As demonstrated above, common to all NGO representatives, whether they consciously categorised their work as rights-based or not, was a belief in the shared values and goals of human rights and development. How then are these ideas used within the day to day work of these NGOs? This section presents responses to the following interview questions:

- How does your organisation use human rights in and for development?

- What are the benefits of using human rights and rights-based approaches in your work?

It will first look at the human rights NGOs, then the development ones, and finally at the two NGOs who combine human rights and development in the form of rights-based approaches. 


\section{FWRM and CCF}

As human rights NGOs, FWRM and CCF both view all issues through a human rights or constitutional rights lens. In doing so, they emphasise the human rights principles of accountability, participation, universality and indivisibility in their day to day work. FWRM and CCF both believe human rights are useful for tackling development issues of poverty, social exclusion and discrimination because of their ability to both redistribute power and to emphasise accountability:

Any broadening of the concept of rights is positive for development ... a human rights approach has the potential to distribute power, especially in a poor developing country (CCF).

One of the things I like about the rights-based approach is...that social justice groups often focus on a hand-out mentality, whereas a rights-based approach really makes duty-bearers accountable. You go to the UN, you are accountable for us getting good education, good housing, all these things, we are citizens of this country and we put the demand on them (FWRM).

One example of FWRM using these ideas of accountability and indivisibility can be seen in its Family Law campaign. This campaign ran from 1991 - 2003. It focused on the shortcomings of the original Family Law Act and pressured the state, as primary dutybearer, to redraft a more equitable version. Throughout the campaign, FWRM consistently connected civil and political rights to economic, social and cultural ones. It argued the maintenance provisions in the original Family Law Act unfairly disadvantaged poor women and that if these were amended there would be a "major and positive impact on alleviating poverty in the poorest sectors of the community" (Jalal, as quoted in George, 2004, p. 12). Due to FWRM's consistent campaigning, a new and more equitable Family Law Act was unanimously passed in October 2003 (FWRM, 2007b). More recently, FWRM has begun to engage with issues of international trade and development, linking these to its core work on women's rights. By connecting international trade agreements with the fulfilment of 'bread and butter' economic, social 
and cultural rights, FWRM asserts "trade is a women's rights issue" (Sani, 2007, p. 10). In this aspect of its work, FWRM liaises with regional and international organisations such as the Pacific Network on Globalisation (PANG), which also includes local and international NGOs like ECREA and Oxfam. FWRM believes the knowledge it gains through this international networking is essential because "we can see what's going on on the outside and can see how it impacts here".

Like FWRM, CCF's work at the government level focuses on accountability, ensuring the government upholds its constitutional obligations. For example, in 2006 it questioned the constitutional legality of the SDL Government's Affirmative Action Bill and 2001 Social Justice $\mathrm{Act}^{50}$. This resulted in the Fiji Human Rights Commission publishing legal analysis which argued the Bill and Act did not comply with the constitution (FHRC, 2006).

At the community level, both FWRM and CCF raise awareness and educate on human rights, from a women's rights and constitutional rights perspective respectively. Often, their community level work takes place with other NGOs who have close ties to local communities. For example, CCF works closely with ECREA on squatter communities and their rights, while FWRM does a lot of its community level work on women's rights in conjunction with WAC. As the FWRM representative says:

Our strength is working at the policy level or the meso or macro level, and for the micro level we work with other community level organisations ...We've often told other NGOs ... 'why don't we work together, you don't want to work with government, you can work with us, and we'll be that link between the two'... that's how we see ourselves in the wider NGO community, we are in the middle, we have that scope, we are able to translate and take information from one side to the other.

\footnotetext{
${ }^{50}$ For more information, see FHRC (2006).
} 


\section{ECREA, WAC and PCDF}

While none of the three community development organisations consciously use rightsbased approaches or view their work solely from a human rights perspective, all incorporate human rights into their day to day development work, often in the form of human rights education. As mentioned above, both ECREA and WAC work closely with CCF and FWRM, and so many of the issues they work on reflect the human rights concerns of these organisations. For example, ECREA is currently working with CCF on squatter rights, focusing on the marginalised squatter communities which surround Suva and other towns in Fiji. ECREA runs workshops on human rights with these communities in order to raise people's awareness of their entitlements:

These people don't know that they've got rights, so when we go to workshops, our aim is really to empower the community, with social analysis workshops, first of all to look at their situation, to say what the problem is and to look at the whole situation in Fiji and how their problems fit into this.

Once communities are aware of their constitutional and international human rights entitlements, ECREA works with them to produce a 'community action plan' in order to work out what to do and how to do it. ECREA also helps individual communities negotiate the appropriate legal channels to claim their rights. For example, in 2006 people in a squatter settlement received eviction notices from the local council. After being approached by the community leader, ECREA contacted the Fiji Human Rights Commission (FHRC) to enquire about taking the council to court as an abuse of the right to housing. As the ECREA representative explained:

The FHRC said 'we've been waiting for a case like this to come!'... and so instead of having an official court case [they] had this idea of getting the government, the city council, the squatter settlements, and ECREA to sit down together and have a discussion. 
The result of the discussion was that the Minister for Housing and Squatter Settlements at the time revoked the eviction order. For ECREA this process demonstrated that human rights could be an effective way to address issues of injustice and inequality:

It was a real big thing and I think it gave our team here a sense that you could use human rights.

Since this successful experience with using human rights to secure basic rights for marginalised people, ECREA has continued to lobby from this perspective. It has established an advocacy group, the People's Community Network, which is made up of over 30000 residents of squatter settlements. It is also in the process of negotiating land purchase agreements for the squatter communities, a process happening in conjunction with the Government, the FHRC and other local NGOs such as WAC and CCF.

Unlike ECREA, WAC does not explicitly refer to human rights in its community level work:

We really don't spend a lot of time linking to specific human rights conventions $\ldots$ but the ideas do come through.

And:

We don't frame our work in specifically human rights terms, we don't say, they are talking about this at an international level therefore we will translate it into an approach. For us, that's something already there, it's in our communities, the community tells us what we work on. We link into other people, some of whom work in human rights frameworks.

However, WAC does use human rights language with its international donors and in its advocacy, because: 
Human rights allow us to frame issues in a language that a lot of people understand ... in our language of analysis and donor reports it does come through. In terms of an advocacy platform we use human rights language just because it's a shared language in that particular group, whereas when I talk to a group of women in the community it doesn't relate.

Also:

Human rights ... help us because [they] are about a set of basic rights that all people are entitled to.

For the WAC representative, while the human rights principles of participation, equality and indivisibility are all important, they are not unique to the international human rights framework. Rather, they are ideals people have been working on "for a millennium". However, this representative noted that human rights do bring with them a sense of accountability which does not exist in traditional development:

The advantage, in theory, is that there is a power to them, they come with a whole set of legal instruments that development language doesn't come with, development is open to interpretation and co-option ... to know that with [human rights] there is that backup ... is good. Where is the backup for development?

Like WAC, PCDF seldom uses human rights in its day to day development work. However, community empowerment is at the heart of PCDF's goal in this respect, as a PCDF representative said:

It is a rights-based approach to development; it's always implicit that people have a right to their own self-determination, to their own development, to their own services, to their own-decision-making (PCDF 3).

Recently, PCDF has started to look at how human rights can be used to empower communities by using them in educational workshops: 
The understanding that we try to give to the community [is] basically that they have the right to access government policies and the right to make changes to policies (PCDF 2).

We touch on the Bill of Rights, the UDHR, the constitution and tell them that 'it's important you know these things to be able to access [them], like if you have children, they have a right to education' (PCDF 1).

However, like WAC, PCDF emphasises its work comes primarily from the needs and concerns of the communities it works with and so:

We don't come out and say that 'today we're going to talk about this', it comes up from the issues that they [the community] talk about, but we don't usually say 'you have the right to do this' (PCDF 1).

Instead, PCDF allows ideas of rights to arise naturally from community concerns. As one PCDF representative said:

Rights are already there, it's just a matter of shedding light on them (PCDF 2).

\section{RRRT and SCF}

RRRT and SCF both consciously use rights-based approaches. As such, they integrate human rights standards and principles into everything they do and analyse and address all issues through a human rights lens. This means they focus their work on the fulfilment of human rights standards and they emphasise the principles of accountability, participation, universality/non-discrimination (RRRT, n/d; SC, 2002). The work of both NGOs takes

place at both the community level, where they educate and support rights-holders to claim their rights, and at the government level, where they strengthen the accountability of duty-bearers towards their human rights obligations through human rights awareness raising and advocacy. Representatives from both NGOs noted this simultaneous 'bottom- 
up' and 'top-down' approach is very important and is one of the benefits of using rightsbased approaches:

I think that you do an injustice if you just work at the community level, if you make people aware of their rights but you don't correspondingly inform MPs and policy makers what those rights are, and then they get a bunch of angry people demanding their rights, and they're completely unequipped to respond to that, so you have to work on both sides (RRRT).

One of the benefits of the rights-based approach is that the community members also recognise that they have rights, and the government realises that it has the duty to fulfil these rights (SCF 2).

Unlike RRRT, which was established on a rights-based model, SCF changed from being a traditional service delivery development NGO to a child rights-based one in 2004 when it joined the international Save the Children Alliance. Since then, SCF has noticed that while it may focus on the rights of children, its work has impacts on the wider community. This has been particularly obvious with SCF's "Mobile Playgroup Project" (MPP). The MPP started as a playgroup van driven into disadvantaged squatter communities to provide children with early childhood education. While the children were learning, parents were taught about the importance of education and health and concepts of child rights were discussed. As an SCF representative noted, providing a service (education) was a platform from which to discuss both children's and human rights:

We use the MPP as an entry point into the communities, and from there people become interested in wanting to learn more (SCF 2).

All the SCF representatives noted that without this tangible service, it would have been much more difficult to interest community members in rights. Today the MPP has evolved into something more permanent, with individual communities working in partnership with SCF and the Ministry of Education to establish their own playgroups, 
staffed by SCF trained local teachers. For many of the communities, this experience at mobilising around the establishment of a playgroup has led to further political engagement and rights advocacy in both local and national government. For an SCF representative, this demonstrates how a rights-based approach can lead to community empowerment:

We see a rights-based approach as the next step ... we feel that children won't receive their rights if parents and communities aren't receiving theirs ... an empowered community will be in a better position to be accountable for their children, and will also be able to claim their rights (SCF 2).

One of the main community level projects used by RRRT is the "Community Paralegal Training Programme" (CPT), in which local community members are educated about human rights and trained to actively promote and protect the rights of those in their communities. Community Paralegals help community members access legal services, negotiate the court system, assert their rights and, reflecting RRRT's emphasis on the indivisibility of both economic, social and cultural rights and civil and political ones, are educated about everything from women's rights to democracy, and from trade and development to poverty. For the RRRT representative, this focus on indivisibility is essential. This is because, as the RRRT representative mentioned above, indivisibility is "not well understood" in Fiji and although people are receptive to talk of 'bread and butter' economic, social and cultural rights, they are usually less interested in civil and political ones:

When you talk to people in communities, the rights that they are most interested in are the basic rights, the right to shelter, water, education ... but we also try to explain to people that without your civil and political rights, then you won't be able to demand water, shelter, food.

\section{Challenges}

This section focuses on the challenges of using human rights in and for development and presents the responses to the following questions: 
- What are the challenges of using human rights and rights-based approaches in your work?

- How do you address these challenges?

As with Chapters Five and Six, for ease of understanding these challenges will be presented according to four interrelated factors: conceptual, political, cultural and operational.

\section{Conceptual}

In Fiji, the main conceptual challenge to the use of human rights in and for development is the perceived gap which exists between human rights and development organisations. As with the case-study NGOs in Chapter Six, all NGOs in Fiji recognised a theoretical overlap between the goals and aspirations of development and human rights, and many believe human rights bring benefits to development in terms of added accountability and legal recourse. However, most NGOs emphasised that in practice there is a distinct divide between human rights and development NGOs. Obviously, this divide has been accentuated by the current political situation in Fiji, in which some NGOs are considered to have supported the coup for its supposed 'pro-poor' economic and social focus and have questioned outcry at the human rights abuses perpetrated by the military against members of the NGO community when:

We have thousands upon thousands of people who are living in squatter settlements ... $60 \%$ of our population are earning wages below the poverty line....and nobody says anything about that (ECREA).

The gap between human rights NGOs and development ones is tied closely to the principle of the indivisibility of the international human rights framework. As with the case-study NGOs in Chapter Six, development NGOs believe human rights ones focus too much on civil and political rights, while human rights NGOs believe the development ones focus too much on economic, social and cultural rights: 
Why are we talking about civil and political rights and not about economic and social rights you know? ... You have to be more balanced in your human rights based approach (ECREA).

Rights are not separate, you need a holistic approach [but] with some of the comments, you realise that people do not necessarily know what they're talking about (FWRM).

The concept [indivisibility] is not well understood, and you saw that during the coup, when organisations were picking and choosing their rights, 'it's ok that people are getting tortured and stuff like that, because in the long run this is a propoor coup, it's anti-corruption'. You can't do that (RRRT).

Although this 'gap' was brought to the forefront of NGO and public attention during the 2006 coup and its aftermath, it had existed for some time. ECREA representatives talked of the difficulties they'd faced in getting support from the NGO community for its campaign against the proposed VAT increase during 2006:

We were saying, "well this is human rights, you've got a right to food"...we called on the other NGOs to come and support us ... and I think that it was only one other NGO that came to give any support, and so all these human rights characters, when it came down to the reality of something that was really affecting people, well, no one was interested.

A second conceptual challenge relates to the comments the WAC representative made:

We don't want to overly privilege the idea of human rights, it's a wonderful framework, but we work from the concept of women working for other women and men and children in communities, and if human rights are a valuable tool, then we work with them, but we don't start with them

And also to comments made by a PCDF representative: 
The work that we do is basically ... for the community (PCDF 2).

As mentioned previously, although WAC, PCDF and ECREA have started to include human rights in their work, none of them considered it necessary to re-orientate themselves towards a rights-based approach, or to analyse and address the issues they worked on primarily from a human rights perspective. They implied this was because many of the characteristics of this approach were already part of their work and underlying philosophies. For example, both ECREA and WAC work from a participatory, empowering platform and in their community workshops encourage analysis of local, national and international problems. PCDF focuses more on local problems, but relates these to state services and policies and works with communities in order to develop community action plans in order to encourage local engagement in and ownership of development.

\section{Political}

Local NGO representatives identified two main political challenges to the use of human rights in and for development. Firstly, within the current political context of Fiji, those organisations who are associated closely with campaigning on human rights and who are openly critical of the current military regime have been threatened and targeted by the military, making their work extremely difficult. A FWRM article on the coup and the treatment of human rights activists summed up this difficulty, stating:

Human rights defenders have been targeted, facing intimidation, detention, and physical violence ... It is becoming increasingly difficult and dangerous for activists to voice their opinions publicly (Chetty, 2007, p. 1).

The distrust of human rights NGOs predates the coup, however. As Chapter Seven noted, the government deregistered CCF's charitable trust status as a result of its opposition to the 2000 coup, meaning it had to reinstate itself as an incorporated company in 2003. 
Secondly, despite rhetorical donor support for all, rather than just civil and political, human rights in development, several NGOs mentioned the reality was somewhat different. For example, because it advocates for all constitutional rights,

Some development organisations and government departments consider $\mathrm{CCF}$ as controversial (CCF).

While in the post-coup period, RRRT wanted to monitor economic, social and cultural as well as civil and political rights, but:

Even as I was trying to convince the gang at the UN that we have to monitor all rights, they were like 'no, just focus on the civil and political ones' (RRRT).

And although rights-based approaches are at the forefront of current donor policy, it seems that in reality, asserting and claiming human rights and criticising the status quo tend to make donors nervous:

Donors are happy to see human rights taught, but when those communities then get up and protest and have marches and demonstrations, they go 'arg!! They only want to go so far, and we're saying 'you've got to fight for your rights', whether the donors like it or not! (ECREA). ,

When we train community paralegals we train them to assert and demand human rights, now, when we use that terminology, everybody hates it, it scares the crap out of states, the Australian government freaks out, the UN freaks out (RRRT).

As with NGOs all over the world, their reliance on donor funding means it is difficult for local Fijian NGOs to survive if they are working on rights or in areas which make donors uncomfortable: 
There are [NGOs] who are doing very good work, but funders or donors, they're not very keen on supporting their communities or their work and a lot of it is because ... they are difficult issues (FWRM).

For the FWRM representative, "to do our work effectively, it's about funds", and to access funds, you need to be able to "sell yourself [and be] very strategic in the way you design and implement programmes" while also knowing:

What your non-negotiables are, you need to know how far you are willing to negotiate and what you are not going to budge on.

\section{Cultural}

All NGOs interviewed identified cultural factors to be a significant challenge to the use of human rights by and for development. As PCDF representatives explained, there is often a lot of public resistance to human rights, generally resulting from misunderstanding about what human rights are and what they mean:

Last week one of the guys...said that 'well you have people in the villages now who don't want to attend village meetings because they have the right not to attend the meeting'. And so people start to take it out of context ... that is the main reason that most indigenous communities don't like the concept of human rights (PCDF 1).

When we started off the session, the first thing I asked people was "have you heard of human rights?' And they say 'yes', and I say 'what have you heard?' And they say, that 'it's bad!' ... And I said 'why is bad'? ... They were thinking of the rights of the child and CEDAW and they were saying things 'oh no women and children are going to be very cheeky and rebellious' ... so we had to explain it to them and then they got to understand it (PCDF 1).

This misunderstanding was also noted by SCF and WAC in relation to children's rights: 
There is the general misconception that giving children rights takes away from the parents (SCF 2).

Parents feel like it is an attack on their family role ... greater work needs to be directed at parents, because they themselves are unclear about what their responsibilities are and what the rights of their children are (WAC).

With women's rights, both WAC and FWRM commented that responses are varied:

Young people are more likely to listen to an argument and decide for themselves, whereas people who are a lot older, they are really set in their ways, and it's really difficult to try to change that mindset (FWRM).

Let's say we're talking about universality, there are issues of gender that are very powerful here, and so some women you may talk to may find the concept empowering, other women think that's an attack on traditional cultural values (WAC).

However, none of the NGOs interviewed considered these challenges insurmountable and all demonstrated innovative approaches and strategies for using human rights at the local level. Many of these approaches to human rights involve aspects of those suggested in Chapter Six - actor-orientated perspectives, social transformation and vernacularisation (An-Na'im, 2002; Merry, 2005; Nyamu-Musembi, 2002). For example, generally NGOs which are first starting human rights work in communities do not use the terms rights or human rights, because doing so encounters resistance:

We don't even use the work human rights out in the villages because it's not liked (ECREA).

We do [talk about rights], but in a subtle way, we don't usually say the word rights ... in the communities we work with, there are two ways you can use the word rights ... you can use dodonu which means your rights, and you can use rala 
which means freedom. And dodonu is a stronger word, and ... community workers prefer to use rala because dodonu can be taken out of context, and people start to abuse it - 'I have the right over you' (PCDF 1).

If you start coming in with human rights this, human rights that, you know, they don't like the word rights (RRRT).

Several NGOs noted that much of the resistance to human rights comes from the church, particularly when it comes to the rights of sexual minorities. For example, the ECREA representative commenting on public consciousness of human rights in Fiji said:

It's slowly coming, there's been a bit of opposition and that maybe has increased awareness, and on the one hand that's not good, but it is making people more aware. And sometime it's been the churches, like with the gay and lesbian community.

The CCF representative argued the church, especially the Methodist Church, is often resistant to human rights, and also noted resistance from local police and provincial council workers who "feel their authority may be threatened".

All NGO representatives emphasised the importance of dialogue in addressing this resistance. A strategy used by RRRT to encourage dialogue and understanding about human rights is to encourage people to identify values themselves, and then to compare these values to the standards and principles of the UDHR:

We start with, 'as a human being, what are the things you need to have a dignified life?' And we get people to write them down, and generally these are the basic human rights, and then we talk about those, the rights to food, shelter, a family, and then we highlight to them where these rights come from, in the UDHR, and then we give them a list of the rights in the UDHR, and get them to decide which ones they would be willing to give up, and which ones are against your culture, initially they can't find any, and we say, 'well, the UDHR is the foundation 
document for the big seven covenants' and we use that as a way of debunking the culture versus human rights idea, and people are sort of 'oh, ok' because they wrote the rights themselves, they came up with them ... So that's normally how we start out with the whole culture and human rights thing, and that usually sets the tone, people go 'oh, ok, human rights are not this big evil demon which wants to give rights to homosexuals' and you know.

Similarly, for SCF, engaging communities in "non-confrontational" discussion and activities based on the CRC has proved to be an effective way to address initial parental resistance to the concept of children's rights:

One of our activities...is asking participants to identify what some of the needs of children are, and then we say, "well when we bring the CFC, we are addressing the needs of children" ... Another ... is that we go through the different areas of the CRC (child survival, protection, participation and development) and give them case studies to analyse, and once they see ... how they can use [the CRC] practically ... then it isn't something foreign and it is something understandable (SCF 2).

SCF's emphasis on encouraging acceptance of human rights by making them practical was a strategy used by many of the NGOs. For example, in its community workshops, CCF focuses on the constitution as it is something "owned" by all Fijian rather than something "imposed from outside" (SCF 2). To make the rights within the constitution practical and real, it focuses on the issues affect people's everyday lives first, and then relates them back to their constitutional rights. For example, CCF representatives will ask workshop participants: "Who has been arrested? What happened? Were you allowed to call a lawyer?"', and will then go on to talk to people about their legal rights. Another important aspect of these community workshops is the use of language that is relevant to the community, for example, rather than talking about reducing corruption, they will talk about "ccleaning up the government"”. 
Another way local NGOs make human rights practical is by starting from the issues generated by the community. For one PCDF representative, this means "we don't come out and say that "today we're going to talk about this"' (PCDF 1). Instead, the focus "comes up from the issues that they [community members] talk about". These are then related to human rights. WAC does the same:

We don't start with them [human rights] ...we start with what's going on here access to water, inequality - we start with what is happening to women, then human rights, feminism, restorative justice, indigenous knowledge come in as valuable tools.

From a feminist perspective, the personal is political, so you start with what affects the person, and work from there.

The WAC representative also noted the importance of being sensitive and respectful of all types of knowledge:

We work with others who are working in all sorts of frameworks of knowledge, and so I don't want to overly privilege the idea of human rights, it's a wonderful framework, but we work from the concept of women working for other women and men and children in communities, and if human rights are a valuable tool, then we work with them, but we don't start with them.

Like WAC, many of the issues FWRM chooses to focus on are generated from comments made by the community in workshops, which it then relates back to constitutional and human rights:

For example ... a lot of women were raising issues like 'we are having babies but then we don't get maternity leave or feeding breaks' so we thought maybe we should do some research on this, on the impact of labour laws on women workers, and we did research on that and on the basis of that we got some direction on where we should be making changes. Most of our work is generated from 
something the community tells us ... once we learn from the community what areas they need researched, then we look to the constitution to see what it says.

\section{Operational}

The final challenges identified by Fijian NGO representatives were operational. The first challenge echoes one identified by NGOs in Chapter Six. As the FWRM representative commented, it can be difficult to evaluate human rights related programmes and this can pose problems with donors. This is because unlike traditional development programmes, some human rights outcomes may be intangible things such as individual and community empowerment, the wider impacts of which can be difficult to measure. For example, for several years FWRM has been running a year long programme called the Emerging Leaders Forum in which young women are educated about everything from human rights and democracy to global trade and development. Project participants regularly refer to the Forum as a life changing experience, and according to the FWRM representative, participants make comments such as:

'I can no longer see the world through my rose tinted glasses, I was so sheltered before but now I see the way the world really operates'.

The FWRM representative notes one benefit of the programme is that other young women notice the change in participants and also want to take part. However, this type of impact, though significant, is difficult for donors to measure:

I remember Oxfam saying 'well, that's not a big impact, because we're looking for structural impacts'. And I said to them 'well, listen, these are little steps we can take you know'. For me, that is a change, and we should be educating to make the change happen...it's small things that bring about change, because they're taking personal ownership.

The WAC representative identified a second operational challenge to the use of human rights by and for development. She commented several times on the disjuncture between formal human rights frameworks (such as national legislation or international treaties) 
and lived reality, or "the gap between holding a right" and "access to rights". The FWRM echoed this comment, noting that "with our constitution, aspects of it haven't been translated into legislation, so they exist in theory, but not in practice, it doesn't comply".

However, for the FWRM representative, the gap between constitutional rights and legislative reality, or between holding and accessing rights, is further reason for NGOs to focus their work at different levels:

But I think it's also about, well we and WAC constantly have this debate, they always say that you guys work in terms of changing a law or a policy, but changing laws and policies isn't going to make any kind of big impact on women's lives, you have to start from their personal lives and work from that, and so our approach to that is to say, right, you're working at that level, but while you're trying to empower those women, there will always be structures that prevent things getting better, so while you're doing that, we will try to remove some of those barriers and structures that are in her way, that are stopping her from fulfilling her full potential.

Finally, the WAC representative believes the structure of the UN system itself, can also pose a challenge to the successful use of human rights for development:

Part of the beauty of rights is that it comes with that [legal] framework. Whether or not it works at a practical level, I am kind of not sure ... There is a total dislocation between the UN level structures and community work, it is very difficult for someone working at a community level to participate, you can find little ways in with the special rapporteurs, but it can be disenchanting ... and you have a Security Council that is completely locked up.

\section{Conclusion}

The findings from Fiji demonstrate that NGOs there have indeed been influenced by the human rights shift in global development policy. As with the case study NGOs in 
Chapter Six, the way human rights are used by Fijian NGOs varies considerably, with some applying rights-based approaches and others using human rights as one among many tools of development and community empowerment. However, no matter how they actually use them in their day to day work, all NGO representatives agreed that human rights have the potential to challenge and transform power relationships and to secure resources for the most poor and marginalised. They also all identified numerous challenges to the successful use of human rights in the Fijian context. These included the divide between human rights and development NGOs, itself associated with the hierarchy between civil and political and economic, social and cultural rights, and the issue of cultural resistance to human rights. The following chapter will analyse these findings and discuss their possible implications for rights-based approaches to development. 


\section{Chapter Nine: Analysis and Discussion}

\section{Introduction}

As Chapter Six demonstrated, local NGOs play a vital role in development, acting as intermediaries between global development theories and approaches and local realities (Merry, 2005; Tvedt, 1998). This role is particularly crucial when it comes to an approach to development based on something as contested as human rights. Local NGOs are not only in an ideal position to construct human rights struggles in locally relevant terms, but are also able to take local concerns and frame them within the universally recognisable language of the international human rights framework (Molyneux \& Lazar, 2003; Pettit \& Wheeler, 2005). Their experiences of doing so can offer valuable insight into the challenges of applying development theories, such as rights-based approaches, in different contexts.

This chapter addresses the research aim by analysing and discussing the findings from the interviews with NGO representatives in Fiji and comparing them to the broader global context. It begins with a summary of the ways Fijian NGOs understand and use human rights for development, and then compares the challenges of using human rights in the Fijian context with those identified globally. Finally, it discusses some of the possible implications of these challenges for the successful application of rights-based approaches.

\section{Understanding and Using Human Rights for Development}

As with the NGO case studies reviewed in Chapter Six, most Fijian NGO representatives could see the theoretical connections between the goals and values of human rights and those of development. They were all aware of the shift towards rights-based approaches in the policies of the global development community, and could all see benefits of viewing poverty and development through a human rights lens. Reflecting the global literature, they described these benefits in various ways, including that human rights provide legal accountability for poverty alleviation, focus attention on the participation

and empowerment of poor and marginalised communities, emphasise social equality, and broaden the understanding of poverty and development to include political as well as material dimensions. Some of these benefits are clearly demonstrated in the work of the 
NGOs interviewed, from ECREA's work demanding state accountability for squatter communities, to the empowerment of participants in FWRM's Emerging Leaders Forum and of local communities in SCF's Mobile Playgroup Project.

Interestingly, one benefit of integrating human rights into development that is widely discussed in the global literature was mentioned neither by Fijian NGO representatives nor by those in the NGO case studies. Proponents writing at the global level argue that an important benefit of viewing development from a human rights perspective is that human rights encourage analysis of not only local but also global power structures (J. Chapman, 2005; Cornwall \& Nyamu-Musembi, 2004a; Uvin, 2007). They point to the way that the legal basis of human rights can be used to hold states accountable for their participation in and support of systems of economics and trade which prevent the realisation of basic human rights. However, in contrast to the global literature, neither Fijian NGO representatives nor the NGO representatives in the case studies raised this benefit of human rights or a rights-based approach. Fijian NGOs working on economic globalisation (such as ECREA, and to a lesser extent FWRM) do focus on the social impacts of economic liberalisation, as responses to recent moves by the Fijian government to sign an Economic Partnership Agreement with the European Union demonstrate (Coates, 2007). Yet while FWRM has done some work linking the impacts of trade liberalisation to women's rights, neither FWRM nor ECREA said they use human rights as a way to frame their work in this area and neither discussed the benefits of doing so (Sani, 2007). This may be because issues of trade liberalisation are relatively new for Fijian NGOs; the umbrella advocacy group on trade liberalisation, PANG, started in 2001 and has two core staff members. Also, although ideas of viewing trade liberalisation through a human rights lens began with the NIEO, they have only recently emerged as a mainstream advocacy strategy and potentially have yet to filter down to the local NGO level.

While all Fijian NGO representatives agreed on the shared goals of human rights and development and could see numerous benefits in viewing development and poverty alleviation through a human rights lens, the way they used human rights varied according to the type of work their NGO did. For the human rights NGOs, CCF and FWRM, 
human rights are understood in terms of constitutional and women's rights respectively, and every aspect of their work is viewed from this human rights perspective. The legal expertise of both organisations means that the majority of their work involves holding the government, as primary duty-bearer, accountable for upholding women's and constitutional rights in its laws and policies. However, both organisations are also involved with work at the rights-holder level, educating people about their rights and framing local issues in human rights terms. As the Fijian Constitution and the women's rights convention CEDAW both incorporate both sides of the human rights framework civil and political and economic, social and cultural rights - undertaking work on development issues (such as the impact of trade negotiations on women's rights, or addressing the rights of those in squatter communities) does not require these human rights organisations to completely change the way they work or think. Rather, it requires them to broaden the scope of issues they work on to include the economic, social and cultural rights that are associated with development.

For the community-based development NGOs, ECREA, WAC and PCDF, work on human rights was a relatively new area. For these groups, the focus was less on completely re-orientating their work around human rights or rights-based approaches, and more on exploring how human rights could be used as one among many tools with which to complement existing philosophies and approaches. Therefore, human rights were mostly used in discrete educational projects among rights-holders or as a means of highlevel advocacy, rather than as a lens through which to view all their work. As these organisations all work closely with local communities, community resistance to human rights, discussed further below, was cited as one factor preventing the move towards the explicit use of a rights-based approach. Another was that, as the WAC representative said, they do not want to "privilege" human rights over and above the various other systems of knowledge and philosophies they work with. Additionally, it appears that while for human rights organisations broadening the focus to include economic, social and cultural rights as well as civil and political ones is a natural progression, for those organisations more involved with local communities and more traditionally development focused, human rights are unfamiliar territory and so require a greater degree of organisational learning and change. 
Finally, for the two explicitly rights-based NGOs, RRRT and SCF, every aspect of day to day work was viewed from a human rights perspective. Both organisations work from the macro to the micro level, combining high-level duty-bearer advocacy with rightsholder education at the community level, and both attempt to work on all types of human rights. SCF also continues to provide communities with tangible services, such as preschool education and assistance after natural disasters. Because these NGOs have close ties to international organisations, the way they understand and use rights-based approaches is very closely tied to the way rights-based approaches are conceptualised at the global level.

\section{Challenges}

\section{Conceptual}

As discussed above, all the Fijian NGO representatives agreed on the theoretical connection between human rights and development and on the usefulness of applying a human rights perspective to development and poverty alleviation. However, an important challenge to the merging of human rights and development ideas in Fiji was the conceptual gap that exists between those NGOs who are perceived to work strictly from a human rights (as in civil and political rights) perspective, and those who are perceived to be more development, social justice or community orientated. This divide is demonstrated by the difficulties ECREA faced when trying to gain NGO support for its protest against the Qarase government's proposed VAT increase, an increase which would have had negative impacts on the economic and social rights of Fiji's poor. The current political situation has exacerbated this gap, with NGO responses to the coup and the changes in policy implemented by the interim administration becoming polarised according to whether NGOs prioritise civil and political rights, democracy and the rule of law, or economic, social and cultural rights, equality, and social justice. This polarity has led people to overlook the overlapping and mutually reinforcing aspects of their work, and of human rights and development in general. 
These findings resonate with those of several NGO case studies discussed in Chapter Six, and, as Naidu (2007) comments, reflect the traditional ideological division between civil and political rights and economic, social and cultural ones. As Chapter Three described, this division has long influenced the way human rights have been understood and practiced, and persists despite the global reaffirmation of indivisibility and interdependence of both sides of the international human rights framework. It means that when it comes to using human rights for development and rights-based approaches, "the issue is not about how to shift from needs to rights, but how to combine them" (Molyneux \& Lazar, 2003, p. 47). Interestingly, this division and the impact it could have locally was generally not considered in the policy papers of the international development community, although, as will be discussed further below, a recurring theme in the criticism of rights-based approaches is that of donor bias toward state-centric civil and political rights.

\section{Political}

For human rights activists in Fiji, as with many of those interviewed in the NGO case studies, engaging in human rights is a necessarily political activity that involves challenging social and political power structures. In any society, even in the most liberal of democracies, challenging power or the status quo can be dangerous ${ }^{51}$. This has been demonstrated repeatedly over the past two decades in Fiji and is particularly obvious in its current political context, in which those critical of the coup have faced military abuse and harassment. The danger inherent in human rights advocacy, whether on civil and political rights, economic, social and cultural rights, or both, can pose challenges to the successful use of human rights for development. This is something that does not tend to occur in traditional, needs-based approaches to development, which, because they rarely challenge the underlying causes of poverty and inequality, are less confrontational and more apolitical.

\footnotetext{
${ }^{51}$ This is particularly relevant in the current global political environment, in which the so called 'war on terror' has been used as a reason to restrict civil liberties in many states, both developed and developing (Duffield, 2002; Ensor \& Gready, 2005).
} 
The second political challenge identified by some from the Fijian NGO community was that despite the rhetoric of indivisibility, donors tend to favour projects on civil and political rights (often manifested in the form of state-centric good governance programmes) and the relatively 'safe' areas of women's and children's rights. Additionally, several NGO representatives commented that donors are also reluctant to support projects which overtly encourage communities to assert, claim or demand their rights, or which look beyond the state to the international dimensions and causes of human rights violations. These donor attitudes meant some NGO representatives were quietly sceptical of the potential for rights-based approaches to truly transform those international structural inequalities which lead to abuses of economic, social and cultural rights. This is particularly true given that, as one representative commented, these inequalities are reflected even within the structure of the UN, most notably in the Security Council, itself (WAC). The scepticism of some Fijian NGO representatives resonates with that in the NGO case studies, as well that of critics such as Mohan and Holland (2001), Slim (2002) and Uvin (2004). Once again, this scepticism relates to the persistent divide between civil and political rights, and economic, social and cultural ones. Globally, this divide is connected to ongoing debates surrounding the most equitable and efficient economic and political models, debates which themselves impact on how development is theorised and practiced.

\section{Cultural}

Cultural resistance to human rights was identified as a key challenge by all Fijian NGO representatives. This clearly echoes the findings of the NGO case studies surveyed in Chapter Six. However, as Ensor (2005) and Piron and O’Neil (2005) comment, much of the global literature on rights-based approaches, particularly the donor policy papers, overlooks this cultural aspect. The NGO representatives in Fiji noted local resistance to human rights was often due to the perception of human rights as being synonymous with civil and political rights and the idea that these are individualistic and western. When people learnt of their constitutional rights, and the fact that human rights were also about access to basic needs such as health, education and welfare, a process which requires a degree of civil and political freedom, they were more willing to accept them. And, as Chapter Six's NGO case studies also demonstrated, when human rights were framed in 
local terms and related back to local concerns, they were also more likely to be accepted. These findings reflect recent anthropological and social constructivist literature on the cultural translation and transformation of human rights, such as actor-oriented approaches, cultural transformation and vernacularisation (An-Na'im, 2002; Merry, 2005; Nyamu-Musembi, 2002). They highlight the important role NGOs have to play in the implementation of any concept of development that uses human rights.

\section{Operational}

As discussed above, Fijian NGO representatives noted that lack of knowledge, both public and organisational, about human rights poses a significant challenge to the successful use of human rights for development. Lack of knowledge means basic human rights education must occur before any further work can take place. Again, this was a challenge discussed by several NGOs in Chapter Six and was also noted in the global literature (Jones, 2005).

A more significant operational challenge mentioned in the global literature, as well as by NGO representatives in Fiji and elsewhere, was the gap between holding and having a right. Several NGO representatives argued that while everyone may in theory have human rights, successfully claiming these rights is dependent on access to adequate legal systems and the ability of the state to provide them, which is difficult even in the context of a mid- range developing state like Fiji. Additionally, it can be hard for small, underfunded local NGOs to access the UN human rights system, and, as the WAC representative noted above, the UN itself (particularly the Security Council) is considered to replicate the very power imbalances that contribute to global inequality.

A final challenge noted in the global literature, the NGO case studies and in the Fiji findings was the difficulty of measuring outcomes of human rights projects, when it is often the case that they may increase people's self esteem, empowerment and knowledge, but may produce few tangible results in the short-term. As several NGOs in both Fiji and elsewhere commented, this can then make it difficult to satisfy donor funding and project requirements. 


\section{Implications}

The experiences of representatives from Fijian NGOs and those elsewhere reveal numerous challenges to the use of human rights for development at the local level. While most of these challenges were also mentioned in the global literature on human rights, development and rights-based approaches, two significant ones were not extensively discussed at the global level: local perceptions of a gap between human rights and development NGOs; and local cultural resistance to human rights discourse. This demonstrates the important influence local historical, political, social and economic factors have on the implementation of any global development theory, particularly any theory based on human rights. It also confirms Minogue's (2002, p. 135) comment that when it comes to translating development theories and approaches from the global to the local level, "at the very least, problems of policy transfer and application will occur".

Though these challenges are significant, the work of Fijian NGOs demonstrated that they are not insurmountable. In terms of the first, that of the politicised gap between human rights and development NGOs, it would seem that it is a case of organisations talking 'across' rather than to one another and overlooking their similarities in the process. In Fiji at least, the NGO community seems to be eager to overcome this gap, and, as Naidu (2007b) suggests, the best way to do this is through dialogue. Through dialogue the interdependence of human rights and development, which underlies rights-based approaches, can be revealed: that basic rights to food, education and shelter can only be claimed in an environment which respects civil and political freedoms; while for civil and political freedoms to be used, citizens must have a certain level of material and physical security. In terms of the second challenge, that of local cultural resistance to human rights, again, it would seem that open debate is the best solution. As the work of local NGOs in both Fiji and elsewhere reveals, discussion on cultural values, beliefs and practices, as well as around the meaning of human rights, has been successfully used to address the various forms of cultural resistance to human rights. Through discussion, people realise that human rights not only have much in common with their own cultural beliefs and values, but also that they offer a means by which to secure basic services, and are much more willing to accept them. The approaches of local NGOs in this respect are 
consistent with recent anthropological and social constructivist perspectives on culture and human rights (An-Na'im, 2002; Merry, 2005; Nyamu-Musembi, 2002). These perspectives emphasise the dynamic nature of culture, and demonstrate the importance of constructing human rights in the context of locally relevant terms and issues. They also emphasise that the international human rights framework is not a static, western imposition but is something that evolves in relation to changing norms and emerging social struggles.

What are the implications of these, and other, challenges for the broader application of rights-based approaches? Firstly, they imply that there is a long way to go before the historical dichotomy between human rights and development or civil and political rights and economic, social and cultural ones, is to be overcome. Despite global reaffirmation of indivisibility and enthusiasm for rights-based approaches, this dichotomy persists at both the local and the global levels. This was clearly demonstrated in Fiji. There, the divide has influenced not only local NGO responses to the coup, but also the way human rights are understood among local communities, with many people not realising human rights actually guarantee basic services as well as rights to vote, speak and participate in political life. The Fiji findings also indicate that this gap is also noticeable at the global level, with donors still prioritising civil and political rights over economic, social and cultural ones, and still seeming reluctant to overtly support people to assert, claim and demand their rights.

A second implication stems from the first. As discussed above, proponents of rightsbased approaches claim they have the ability to challenge power structures at every level, particularly at the global level (J. Chapman, 2005; Smaller, 2005; VeneKlasen, 2004). However, the position of government donors within these structures makes it very difficult for them to use or support rights-based approaches to challenge wider structural causes of human rights violations (L.H Piron \& O’Neil, 2005). This suggests, as some critics argue, that for rights-based approaches to really affect change, it is groups such as local NGOs, with support from their international counterparts, who will need to use them (Slim, 2002; Uvin, 2004, 2007). The intermediary role of local NGOs not only allows them to translate human rights and development ideas from the global to the local 
and back again, but it also means they can operate in a space removed from power itself, putting them in a better position to advocate for change (Merry, 2005; Tvedt, 2006). However, in Fiji at least, it appears that ideas of using human rights to address these broader structural concerns were in their infancy, with most NGOs using them instead to concentrate on a state-centric model of accountability for specific human rights.

\section{Conclusion}

While most of the NGOs in Fiji were not using rights-based approaches exactly as they are articulated at the global level, all used human rights in some way in their work and all described the generally positive experiences of doing so. The challenges identified in the Fiji context resonate with those identified in the NGO case studies and in the global literature on rights-based approaches, although two of the most significant ones - the divide between human rights and development NGOs, and the issue of cultural resistance to human rights - were not widely discussed within the policy documents of the global development community. These two key challenges relate to contested issue of the indivisibility of the two sides of the international human rights framework, and suggest that although rights-based approaches to development have the potential to address global structural causes of human rights violations, this potential is difficult to realise in practice. 


\section{Chapter Ten: Conclusion}

This thesis investigated if and how the shift towards human rights in global development policy is reflected at the local level. In order to contextualise contemporary donor discourse on human rights, it examined the international human rights framework and some of the main issues it faces today: the role of non-state actors, the hierarchy of rights and ongoing debates over the place of human rights in non-western cultures. It then analysed the historical connections between human rights and development, demonstrating that the current discourse has its origins in some of the earliest criticisms of development. Following a discussion on the theoretical relationship between human rights and development, it focused on rights-based approaches to development. Proponents of rights-based approaches claim that they draw attention to the fundamental links between denial of a voice and denial of resources. At their best, they move development from an act of charity to one of legal obligation, and have the ability to empower people and to transform the global structural inequalities which cause poverty and underdevelopment (VeneKlasen, 2004). Critics argue that while the legal basis of human rights does bring a degree of accountability to development and poverty alleviation, in reality, there are numerous conceptual, political, cultural and operational challenges that constrain the transformative potential of rights-based approaches (Uvin, 2007). These include the fact that any close investigation of the causes of human rights violations, particularly of violations of economic, social and cultural rights, inevitably requires government donors to acknowledge the role of the developed world in perpetuating the economic, trade and political structures which prevent developing states from fulfilling their human rights obligations.

The second part of this thesis moved to the local level, to look at if and how donor rhetoric on human rights, development and rights-based approaches is reflected in the work of local NGOs in developing countries. After reviewing various case studies of local NGOs working in human rights and development, it focused on how local NGOs in Fiji understand and use human rights in and for development. It also identified some important challenges to the use of human rights for development at this local level, and 
discussed the implications of these challenges for the broader practice of rights-based approaches to development.

The main findings of this thesis were that local NGOs are indeed aware of and influenced by the global discourse on human rights and development. However, few of the local NGOs surveyed in the case studies or in Fiji are adopting rights-based approaches exactly as they are articulated in the global literature. Rather, the majority of the local NGOs, particularly those coming from a community development background, tend to use human rights selectively in order to complement their existing development philosophies and approaches.

Numerous challenges to the use of human rights in and for development were identified at the local level, many of which reflected those identified in the global literature. However, two important challenges which were apparent in Fiji and in some of the NGO case studies were not widely discussed at the global level. These were the politicised gap between human rights and development or social justice organisations, and the issue of cultural resistance to human rights. Both these challenges relate to the human rights principle of indivisibility, or the idea that both sides of the international human rights framework (of civil and political rights, and economic, social and cultural ones) are of equal importance; that without a political voice, it is difficult to claim economic and social rights, and without basic provision of basic needs, it is difficult to assert civil and political rights. Indivisibility has been reaffirmed on numerous occasions at the global level. However, it appears that in practice there remains a bias towards civil and political rights on the part of government donors, and some reluctance to support projects in which people are overtly encouraged to assert, demand or claim their human rights, or to investigate the wider structural causes of human rights violations. As Chapters Three and Four discussed, this bias has existed since the Cold War and reflects the ideological debates over the role of the state in the provision of basic social services. In today's environment of neoliberalism, this debate is of continued relevance and still influences many areas of development and human rights practice. 
While these factors certainly pose a significant challenge to the successful use of human rights in and for development, the work of NGOs in Fiji and elsewhere shows that human rights can be used with great success at the local level, even if they are not yet being used to challenge wider structural problems. They also demonstrate that, as their proponents argue, human rights can empower and provide a voice for the marginalised and poor, a voice they can use to claim their economic, social and cultural rights. These findings confirm the proposition that local NGOs, as intermediaries between global ideas and local contexts, are in the best position to navigate the political and cultural challenges of using human rights for development. They also suggest that if local NGOs can receive the necessary support, perhaps from their northern NGO counterparts, they are in a better position than government donor agencies to fulfil the socially transformative potential of rights-based approaches.

This thesis intended to provide a picture of how global ideas of human rights and development are reflected at the local level. Focusing the fieldwork on a particular local context - Fiji - enabled the voices and experiences of local NGO representatives there to be compared to the broader literature on human rights, development and rights-based approaches. As such, the findings provide a good starting point for more specific research into the way human rights and development can be used at the local level. Suggested areas for future research include:

- Undertaking a human rights analysis of the Fiji budget or of specific government policies;

- Undertaking a human rights analysis of the impacts of trade liberalisation in Fiji and of the impending Economic Partnership Agreement with the European Union;

- Working with a community development NGO such as ECREA, PCDF or WAC to investigate how a rights-based approach could be fully applied in a particular context, for example with regard to squatter rights, or the rights of ethnic or sexual minorities;

- Working with SCF to analyse and record the lessons learned in its move from a service-based to a rights-based framework; or, 
- Looking closely at successful strategies used by Fijian NGOs to overcome cultural resistance to human rights.

Further investigation into if and how human rights can be used by local NGOs is important if rights-based approaches are to move beyond their current state-centric use to truly transform the causes of the social and economic inequalities that characterise today's world. As the findings from this research demonstrate, human rights can be used to identify and challenge the local structures that cause poverty and underdevelopment, and so do have the ability to do the same at the global level. The findings also demonstrate that the process of discussing, claiming and securing human rights can give power to those whose voices are normally marginalised, whether this is women, children, squatters or the poor. This sense of empowerment, related as it is to accountability, is perhaps the most important benefit of rights-based approaches. It is the first step towards securing more tangible gains, and towards transforming the wider socio-political structures which cause poverty, discrimination and underdevelopment. This aspect of human rights predates contemporary discussions of rights-based approaches that are "mouthed by power itself", linking back to the revolutionary, grassroots origins of rights discourse (Slim, 2002, p. 4). The practical examples of NGOs using human rights to speak back to power itself demonstrate that at heart, human rights are about people challenging the status quo in order to create a more just and equitable society, a vision shared with most alternative and critical approaches to development. 


\section{References}

AAA. (1947). Statement on Human Rights. American Anthropologist, 49, 539 - 541.

AAA. (1998). New Declaration on Human Rights. Anthropology Newsletter, 9.

Ahmed, S., \& Potter, D. M. (2006). NGOs in International Politics. Bloomfield, CT:

Kumarian Press

AI. (2005). Human Rights for Human Dignity: A Primer on Economic, Social and Cultural Rights. Oxford: Alden Press.

AI. (2007). Amnesty International Takes on Divided World (Press Release). New Zealand: Amnesty International New Zealand.

Ali, I. (2006). The Commercial Sexual Exploitation of Children Challenge. Suva: Save the Children Fiji (SCF).

Alston, P. (1981). Development and the Rule of Law: Prevention Versus Cure as a Human Rights Strategy. In ICJ (Ed.), Development, Human Rights and the Rule of Law. Oxford: Pergamon Press.

Alston, P. (Ed.). (2005). Non-State Actors and Human Rights. Oxford: Oxford University Press.

Alston, P., \& Robinson, M. (Eds.). (2005). Human Rights and Development: Towards a Mutual Reinforcement. Oxford; New York: Oxford University Press.

Alston, P., \& Steiner, H. J. (2002). International Human Rights in Context: Law, Politics, Morals (2nd. ed.). Oxford: Oxford University Press.

An-Na'im, A. (Ed.). (2002). Cultural Transformation and Human Rights in Africa. London: Zed Books.

Anderson, K., \& Rieff, D. (2005). Global Civil Society: a Sceptical View. In H. Anheier, M. Glasius \& M. Kaldor (Eds.), Global Civil Society 2004/5. London: Sage.

Andrenopolis, G., Arat, Z. K., \& Juviler, P. (Eds.). (2006). Non-State Actors in the Human Rights Universe. Bloomfield, CA: Kumarian Press.

Appadurai, A. (2004). The Capacity to Aspire: Culture and the Terms of Recognition. In V. Rao \& M. Walton (Eds.), Culture and Public Action (pp. 59 - 84). Stanford: Stanford University Press.

Appleyard, S. (2002). A Rights-Based Approach to Development: What the Policy Documents fo the UN, Development Cooperation and NGO Agencies Say. Bangkok: United Nations Office of the Hight Commissioner for Human Rights Asia Pacific.

AU. (1981). African Charter on Human and Peoples' Rights. Retrieved August 26, 2007, from http://www.hrcr.org/docs/Banjul/afrhr2.html

AUSAID. (2007). Human Rights Small Grants Scheme. from http://www.ausaid.gov.au/business/other opps/humanrights scheme.cfm

Bainimarama, V. (2007). History Denotes Elections Cannot Solve Coup Culture Retrieved November 7, 2007

Ball, O. (2005). Conclusion. In J. Ensor \& P. Gready (Eds.), Reinventing Development? Translating Rights-Based Approaches from Theory into Practice (pp. 278 - 300). London: Zed Books.

Banerjee, U. D. (Ed.). (2005). Lessons Learned From Rights-Based Approaches in the Asia-Pacific Region: Documentation of Case Studies. Bangkok: OHCHR Regional Office for Asia-Pacific. 
Barr, F. K. (2003). Christianity, Poverty and Wealth at the Start of the 21st Century. Suva: Ecumenical Centre for Research and Advocacy.

Barr, F. K. (2006). Making Poverty History. Suva: Ecumenical Centre for Research and Advocacy.

Bedford, R. (1989). Out of Fiji...A Perspective on Migriton After the Coups Pacific Viewpoint, 30(2), 142- 153.

Bell, L. S., Nathan, A. J., \& Peleg, I. (Eds.). (2001). Negotiating Culture and Human Rights. New York Chichester: Columbia University Press.

Boli, J., \& Thomas, G. (1999). Constructing World Culture: International NonGovernmental Organisations Since 1875. Stanford, CA: Stanford University Press.

Brockington, D., \& Sullivan, S. (2003). Qualitative Research. In R. Schyvens \& D. Story (Eds.), Development Fieldwork: a Practical Guide (pp. 57-74). London: Sage Publications.

Brocklesby, M. A., \& Crawford, S. (2004). Operationalising the Rights Agenda: DFID's Participatory Rights Assessment Methodologies (PRAMs) Project. Retrieved 22 August, 2007, from http://www.swan.ac.uk/cds/pdffiles/PRAMS-DAC.pdf

Brouwer, M., Grady, H., Traore, V., \& Wordofa, D. (2005). The Experiences of Oxfam International and its Affiliates in Rights-Based Programming and Campaigning. In P. Gready \& J. Ensor (Eds.), Reinventing Development? Translating RightsBased Approaches from Theory into Practice. London: Zed Books.

CCF. (2007). Introduction to CCF. Retrieved October 17, 2007, from http://www.ccf.org.fj/aboutccf.php?PHPSESSID=c58d0904f11503333e99010a123c4e43

CESCR. (2007). The Nature of State Party Obligations. Retrieved 24 October 2007, from http://cesr.org/generalcomment3

Chambers, R. (1983). Rural Development: Putting the Last First New York: Wiley.

Chambers, R. (2005). Ideas for Development. London: Earthscan.

Chapman, A. R. (1996). A "Violations Approach" for Monitoring the International Covenant on Economic, Social and Cultural Rights. Human Rights Quarterly, $18(1), 23-66$.

Chapman, J. (2005). Rights-Based Development: The Challenge of Change and Power. Paper presented at the Winners and Losers from Rights-Based Approaches to Development, Manchester.

Chetty, T. (2007, March). Suva by Night: Targeting Local Human Rights Defenders. Balance: the FWRM Magazine, 4, 1.

CID. (2005). A Rights-Based Approach to Development. Wellington: Council for International Development.

Clapham, A. (2006). Human Rights Obligations of Non-State Actors Oxford: Oxford University Press.

Coates, B. (2007, Tuesday April 17). It's Time for a Fairer Deal. The Fiji Times, p. 6.

Cole, R. V. (1989). The Fiji Economy: From Go to Woe. Pacific Viewpoint, 30(2), 154 162.

Commins, S. (2000). NGOs: Ladles in the Global Soup Kitchen? In D. Eade (Ed.), Development, NGOs, and Civil Society (pp. 70 - 74). Oxford: Oxfam. 
Cornia, G. A., Jolly, R., \& Stewart, F. (1987). Adjustment with a Human Face: Protecting the Vulnerable and Promoting Growth. Oxford: Oxford University Press.

Cornwall, A., \& Nyamu-Musembi, C. (2004a). Putting the 'Rights-Based Approach' to Development into Perspective Third World Quarterly, 25(8), 1415 - 1437.

Cornwall, A., \& Nyamu-Musembi, C. (2004b). What is the "Rights-Based Approach" All About? Perspectives from International Development Agencies. IDS Working Paper $234 \quad$ Retrieved 15 August, 2007, from http://www.ntd.co.uk/idsbookshop/details.asp?id=847

Crotty, M. (1998). The Foundations of Social Research. Crow Nest, NSW: Allen \& Unwin.

Derrick, R. A. (1950). A History of Fiji Suva: Government Printer.

DFAT. (2004). Human Rights Manual. Retrieved August 22, 2007, from http://www.dfat.gov.au/hr/hr manual 2004/chp7.html

DFID. (1997). White Paper on International Development. London: Department for International Development.

DFID. (2000). Realising Human Rights for Poor People. London: UK Department for International Development.

Donnelly, J. (1999). Human Rights, Democracy and Development. Human Rights Quarterly, 21(3), 608-632.

Donnelly, J. (2003). Universal Human Rights in Theory and Practice. Ithaca: Cornell University Press.

Douglas, M. (2004). Traditional Culture: Let's Hear No More About It. In V. Rao \& M. Walton (Eds.), Culture and Public Action (pp. 85-109). Stanford: Stanford University Press.

Downey, J. K. (2003). Suffering as Common Ground. In M. Monshipouri, N. Englehart, A. J. Nathan \& K. Philip (Eds.), Constructing Human Rights in the Age of Globalisation (pp. 308-328). New York: M.E Sharpe.

Duffield, M. (2002). Global Governance and the New Wars: The Merging of Development and Security. London: Zed Books.

Eade, D. (Ed.). (2000). Development, NGOs, and Civil Society. Oxford: Oxfam Great Britain.

ECREA. (2006). Press Release. Retrieved November 9, 2007, from www.ecrea.org.fj

ECREA. (2007a). About Us. Retrieved December 5, 2007, from http://www.ecrea.org.fj/index.php?option=com content\&task=view\&id=13\&Item $\underline{\mathrm{id}=50}$

ECREA. (2007b). Social Empowerment, Education Programme (SEEP). Retrieved November 22, 2007, from http://www.ecrea.org.fj/index.php?option=com_content\&task=view\&id=26\&Item $\mathrm{id}=47$

Emberson-Bain, A. (Ed.). (1995). Sustainable Development or Malignant Growth? Perspectives of Pacific Island Women. Suva: Marama Publications.

Englehart, N. (Ed.). (2003). Constructing Human Rights in an Age of Globalisation. New York: M.E Sharpe.

Ensor, J. (2005). Linking Rights and Culture - Implications for Rights-Based Approaches. In P. Gready \& J. Ensor (Eds.), Reinventing Development? Translating RightsBased Approaches form Theory into Practice (pp. 254-277). London: Zed Books. 
Ensor, J., \& Gready, P. (Eds.). (2005). Reinventing Development? Translating RightsBased Approaches from Theory into Practice. London: Zed Books.

Evans, T. (2005). International Human Rights Law as Power/Knowledge. Human Rights Quarterly, 27.

Eyben, R. (2003). The Rise of Rights: Rights-Based Approaches to International Development. IDS Policy Briefing(17), 1-4.

Falk, R. (2000). Human Rights Horizons: The Pursuit of Justice in a Globalising World. New York Routledge.

FHRC. (2006). Report for Government's Affirmative Action Programmes, 2020 Plan for Indigenous Fijians and Rotumans, and the Blueprint. Retrieved October 17, 2007, from http://www.humanrights.org.fj/pdf/AA_report.pdf

FHRC, \& NZHRC. (2006). Forms of National Human Rights Institutions for Small Pacific States: Draft Research Paper. Retrieved November 9, 2007, from http://www.hrc.co.nz/hrc new/hrc/cms/files/documents/20-Dec-2006 11-47-

22 Draft_paper_Pacific_Human_rights_institutions_dec_06.doc

Filmer-Wilson, E. (2005). The Human Rights Approach to Development: The Right to Water. Netherlands Quarterly of Human Rights, 23(2), 213-241.

Forsythe, D. P. (2000). Human Rights in International Relations. New York: Cambridge University Press.

Fraenkel, J. (2007). Addendum: The Fiji Coup of December 2006: Who, What, Where and Why? In S. Firth \& J. Fraenkel (Eds.), From Election to Coup in Fiji; The 2006 Campaign \& Its Aftermath (pp. 420-449). Suva: Institute of Pacific Studies.

France, P. (1969). The Charter of the Land: Custom and Colonisation in Fiji. Melbourne: Oxford University Press.

Fukuyama, F. (1989) ). The End of History. The National Interest, Summer, 3-18.

FWRM. (2007a). HerStory. Retrieved December 5, 2007, from http://www.fwrm.org.fj/index.cfml?go=view\&pgID=30

FWRM. (2007b, March). Twenty Years of Change: A Herstory of Activism Balance: the FWRM Magazine, 4, 6.

Gaventa, J., \& Jones, E. (2002). Concepts of Citizenship. Brighton Institute of Development Studies.

George, N. (2004). Advocacy or Activism: Gender Politics in Fiji. Canberra: Australian National University.

Giddens, A. (1984). Th Constitution of Society: Outline of the Theory of Structuration. Cambridge: Polity Press.

Gledhill, J. (1997). Liberalism, Socio-economic Rights and the Politics of Identity: From Moral Economy to Indigenous Rights. In R. Wilson (Ed.), Human Rights, Culture and Context: Anthropological Perspectives (pp. 70-110). London: Pluto Press.

Gledhill, J. (2001). Rights and the Poor. Paper presented at the Anthropological Perspectives on Human Rights Conference, University of Sussex.

Goonesekere, S. (2003). A Rights-Based Approach to Realising Gender Equality. $\begin{array}{llll}\text { Retrieved } \quad \text { March 6, 2007, from } & \end{array}$ http://www.un.org/womenwatch/daw/news/savitri.htm

Gregory, A. (2007, May 12 2007). Fiji: Tough Living in Coup Coup Land. New Zealand Herald, p. B10.

Grynberg, R., Munro, D., \& White, M. (2002). Collapse of the National Bank of Fiji. Belair: Crawford House Publishing 
Harrison, L. E., \& Huntington, S. P. (Eds.). (2000). Culture Matters: How Values Shape Human Progress. New York: Basic Books.

Hau'ofa, E. (1987). The New South Pacific Society: Integration and Independence. In A. Hooper \& e. al (Eds.), Class and Culture in the South Pacific (pp. 1-15). Suva and Auckland: Centre for Pacific Studies, University of Auckland and University of the South Pacific.

Hausermann, J. (1998a). A Human Rights Approach to Development. London: Rights and Humanity.

Hausermann, J. (1998b). A Human Rights Approach to Human Development. Oslo: Conference on Human Rights and Development.

Hilhorst, D. (2003). The Real World of NGOs: Discourse, Diversity and Development. London: Zed Books.

Hill, H. (1994). Th Politics of Non-Governmental Organisations. In W. V. Busch (Ed.), New Politics in the South Pacific (pp. 123-138). Suva: Institute of Pacific Studies.

HRC. (2006). Submission on NZAID's Draft Gender Policy. Retrieved 26 August, 2007, from http://www.hrc.co.nz/hrc new/hrc/cms/files/documents/06-Nov-2006 1357-19_NZAID_draft_Gender_policy_8_aug_06_website_Letter.doc

HRCA. (1995). The Rights Way to Development: A Human Rights Approach to Development Assistance. Maroubra: The Human Rights Council of Australia.

Hunt, P., Osmani, S., \& Nowak, M. (2004). Summary of the Draft Guidelines on a Human Rights Approach to Poverty Reduction. Retrieved August 9, 2007, from http://www.unhchr.ch/development/SwissSummary1.doc

ICJ. (1981). Development, Human Rights and the Rule of Law. Oxford: Pergamon Press.

ILO. (2007). Minimum Wages Database Retrieved November 9, 2007, from http://www.ilo.org/travaildatabase/servlet/minimumwages?pageClass=org.ilo.legi slation.work.web.ReferencePage\&LinkId=9132

Ishay, M. R. (2004). The History of Human Rights: From Ancient Times to the Globalisation Era. Berkeley: University of California Press.

Jahan, S. (2004). Human Rights-Based Approach to Poverty Reduction - Analytical Linkages, Practical Work and UNDP. from http://www.undp.org/poverty/docs/employment/HRPR.doc

Jalal, I. (2005). The Situation of Human Rights Defenders in the Pacific Islands. Suva: Regional Rights Resource Team.

Jasis, M., \& Garcia, M. (2004). Linking Rights and Participation: Mexico Country Study. $\begin{array}{llll}\text { Retrieved } & \text { March, 2007, from }\end{array}$ http://www.ids.ac.uk/ids/participation/research/rights/

Jochnick, C. (1999). Confronting the Impunity of Non-State Actors: New Fields for the Promotion of Human Rights. Human Rights Quarterly, 21(1), 56-79.

Jones, A. (2005). The Case of Care International in Rwanda. In P. Gready \& J. Ensor (Eds.), Reinventing Development? Translating Rights-Based Approaches from Theory into Practice (pp. 79 - 107). London: Zed Books.

Jonsson, U. (2003). Human Rights Approach to Development Programming. Nairobi: UNICEF.

Jonsson, U. (2005). A Human Rights-Based Approach to Programming. In P. Gready \& J. Ensor (Eds.), Reinventing Development? Translating Rights-Based Approaches from Theory into Practice (pp. 47-62). London Zed Books 
Josephides, L. (2003). The Rights of Being Human. In J. P. Mitchell \& R. Wilson (Eds.), Human Rights in Global Perspective: Anthropological Studies of Rights, Claims and Entitlements (pp. 229-250). London: Routledge.

Junior, A. P., Antunes, M., \& Romano, J. O. (2004). Linking Rights and Participation: Brazil Country Study. from http://www.ids.ac.uk/ids/participation/research/rights/

Kelsey, J. (2004). A People's Guide to PACER. Retrieved December 2, 2007, from http://www.bilaterals.org/IMG/pdf/A Peoples Guide to PACER.pdf

Khan, C. A., \& Barr, K. J. (2003). Christianity, Poverty and Wealth at the Start of the 21 st Century. Suva: Ecumenical Centre for Research and Advocacy (ECREA).

Kolthari, U., \& Minogue, M. (Eds.). (2002). Development Theory and Practice: Critical Perspectives. New York: Palgrave.

Korten, D. (1990). Getting to the 21st Century: Voluntary Action and the Global Agenda. West Hartford, CT: Kumarian Press.

Kvale, S. (1996). InterViews: An Introduction to Qualitative Reserach Interviewing. Thousand Oaks: Sage Publications.

Lal, B. V. (1983). Girmitiyas: The Origins of the Fijian Indians. Canberra: The Journal of Pacifc History.

Lal, B. V. (1992). Broken Waves: A History of the Fiji Islands in the Twentieth Century. Honolulu: University of Hawaii Press.

Lal, B. V. (2003). Heartbreak Islands: Reflections on Fiji in Transition. Asia Pacific Viewpoint, 44(3), 335-350.

Lal, B. V. (2004 ). Girmitiyas: The Origins of the Fiji Indians Suva: Fiji Institute of Applied Studies.

Lauren, P. G. (2003). The Evolution of International Human Rights: Visions Seen. Philadelphia: University of Pennsylvania Press.

Lawson, S. (1990). The Myth of Cultural Homogeneity and Its Implications for Chiefly Power and Politics in Fiji. Comparative Studies in Society and History, 32(4), 795-821.

Leonard, E. K. (2006). Globalisation and the Construction of Human Rights. Human Rights and Human Welfare, 6, 151-163.

Lewis, D., \& Opoku-Mensah, P. (2006). Moving Forward Research Agendas on International NGOs: Theory, Agency and Context. Journal of International Development, 18(5), 665 - 675.

Ljungman, C. M. (2005). Applying a Rights-Based Approach to Development: Concepts and Principles. Paper presented at the The Winners and Losers from RightsBased Approaches to Development, Manchester University.

Lumbantobing, D., \& Zulminarni, N. (2004). Linking Rights and Participation: Indonesia Country Study. Retrieved 14 March, 2007, from http://www.ids.ac.uk/ids/participation/research/rights/

MacNaught, T. J. (1982). The Fijian Colonial Experience: A Study of the Neotraditional Order Under British Colonial Rule Prior to World War One. Canberra: Australian National University Press.

Madraiwiwi, R. J. (2006). Navigating Passage Between Human Rights and Culture in Fijian Waters. In M. Powles (Ed.), Pacific Futures (pp. 50-52). Canberra: Pandanus. 
Madraiwiwi, R. J. (2007). Mythic Constitutionalism: Whither Fiji's Course in June 2007? Paper presented at the The Fiji Coup - Six Months On, Australian National University, Canberra.

Makanje, R., Shaba, L. M., \& Win, E. J. (2004). Linking Rights and Participation: Zimbabwe Country Study. Retrieved March 15, 2007, from http://www.ids.ac.uk/ids/participation/research/rights/

McDonald, H. (2007, Saturday October 27). Leading the Revolution. The Dominion Post, p. B5.

Merry, S. E. (2001). Changing Rights, Changing Culture. In J. K. Cowan, M.-B. Dembour \& R. A. Wilson (Eds.), Culture and Rights: Anthropological Perspectives (pp. 31-55). Cambridge: Cambridge University Press.

Merry, S. E. (2005). Human Rights and Gender Violence: Translating International Law into Local Justice. Chicago: University of Chicago Press.

MFAT. (2003). New Zealand Handbook on Human Rights. Wellington: Ministry of Foreign Affairs and Trade.

Mikkelsen, B. (2005). Methods for Development Work and Research: A New Guide for Practitioners (2nd ed.). New Delhi: Sage Publications.

Minogue, M. (2002). Power to the People? Good Governance and the Reshaping of the State. In M. Minogue \& U. Kolthari (Eds.), Development Theory and Practice: Critical Perspectives (pp. 117-135). New York: Palgrave.

Mitchell, J. P., \& Wilson, R. A. (Eds.). (2003). Human Rights in Global Perspective: Anthropological Studies fo Rights, Claims and Entitlements. London: Routledge.

Mohan, G., \& Holland, J. (2001). Human Rights and Development in Africa: Moral Intrustion or Empowering Opportunity? Review of African Political Economy, 28(88), 177-196.

Molyneux, M., \& Lazar, S. (2003). Doing the Rights Thing: Rights-Based Development and Latin American NGOs. London: ITDG Publishing.

Moser, C., \& Norten, A. (2001). To Claim Our Rights: Livelihood Security, Human Rights and Sustainable Development. Rights in Action Retrieved August 28, 2007, from http://www.odi.org.uk/rights/Publications/tcor.pdf

Naidu, V. (2007a). Coups in Fiji: Seesawing Democratic Multiracialism and EthnoNationalist Extremism. Devforum, 24-33.

Naidu, V. (2007b). Human Rights and Social Justice: Moving Beyond the Divide. Paper presented at the The Annual Rev. Paula Niukula Lecture, University of the South Pacific.

Narsey, W. (2007, Sunday June 10). The Truth Behind Our Poverty. Fiji Times, p. 1.

NCAS. (2004). Linking Rights and Participation: India Country Study. Retrieved 10 March, 2007, from http://www.ids.ac.uk/ids/participation/research/rights/

NMT. (1950). Charter and Judgement of the Nurenburg Tribunal [Electronic Version]. $\begin{array}{lllll}\text { Retrieved } & 19 & \text { June } & 2007 & \text { from }\end{array}$ http://www.icrc.org/ihl.nsf/FULL/390?OpenDocument.

Nyamu-Musembi, C. (2002). Towards an Actor-Orientated Perspective on Human Rights. Brighton: Institute of Development Studies.

Nyamu-Musembi, C., \& Musyoki, S. (2004). Kenyan Civil Society Perspectives on Rights, Rights-Based Approaches to Development, and Participation. Retrieved 14 March, 2007, from http://www.ids.ac.uk/ids/participation/research/rights/ 
NZAID. (2002). Human Rights Policy Statement. Retrieved August 26, 2007, from http://www.nzaid.govt.nz/library/docs/nzaid-human-rights-policy.pdf

NZAID. (2004). Human Rights Policy: Implementation Plan of Action 2004-2009. Retrieved 26 August, 2007, from http://www.nzaid.govt.nz/library/docs/nzaidhuman-rights-poa.pdf

NZAID. (2005). Fiji Bacnkground Paper and NZAID/Fiji Country Programme Strategy. Wellington: NZAID.

NZAID. (2007). Draft Growth and Livelihoods Strategy. Retrieved August 26, 2007, from http://www.nzaid.govt.nz/library/docs/growth-livelihoods.pdf

NZLC. (2006). Converging Currents: Custom and Human Rights in the Pacific. Wellington: New Zealand Law Commission.

O'Brien, R., \& Williams, M. (2004). Global Political Economy: Evolution and Dynamics. New York: Palgrave MacMillan.

O'Byrne, D. J. (2003). Human Rights: An Introduction. Harlow: Pearson Education.

ODI. (2001). Economic Theory, Freedom and Human Rights: The Work of Amartya Sen. ODI Briefing Papers Retrieved 30 June, 2007, from http://www.odi.org.uk/publications/briefing/poly_final.pdf

Okille, P. A. (2005). Rights In Practice - Assessing the Impact of Rights-Based Training in Uganda. In P. Gready \& J. Ensor (Eds.), Reinventing Development? Translating Rights-Based Approaches from Theory into Practice (pp. 99-107). London: Zed Books.

Onuf, N. (1998). Constructivism: A User's Manual. In N. Onuf, V. Kubalkova \& P. Kowert (Eds.), International Relations in a Constructed World (pp. 58-78). Armonk, NY: M.E Sharpe.

Oxfam. (2007a). Submission on NZAID Draft Growth and Livelihoods Strategy. Retrieved August 26, 2007, from http://www.oxfam.org.nz/imgs/pdf/onz_submission_nzaidgrowthlivelihoods_final .pdf

Oxfam. (2007b). Suspension of the Doha Round: A Wasted Opportunity. Retrieved December 8, 2007, from http://www.maketradefair.com/en/index.php?file=qa_doha_suspended.html

Parekh, B. (1999). Non-Ethnocentric Universalism. In T. Dunne (Ed.), Human RIghts in Global Politics (pp. 128-159). Cambridge: Cambridge University Press.

PCDF. (2007). Partners in Community Development Fiji: Our Vision. Retrieved November 22, 2007, from http://www.fspi.org.fj/affiliates/fiji/mission.htm

Petitti, L.-E., \& Meyer-Bisch, P. (1998). Human Rights and Extreme Poverty. In J. Symonides (Ed.), Human Rights: New Dimensions and Challenges (pp. 157-180). Dartmouth: Ashgate.

Pettit, J., \& Wheeler, J. (2005). Developing Rights? Relating Discourse to Context and Practice. IDS Bulletin, 36(1), 1-7.

PIF. (2004). Auckland Declaration. Retrieved 5 December, 2007, from http://www.forumsec.org/ resources/article/files/Auckland\%20Declaration.pdf

Piron, L.-H. (2005). The Role of Human Rights in Promoting Donor Accountability. London: Overseas Development Institute - Rights in Action Programme.

Piron, L.-H., \& Watkins, F. (2004). DFID Human Rights Review: A Review of How DFID Has Integrated Human Rights Into Its Work. London: Overseas Development Institute - Rights in Action Programme. 
Piron, L. H. (2002). The Right to Development. Rights in Action Retrieved August 28, 2007, from http://www.odi.org.uk/rights/Publications/right to dev.pdf

Piron, L. H., \& O’Neil, T. (2005). Integrating Human Rights into Development: A Synthesis of Donor Approaches and Experiences. London: Overseas Development Institute - Rights in Action Programme.

Putnam, R. (1993). The Prosperous Community: Social Capital and Public Life. American Prospect, 4(13.1), 80-91.

Ram, K. (1995). Militarism and Market Mania in Fiji. In A. Emberson-Bain (Ed.), Sustainable Development or Malignant Growth? Perspectives of Pacific Island Women (pp. 237-250). Suva: Marama Publications.

Rao, V., \& Walton, M. (2004). Culture and Public Action: Relationality, Equality of Agency, and Development. In V. Rao \& M. Walton (Eds.), Culture and Public Action (pp. 3-36). Standford: Standford University Press.

Ratuva, S. (2007). The Paradox of Multiculturalism: An Assessment of Ethno-Political Conflict in Fiji. In A. M. Brown (Ed.), Security and Development in the Pacific Islands: Social Resilience in Emerging States (pp. 197-224). Boulder, Colorado: Lynne Rienner.

Reinsich, A. (2002). The Changing International Legal Framework for Dealing with NonState Actors. In P. Alston (Ed.), Non-State Actors and Human Rights (pp. 37-89). Oxfrod: Oxford University Press.

Reiss, H. (Ed.). (1970). Kant's Political Writings Cambridge: Cambridge University Press.

Robertson, R. (1998). Multiculturalism and Reconciliation in an Indulgent Republic. Suva: Fiji Institute of Applied Studies.

Robertson, R. (2005). From Multiculturalism to Transculturalism: Moving Beyond Postcolonialism in Fiji. Suva: USP.

Robinson, M. (2000). Development and Rights: the Undeniable Nexus. Retrieved July 31, 2007, from http://www.unhchr.ch/huricane/huricane.nsf/view01/F31C625AA489D31BC1256 90A0053C8DE?opendocument

Robinson, M. (2002). Draft Guidelines on a Human Rights Approach to Poverty Reduction Strategies. Geneva: UNOHCHR

Robinson, M. (2005). What Rights Can Add to Good Development Practice. In P. Alston \& M. Robinson (Eds.), Human Rights and Development: Towards Mutual Reinforcement (pp. 25-44). Oxford; New York: Oxford.

Robinson, M. (2006). A Voice for Human Rights. Philadelphia: University of Pennsylvania Press.

Rodrik, D. (2006). Goodbye Washington Consensus, Hello Washington Confusion? Journal of Economic Literature, 44(4), 973-987.

Routledge, D. (1985). Matanitu: The Struggle for Power in Early Fiji. Suva: University of the South Pacific

RRRT. (2004). Annual Report 2004. Suva: RRRT.

RRRT. (2007). About Us. Retrieved December 5, 2007, from http://www.rrrt.org/page.asp?active page $\mathrm{id}=88$

RRRT. (n/d). Promoting Human Rights Together. Suva: Regional Rights Resource Team.

Sanday, J. (1989). The Coups of 1987: A Personal Analysis Pacific Viewpoint, 30(2), 116-131. 
Sani, R. (2007, March). Warning! Dangerous Dealings. Balance: the FWRM Magazine, $4,10$.

SC. (2002). Child Rights Programming: What, Why and How? London: Save the Children Sweden

International Save the Children Alliance.

Sen, A. (1981). Poverty and Famines: An Essay on Entitlement and Deprivation. Oxford: Oxford University Press.

Sen, A. (1992). Inequality Reexamined. Oxford Oxford University Press.

Sen, A. (1998). Universal Truths: Human Rights and the Westernising Illusion. The Harvard International Review, 20(3), 40-43.

Sen, A. (2004). How Dow Culture Matter? In V. Rao \& M. Walton (Eds.), Culture and Public Action (pp. 37-58). Stanford: Stanford University Press

Shameem, S. (2006). The Assumption of Executive Authority on December 5th 2006 by Commodore J.V. Bainimarama, Commander of the Republic of Fiji Military Forces: Legal, Constitutional and Human Rights Issues. Retrieved 9 November, 2007 , from http://www.humanrights.org.fj/publications/2007/Investigation\%20Report\%20on \%20Events\%20of\%20December\%206\%202006.pdf

Slatter, C. (1995). Banking on the Growth Model? The World Bank and Market Policies in the Pacific. In A. Emberson-Bain (Ed.), Sustainable Development or Malignant Growth? Perspectives of Pacific Island Women (pp. 17-38). Suva Marama Publications.

Slim, H. (2002). A Response to Peter Uvin - Making Moral Low Ground: Rights as the Struggle for Justice and the Abolition of Development. Praxis, 17.

Smaller, C. (2005). Planting the Rights Seed: A Human Rights Perspective on Agriculture, Trade and the WTO. Retrieved December 5, 2007, from http://www.3dthree.org/en/pages.php?IDcat=6

Stammers, N. (1999). Social Movements and the Social Construction of Human Rights. Human Rights Quarterly, 20(2), 379-412.

Stammers, N. (2005). The Emergence of Human Rights in the North: Towards Historical Re-Evaluation. In N. Kabeer (Ed.), Inclusive Citizenship: Meanings and Expressions (pp. 50-68). London: Zed Books.

Stiglitz, J. (2003). Globalisation and its Discontents. New York: Norton.

Sutherland, W. (1989). The New Political Economy of Fiji. Pacific Viewpoint, 30(2), 132 $-141$.

Tarte, S. (2007, 21 March). Fiji: Where to From Here? Paper presented at the Leadership in Fiji Conference, University of the South Pacific.

Theis, J., \& O'Kane, C. (2005). Children's Participation, Civil Rights and Power. In P. Gready \& J. Ensore (Eds.), Reinventing Development: Translating Rights-Based Approaches from Theory into Practice (pp. 156- 170). London: Zed Books.

Thomas, A. (2000). Povery and the 'End of Development'. In T. Allen \& A. Thomas (Eds.), Poverty and Development in the 21st Century (pp. 3-22). Oxford: Oxford University Press.

Thomas, N. (1989). The Force of Ethnology: Origins and Significance of the Melanesia/Polynesia Division. Current Anthropology, 30(1), 34-40. 
Toyo, N. (2004). Linking Rights and Participation: Nigeria Country Study. Linking Rights and Participation Retrieved March 15, 2007, from http://www.ids.ac.uk/ids/participation/research/rights/

Truman, H. (1949). Inaugural Address. Retrieved November 20, 2007, from http://www.bartleby.com/124/pres53.html

Tskiata, D. (2004). The Rights-Based Approach to Development: Potential for Change or More of the Same? IDS Bulletin, 35(4), 130-133.

Tvedt, T. (1998). Angels of Mercy or Development Diplomats? NGOs and Foreign Aid. Trenton, NJ: Africa World Press.

Tvedt, T. (2006). The International Aid System and Non-Governmental Organisations: A New Reserach Agenda. Journal of International Development, 18(5), 677 - 690.

UN. (1948). Universal Declaration of Human Rights. Retrieved June 13, 2007, from http://www.un.org/Overview/rights.html

UN. (1966). International Covenant on Civil and Political Rights. Retrieved 23 June, 2007, from http://www.ohchr.org/english/law/ccpr.htm

UN. (1969). Declaration on Social Progress and Development. Retrieved 8 August, 2007, from http://www.unhchr.ch/html/menu3/b/m_progre.htm

UN. (1986). Declaration on the Right to Development. Retrieved 29 July, 2007, from http://www.unhchr.ch/html/menu3/b/74.htm

UN. (1993). Vienna Declaration on Human Rights. Retrieved 15 June, 2007, from http://www.unhchr.ch/huridocda/huridoca.nsf/(Symbol)/A.CONF.157.23.En

UN. (2002). Treaty Handbook. Geneva: United Nations Office of Legal Affairs Treaty Section.

UN. (2003a). The Human Rights-Based Approach to Development Cooperation: Towards a Common Understanding Among the UN Agencies Geneva: United Nations.

UN. (2003b). Norms on the Responsibilities of Transnational Corporations and Other Business Enterprises with Regard to Human RIghts. Retrieved 23 June, 2007, from http://www1.umn.edu/humanrts/links/norms-Aug2003.html

UN. (2006). Resolution Adopted by the General Assembly 60/251. Retrieved 13.6.07, 2007 ,

http://www.ohchr.org/english/bodies/hrcouncil/docs/A.RES.60.251_En.pdf

UN. (2007). UN Documentation: Human Rights Research Guide. Retrieved November 30, 2007, from http://www.un.org/Depts/dhl/resguide/spechr.htm

UNCESCR. (1990). The Nature of State Party Obligations: CESCR General Comment no. 3. Retrieved 27 June, 2007, from http://www.unhchr.ch/tbs/docs.

UNCESCR. (2001). Poverty and the International Covenant on Economic, Social and Cultural Rights: Statement E/C.12/2001/10. Retrieved 29 July, 2007, from http://www.unhchr.ch/tbs/docs

UNCESCR. (2002). The Millenium Development Goals and Economic, Social and Cultural Rights. Retrieved August 9, 2007, from http://www.unhchr.ch/housing/MDG.doc

UNCTAD. (2006). Commodities and Development UNCTAD Debates the Crisis in Commodities

UNDAW. (1995). Beijing Platform for Action. Retrieved November 13, 2007, from http://www.un.org/womenwatch/daw/beijing/platform/

UNDP. (1990). The Concept and Measurement of Human Development. New York: Oxford University Press. 
UNDP. (1992). Global Dimensions of Human Development. New York: Oxford University Press.

UNDP. (1997). Fiji Poverty Report. Suva: UNDP.

UNDP. (1998). Integrating Human Rights with Sustainable Human Development. Retrieved August 23, 1997, from http://www.undp.org/governance/docs/HR_Pub_policy5.htm

UNDP. (2000). Human Rights and Human Development. New York: Oxford University Press.

UNDP. (2002). Deepening Democracy in a Fragmented World. Oxford: Oxford University Press.

UNDP. (2006). Beyond Scarcity: Power, Poverty and the Global Water Crisis. Oxford: Oxford University Press.

UNDP. (2007a). Human Rights-Based Approach (HRBA) Checklist for Programme Staff. $\quad$ Retrieved August 26, 2007, from http://hdr.undp.org/docs/network/hdr/thematics/HRBA_Checklist.pdf

UNDP. (2007b). Human Rights \& Development - An Emerging Nexus Retrieved August 21, 2007, from http://www.undp.org/rbap/rights/Nexus.htm

UNHCHR. (2007). Human Rights and the Millennium Development Goals. Retrieved November 9, 2007, from http://www.unhchr.ch/development/mdg.html

UNHRC. (2006). Frequently Asked Questions on the Human Rights Council. Retrieved 13 June, 2007, from http://www.ohchr.org/english/press/hrc/kit/kit-english.pdf

UNOHCHR. (2006). Frequently Asked Questions on a Human-Rights Based Approach to Development Cooperation. Geneva: United Nations Office for the High Commissioner for Human Rights.

UNOHCHR. (2007). Human Rights in Development: What Is It All About? Retrieved August 8, 2007, from http://www.unhchr.ch/development/

Uvin, P. (2004). Human Rights and Development. Bloomfield, CT: Kumarian Press.

Uvin, P. (2007). From the Right to Development to the Rights-Based Approach: How 'Human Rights' Entered Development. Development in Practice, 17(4-5), 597606.

van Weerelt, P. (2001). A Human Rights-Based Approach to Development Programming in UNDP: Adding the Missing Link. Retrieved March 6, 2007, from http://www.undp.org/governance/docs/HR_Pub_Missinglink.pdf

VeneKlasen, L. (2004). Rights-Based Approaches and Beyond: Challenges of Linking Rights and Participation. Brighton: Institute of Development Studies.

Vieria de Mello, S. (2003, May 5-7 ). Opening Statement. Paper presented at the Second Interagency Workshop Implementing a Human Rights Based Approach in the Context of UN Reform, Stamford.

WAC. (2006). WacWomen. WAC Women E-Letter, 1(1), 1-4.

Wallace, T., Bornstein, L., \& Chapman, J. (2006). Coercion and Commitment: Development NGOs and the Aid Chain. Rugby: ITDG Publishing.

Walsh, C. (2005). The Essential Research Skills. Suva: Amokura Publications.

WB. (1997). World Development Report 1996-1997: The State in a Changing World. Oxford: Oxford University Press.

WB. (1998). Development and Human Rights: The Role of the World Bank. Washington DC: World Bank. 
WB. (2001). World Development Report 2000/2001: Attacking Poverty. Washington DC: World Bank.

WB. (2005). Economic Growth in the 1990s: Learning from a Decade of Reform Washington D.C: World Bank.

Whaites, A. (2000). Let's Get Civil Society Straight: NGOs, the State and Political Theory. In D. Eade (Ed.), Development, NGOs, and Civil Society (pp. 124-141). Oxford: Oxfam.

Wilson, R. A. (1997a). Introduction. In R. A. Wilson (Ed.), Human Rights, Culture and Context: Anthropological Perspectives (pp. 1-26). London: Pluto Press.

Wilson, R. A. (Ed.). (1997b). Human Rights, Culture and Context: Anthropological Perspectives. London: Pluto Press. 


\section{Appendix One: Human Rights and the MDGs}

\begin{tabular}{|l|l|}
\hline \multicolumn{1}{|c|}{ Millennium Development Goals } & \multicolumn{1}{c|}{ Relevant Convention } \\
\hline $\begin{array}{l}\text { Goal 1 } \\
\text { Eradicate extreme poverty and hunger }\end{array}$ & $\begin{array}{l}\text { ICESCR (article 11), GC 12, CRC } \\
\text { (articles 24 para. 2 and 27 para. 3) }\end{array}$ \\
\hline $\begin{array}{l}\text { Goal 2 } \\
\text { Achieve universal primary education }\end{array}$ & $\begin{array}{l}\text { ICESCR (articles 13 and 14, and GC 11), } \\
\text { CRC (article 28 a and GC 1), CERD } \\
\text { (articles 5 and 7) }\end{array}$ \\
\hline $\begin{array}{l}\text { Goal 3 } \\
\text { Promote gender equality and empower } \\
\text { women }\end{array}$ & $\begin{array}{l}\text { CEDAW; ICESCR (articles 3 and 7 para. } \\
\text { A (i));ICCPR (articles 3, 6 para. 5 and 23 } \\
\text { para. 2); CRC (article 2); CERD (GC 25) }\end{array}$ \\
\hline $\begin{array}{l}\text { Goal 4 } \\
\text { Reduce child mortality }\end{array}$ & $\begin{array}{l}\text { CRC (articles 6 and 24 para. 2.a); } \\
\text { ICESCR (article 12 para. 2 a, GC 14) }\end{array}$ \\
\hline $\begin{array}{l}\text { Goal 5 } \\
\text { Improve maternal health }\end{array}$ & $\begin{array}{l}\text { CEDAW (articles 10 h, 11 f, 12 para. 1, } \\
\text { 14 b, and GC 24; CERD (article 5 e iv) }\end{array}$ \\
\hline $\begin{array}{l}\text { Goal 6 } \\
\text { Combat HIV/AIDS, malaria and other } \\
\text { diseases }\end{array}$ & $\begin{array}{l}\text { International guidelines on HIV/AIDS and } \\
\text { human rights, ICESCR: GC 14; CRC } \\
\text { (article 24 c) }\end{array}$ \\
\hline $\begin{array}{l}\text { Goal 7 } \\
\text { Ensure environmental sustainability }\end{array}$ & $\begin{array}{l}\text { Safe drinking water: ICESCR: draft } \\
\text { General Comment (to be considered in } \\
\text { November 2002) and GC 14; Slum } \\
\text { dwellers: ICESCR:GC 4 and GC7 }\end{array}$ \\
\hline $\begin{array}{l}\text { Goal 8 } \\
\text { Develop a global partnership for } \\
\text { development }\end{array}$ & $\begin{array}{l}\text { Charter of the United Nations (article 1 } \\
\text { para. 3), ICESCR (article 2), CRC (article } \\
\text { 4). }\end{array}$ \\
\hline
\end{tabular}

Table 5: The Relationship between the MDGS and Human Rights

(UNHCHR, 2007, p. 1) 


\begin{tabular}{|c|l|}
\hline $\begin{array}{c}\text { Millennium } \\
\text { Human } \\
\text { Rights Goal }\end{array}$ & \multicolumn{1}{c|}{ Description } \\
\hline Goal 1 & $\begin{array}{l}\text { To respect and fully uphold the Universal Declaration of Human Rights } \\
\text { and strive for the full protection and promotion in all countries of civil, } \\
\text { political, economic, social and cultural rights for all }\end{array}$ \\
\hline Goal 2 & $\begin{array}{l}\text { To strengthen the capacity of all our countries to implement the } \\
\text { principles and practices of democracy and human rights, including } \\
\text { minority rights }\end{array}$ \\
\hline Goal 3 & $\begin{array}{l}\text { To combat all forms of violence against women and to implement the } \\
\text { Convention on the Elimination of All Forms of Discrimination against } \\
\text { Women }\end{array}$ \\
\hline Goal 4 & $\begin{array}{l}\text { To take measures to ensure respect for and the protection of the human } \\
\text { rights of migrants, migrant workers and their families, to eliminate the } \\
\text { increasing acts of racism and xenophobia in many societies, and } \\
\text { topromote greater harmony and tolerance in all societies }\end{array}$ \\
\hline Goal 6 & $\begin{array}{l}\text { To work collectively for more inclusive political processes, allowing } \\
\text { genuine participation by all citizens in all our countries }\end{array}$ \\
\hline To ensure the freedom of the media to perform their essential role and \\
the right of the public to have access to information
\end{tabular}

Table 6: The Millennium Human Rights Goals

(UNCESCR, 2002, p. 4) 


\section{Appendix Two: Rights-Based Approaches in Donor Policy}

Over the past decade there has been a shift towards human rights in the policy of the multilateral institutions, international NGOs and government donor agencies that make up the global development community. While the difference between policy and practice means that policies "cannot in themselves be taken as a shift in approach or practice across the agency as a whole", they do provide some insight into organisational thinking and action (Cornwall \& Nyamu-Musembi, 2004b, p. 14). With this in mind, this appendix examines the way human rights and rights-based approaches are understood and used in the policies of donors with links to Fiji ${ }^{52}$.

\section{UNDP}

Kofi Annan called for human rights to be mainstreamed across the entire UN system in 1997. Since then, UN agencies have started to explore the ways human rights can be applied to their various areas of work. As its HDR Human Rights and Human Development (UNDP, 2000) demonstrates, UNDP was at the forefront of analysis into the theoretical and practical implications of the relationship between human rights and development. Its work in this area led to the creation of the Common Understanding (UN, 2003a), a framework to guide the work of all UN agencies in their efforts to integrate human rights into their work. The Common Understanding stipulates (UN, 2003a, p. 1):

1. All programmes of development cooperation, policies and technical assistance should further the realisation of human rights as laid down in the Universal Declaration of Human Rights and other international human rights instruments.

2. Human rights standards contained in, and principles derived from, the Universal Declaration of Human Rights and other international human rights instruments guide all development cooperation and programming in all sectors and in all phases of the programming process.

\footnotetext{
${ }^{52}$ For comprehensive overviews of human rights and development and rights-based approaches used by the international development community, see Appleyard (2002), Cornwall and Nyamu-Musembi (2004a and b) and Piron and O’Neil (2005).
} 
3. Development cooperation contributes to the development of the capacities of "dutybearers" to meet their obligations and/or of "rights-holders" to claim their rights.

In terms of a more specific rights-based approach, UNDP defines this as "the conceptual and practical framework for the realisation of human rights through the development process" (UNDP, 2007b, p. 1). It bases its approach on four sets of human rights principles which influence every aspect of the development process: universality and indivisibility; equality and non-discrimination; participation and inclusion and accountability and rule of law.

In practice, UNDP's rights-based approach is guided by the National Action Plans of its partner states, in order to work on the human rights that are most relevant. The approach is based on a two step process of assessment and analysis which is described in UNDP's Human Rights Based Approach Checklist for Programming Staff (UNDP, 2007a). The assessment process evaluates the human rights situation within a partner state, focusing on which international human rights treaties have been ratified, which have been reported on, what mechanisms are in place for monitoring and protecting human rights, what social and cultural obstacles there are to realising rights and what accountability processes there are in place. Analysis then looks at specific rights, gathering information around the access to these rights by different groups within society in order to assess those with the greatest needs.

Projects are chosen on the basis of this assessment and analysis and they generally focus on the following four areas: advocacy; capacity; implementation and monitoring (Jahan, 2004). Nyamu-Musembi and Cornwall (2004 b) argue that the projects conducted within UNDP's rights-based approach have so far tended to focus on civil and political rights: supporting democratic governance through parliamentary support; judicial reform; civil service reform; media support; anti-corruption; and the work of civil society NGOs working in these areas. Applying its rights-based approach to economic, social and cultural rights remains an evolving area for UNDP, and one currently being investigated by its 'Human Rights Strengthening Programme' (Cornwall \& Nyamu-Musembi, 2004b). 


\section{UNICEF}

UNICEF has a history of engagement with alternative approaches to development, as demonstrated by its criticisms of SAPs and its call for human-centred development in Adjustment with a Human Face (Cornia, Jolly, \& Stewart, 1987). Since 1996 the UN Convention on the Rights of the Child (CRC) and, to a lesser extent, the Convention on the Elimination of All Forms of Discrimination Against Women (CEDAW), have served as a framework to guide all aspects of UNICEF's work and recently it has moved to a conscious application of a rights-based approach (Jonsson, 2003). The CRC gives legal expression to the idea that children have independent human rights and is built on four general principles: non-discrimination; the best interests of the child; participation and survival and development (SC, 2002, p. 5). The vision of the CRC is an environment in which children are recognised as legitimate holders of rights, competent participants in society and in special need of additional protection. According to UNICEF's former Regional Director for Eastern and Southern Africa Urban Jonnson (2003), UNICEF understands a child rights-based approach as providing a normative and ethical basis for its activities.

In practice, UNICEF's rights-based approach is incorporated into its Community Capacity Development Strategy, and guides both the processes UNICEF use and the projects it chooses to implement. In terms of process, UNICEF uses the human rights framework to direct in-country situational analysis and programme design, which involves the analytical steps outlined in Chapter Five (Jonsson, 2003). The types of projects chosen reflect the findings of the analysis and may include social mobilisation, information, awareness raising, service delivery or advocacy. In general, the projects chosen by UNICEF aim to both strengthen the capacity of duty-bearers to fulfil their human rights obligations, and the ability of rights-holders, particularly children, to claim their rights. However, UNICEF emphasises that any programmes or projects chosen depend on local priorities and circumstances, and it places great importance on gradual assimilation of human rights values into the local context (Cornwall \& Nyamu-Musembi, 2004b). As Cornwall \& Nyamu-Musembi (2004) note, it is perhaps easier for UNICEF to work from a rights-based approach as the claims of its focus group, children, are generally accepted, as the widespread ratification of the CRC demonstrates. 


\section{DFID}

DFID was one of the earliest government donors to explore the relationship between human rights and development, releasing its strategy paper Realising Human Rights for Poor People in 2000. Realising Human Rights for Poor People outlines how DFID understands the rights-based approach. Its definition encompasses various elements but the key one is that a rights-based approach involves "empowering people to make their own decisions, rather than being the passive objects of choices made on their behalf" (DFID, 2000, p. 1). DFID has identified three human rights principles around which to orientate its rights-based approach: participation, inclusion and accountability or fulfilling obligation. DFID defines participation as enabling people to realise their rights to participate in decision-making processes. Inclusion is defined as building inclusive societies based on equality and non-discrimination "through development which promotes all human rights for all people" (DFID, 2000, p. 1). Fulfilling obligation means strengthening institutions and policies to ensure states and other duty-bearers are able to fulfil their human rights obligations (DFID, 2000). DFID's understanding of its rightsbased approach is notable for two reasons: it refers to development as promoting all human rights (as opposed to one side of the international human rights framework); and it emphasises non-state actor obligations, including those of transnational corporations and international financial institutions (DFID, 2000, pp. 19-20).

In practice, the processes and projects which constitute DFID's rights-based approach are structured around the three principles mentioned above (DFID, 2000). Under the participation principle, DFID's rights-based approach focuses on increasing participatory processes of research and analysis ${ }^{53}$, and on projects which strengthen formal (e.g. free and fair electoral systems) and informal (e.g. citizen's groups and civil society groups)

${ }^{53}$ In order to aid the implementation of rights-based approaches, DFID has developed Participatory Rights Assessment Methodologies (PRAMs), an instrument with which to aid people's own identification and assessment of their rights. PRAMs involve:

- Understanding and agreement between stakeholders of the obstacles poor people face in accessing those rights

- Identification of actions to support governments and other duty-bearers in the protection, promotion and realisation of human rights

- Institutional change and the opening up of new channels of institutional engagement between citizens and duty-bearers towards these ends (Brocklesby \& Crawford, 2004, p. 4) 
democratic mechanisms. Participation also involves projects which strengthen accessibility of information and those which ensure government accountability. In terms of the inclusion principle, processes include encouraging the participation of the most marginalised within society, and using data disaggregated according to demographic, gender, ethnicity, religion, disability and geographical location. Projects to enhance inclusion involve those which examine the power relations that lead to discrimination and inequality. These include the promotion of national and international human rights analysis and the support of cultural diversity, minority rights, and women's rights. Finally, projects mentioned under the fulfilling obligation principle include working with international financial institutions to recognise the importance of human rights, encouraging private sector awareness of human rights, supporting states in their ratification of and reporting on human rights treaties, technical support to reform legislation and judicial institutions, promoting advocacy focused civil society groups, and helping national human rights institutions focus on representing voices of the most marginalised.

As the above survey demonstrates, DFID's rights-based approach covers a variety of projects and works to both strengthen the ability of rights-holders to claim their rights, and the capacity of duty-bearers to fulfil them. In reality however, DFID seems to focus its rights-based projects on the rights-holder side: on civil society, advocacy and community participation in service delivery (L.H Piron \& O’Neil, 2005). Additionally, while DFID's policy documents emphasise the importance of economic, social and cultural rights, Piron and Watkins (2004, p. 78) argue that "there seems to have been a limited number of activities in the social sectors reviewed here, apart from the significant amount of work on core labour standards".

\section{AUSAID}

AUSAID's understanding of the relationship between human rights and development is outlined in Australia's Department of Foreign Affairs and Trade's Human Rights Manual (2004). This states that "human rights and development are mutually reinforcing", that "civil and political rights are ranked equally with economic, social and cultural rights" and that AUSAID's projects “support the advancement of human rights” (DFAT, 2004, p. 
1). However, although AUSAID recognises a relationship between human rights and development, it explicitly says it does not apply a rights-based approach and does not have an overall human rights policy (L.H Piron \& O’Neil, 2005). It defines a rightsbased approach as "not only mainstreaming human rights within development cooperation programs and activities, but [using] the achievement of specific human rights objectives as the foundation for development cooperation policy implementation" (DFAT, 2004, p. 1). Its stated yet unsubstantiated reasons for not following a rightsbased approach are that it (DFAT, 2004, p. 1):

- runs the risk of focusing development on activities that promote certain rights over others or not adequately addressing the real development needs of the partner country concerned;

- does not sufficiently address the role and responsibility of developing countries in addressing their citizens' rights to basic needs and development and risks entrenching developing countries' dependency on development;

- may also pre-determine (and limit) the mechanisms for delivering assistance.

Although it does not explicitly follow a rights-based approach or include specific human rights principles or standards in its policies, in practice AUSAID does support many human rights projects in its work across the Asia-Pacific region. It does this through its Human Rights Fund. The Human Rights Fund supports discrete human rights projects at the bilateral, multilateral and NGO level. For example, it supports the Asia Pacific Forum of National Human Rights Institutions, training workshops on the investigation of human rights abuses in Indonesia, victims of child trafficking in Thailand, labour rights in Jordan, and a popular theatre program to educate poor rural communities in Bangladesh on their legal rights (AUSAID, 2007). However, the majority of AUSAID's human rights activities do appear to prioritise civil and political rights. This is in line with AUSAID's focus on good governance, which it defines in terms of economic reform, democracy and the rule of law (DFAT, 2004). These good governance projects aim to promote sound economic and financial management and increase public sector effectiveness, which for AUSAID is the basis for sustainable development and the realisation of economic, social and cultural rights (Appleyard, 2002; DFAT, 2004). 


\section{NZAID}

NZAID's Human Rights Policy Statement explains its view that the relationship between human rights and development is mutually interdependent. NZAID considers that "working to eliminate poverty and remove inequalities directly addresses fundamental human rights set out in the UDHR" (2002, p. 3). Additionally, it believes that "development is essential to realising human rights, and realising human rights is essential to addressing poverty and promoting development" (NZAID, 2002, p. 5). As the Human Rights Policy Statement and the subsequent Implementation Plan of Action (2004) note, NZAID is in the process of adopting a rights-based approach to development, an approach it defines as integrating the standards and principles of the international human rights framework into the plans, policies and processes of development. For NZAID this involves using human rights in every aspect of the development process - from initial appraisal to evaluation and impact assessment. It also means "walking the talk", that is, integrating human rights into the organisational culture of NZAID itself (NZAID, 2004, p. 10).

Perhaps because the rights-based approach is still in the process of being adopted, a reading of specific NZAID policy documents suggests that it does not yet align its policy and project outcomes to the fulfilment of specific human rights standards. This has been criticised recently by both the Human Rights Commission (in relation to the recent Draft Gender Policy) and Oxfam NZ, which lamented the lack of references to human rights in the core programming areas of NZAID's Draft Growth and Livelihoods Strategy (HRC, 2006; NZAID, 2007; Oxfam, 2007a, p. 252). However, NZAID supports the work of many NGOs who do promote human rights, including RRRT, FWRM, ECREA, and Oxfam.

\section{Save the Children Fund}

Like UNICEF, Save the Children's (SC) understanding of a rights-based approach is based on the CRC. Calling its approach 'Child Rights Programming', SC aims to "transform the vision of the CRC into a concrete strategy for child focused development" (SC, 2002, p. 4). This is a marked change from SC's earlier needs-based approach to child development and according to SC the benefits of applying a rights lens are many, 
including the fact it provides a "long-term goal towards which all work is directed", "sets the standards to measure progress" and "identifies the responsibilities for governments, donors, private sector, civil society, communities and individuals"(SC, 2002, p. 4). The last point is notable for the emphasis SC, like DFID, places on non-state actor accountability for human rights.

In practice, SC's Child Rights Programming involves incorporating the CRC's principles of participation, equity, sustainability, non-discrimination, poverty eradication and multisectoral work into all areas of work (Theis \& O'Kane, 2005). It also involves choosing projects that work with both rights-holders and duty-bearers and that are relevant to the local context in which individual SCs operate (Theis \& O'Kane, 2005). Examples of the former include practical responses to violations of rights, awareness raising campaigns, community empowerment activities, service provision. Examples of the latter include child rights education of decision-makers at both the local and international level, and advocacy to improve existing structures and establish new structures to support child rights. As SC emphasises, it has not abandoned its earlier service provision model entirely, rather, it has incorporated it into its new concern with child rights and the wider structural issues which prevent the fulfilment of these rights (SC, 2002).

\section{Oxfam}

Since late 2000 Oxfam has applied a rights-based approach to its development and humanitarian work. The decision to adopt a rights-based approach was, as with SC, a response to the fact its service based "traditional ways of thinking and working were becoming less effective" in the face of increasing inequalities within and between societies, entrenched poverty and the appropriation of development resources by a corrupt elite (Brouwer, Grady, Traore, \& Wordofa, 2005, p. 63). For Oxfam, a rightsbased approach includes all UDHR rights, both civil and political and economic, social and cultural, but, for ease of programming and understanding these are reframed as:

- The right to a sustainable livelihood

- The right to basic services such as health, education, safe water

- The right to life and security 
- The right to be heard

- The right to an identity

In practice, these rights are used as a framework for development programmes and interventions, while the human rights principles of equality, non-discrimination, participation and accountability guide the processes used to implement programmes. Specific projects chosen by the different branches of Oxfam relate to local contexts but, as with SC, all projects work on either or both strengthening the ability of rights-holders to claim their rights, and strengthening the capacity of duty-bearers to fulfil their fights obligations. Importantly, Oxfam recognises the interdependence of human rights and incorporates this perspective into its projects. For example, when working with coffee farmers in Ethiopia, it focused not only on increasing income and productivity, but also on providing support and information in order to strengthen the capacity of coffee farmers to advocate and lobby the government for fairer trade rules (Brouwer, Grady, Traore, \& Wordofa, 2005). In general, Oxfam has noted "the unequal power relations that constrain human development can be confronted more forcefully when international principles and instruments of human rights can be brought to bear on national legislation, and in turn, citizens can draw on both levels to demand their rights" (Brouwer, Grady, Traore, \& Wordofa, 2005, p. 76).

\section{Commonalities}

As Nguyen (2002), Uvin (2004) and Cornwall \& Nyamu-Musembi (2004a) all note and the above survey demonstrates, there are varying 'starting points' or levels of integration of a human rights perspective into development and therefore varying ways of understanding rights-based approaches. For example, the way AUSAID integrates human rights into its development is quite different to the way DFID does. For DFID, integration of human rights involves entirely rethinking the way it delivers development and implies an investigation of power relationships at both a national and international level. For AUSAID human rights are simply an aspect of its wider development and good governance agenda and, as the very existence of a separate Human Rights Fund demonstrates, are not at all mainstreamed into the way AUSAID 'does' development. In 
general, the UN agencies and international NGOs have been able to reorient their work around rights-based approaches to a much great degree than the government agencies, which is possible to do with the fact they are less constrained by political considerations. Finally, while few development actors incorporate the standards of the international human rights framework as direct outcomes of their work, most find it easy to include human rights principles such as participation, non-discrimination, and accountability even if the latter relates less to their own or international accountability and more to the accountability of individual states. 


\section{Appendix Three: Ethics Forms}

\section{Participant Information Sheet}

My name is Mary Llewellyn-Fowler and I am a Masters of Development Studies student at Victoria University of Wellington, New Zealand. As part of my degree I am writing a thesis on the use of human rights for development.

I would like to invite you, as a representative of a Fijian NGO, to participate in an approximately forty-five minute interview in which you will be able to share your experiences and stories of working within the human rights and development fields. I am interested in what human rights and development mean to the NGO you represent, in the ways your NGO uses the international human rights framework in its day to day work, and the challenges and benefits of doing so.

Given the current political situation in Fiji, I understand you may have security concerns relating to participation in this research. Therefore, participant safety will be paramount both during and after the interview process: written and electronically recorded material made during the interview will remain confidential and will only be seen by myself and my supervisor; it will be destroyed on completion of the thesis; and it will be your decision as to whether you and your organisation will be identified or will remain anonymous in the published thesis. Additionally, you may withdraw yourself and any information you provide at any time, and you will have an opportunity to check the information you have given me before it is published.

Upon completion of my thesis, a copy will be lodged in the Victoria University library and a summary of findings will be made available to you, if this is of interest. The research may also be published in academic or professional journals and/or disseminated at academic or professional conferences as the opportunity arises.

I hope you will agree to participate in this research and I look forward to hearing from you soon.

Kind regards,

Mary Llewellyn-Fowler

llewelmary@student.vuw.ac.nz

mllewellynfowler@gmail.com
Professor John Overton (Supervisor)

John.Overton@vuw.ac.nz 


\section{Consent Form}

\section{Please tick as appropriate:}

I have read the information sheet and understand the purpose of this research project.

I consent to my name being used when my comments or opinions are used in this research (see attached waiver of confidentiality).

or

I request my name to be omitted and a pseudonym to be used if my comments or opinions are included in this research.

I consent to the name of the organisation I work for being used in this research (see attached waiver of confidentiality).

or

I request the name of the organisation I work for to be omitted from this research.

I understand I will have an opportunity to see a transcript of the interview before it is published.

I understand the interview will be electronically recorded and any notes or recorded material from interviews will be destroyed at the end of the research process.

I understand all information I provide will be kept confidential and accessed only by the researcher and research supervisor.

I understand I may, at any stage, withdraw myself, and any information I have provided, from this research project without explanation.

I understand the results of this research will be included in a thesis and may be used for publication in academic or professional journals, and for dissemination at academic or professional conferences.

I would like to receive a summary of the results of this research when it is completed.

I agree to take part in this research.

Name:

Date:

Signed: 


\section{Waiver of Confidentiality}

$\mathrm{I}$, (name) from (organisation) have been interviewed by Mary Llewellyn-Fowler as part of the above research project.

I have chosen:

- my identity and/or

- the identity of my organisation,

will not remain confidential (tick as appropriate).

Mary Llewellyn-Fowler, Victoria University of Wellington, and any publications which use material from this research project have my permission to publicly identify me and/or my organisation by name and to use the transcript of my interview as an accurate representation of what I have said.

Signature:

Name:

Date: 